\title{
WestVirginiaUniversity
}

THE RESEARCH REPOSITORY @ WVU

Graduate Theses, Dissertations, and Problem Reports

1999

\section{Numerical analysis of direct-chill casting of aluminum ingot}

\author{
Yaping $\mathrm{Wu}$ \\ West Virginia University
}

Follow this and additional works at: https://researchrepository.wvu.edu/etd

\section{Recommended Citation}

Wu, Yaping, "Numerical analysis of direct-chill casting of aluminum ingot" (1999). Graduate Theses, Dissertations, and Problem Reports. 961.

https://researchrepository.wvu.edu/etd/961

This Thesis is protected by copyright and/or related rights. It has been brought to you by the The Research Repository @ WVU with permission from the rights-holder(s). You are free to use this Thesis in any way that is permitted by the copyright and related rights legislation that applies to your use. For other uses you must obtain permission from the rights-holder(s) directly, unless additional rights are indicated by a Creative Commons license in the record and/ or on the work itself. This Thesis has been accepted for inclusion in WVU Graduate Theses, Dissertations, and Problem Reports collection by an authorized administrator of The Research Repository @ WVU. For more information, please contact researchrepository@mail.wvu.edu. 


\title{
Numerical Analysis of Direct-Chill Casting of Aluminum Ingot
}

\author{
By \\ Yaping $\mathrm{Wu}$ \\ A THESIS \\ Submitted to \\ Department of Mechanical and Aerospace Engineering \\ College of Engineering and Mineral Resources \\ West Virginia University \\ In Partial Fulfillment of the Requirements \\ For the Degree of \\ Master of Science \\ In \\ Mechanical Engineering \\ Bruce Kang, Ph.D., Chairman \\ Keh-Minn Chang, Ph.D. \\ Kenneth Means, Ph.D.
}

Morgantown, West Virginia

1999

Keyword: Direct-Chill Casting, Maximum Principle Stress, Failure Mode Prediction Copyright 1999 Yaping Wu 


\title{
Numerical Analysis of Direct-Chill Casting of Aluminum Ingot
}

\author{
By \\ Yaping $\mathrm{Wu}$
}

\begin{abstract}
Direct chill (DC) semi-continuous casting is the most efficient way to produce large aluminum ingots. This process consists of three main stages; transient stage, steady-state stage, and post-drop stage. During transient stage, the ingot is subjected to rapid cooling rate and thus resulted in the build-up of high thermal stresses that can often lead to ingot cracking failure.

Based on a fully coupled heat-transfer and thermal-stress analysis model, which has been developed using a commercial finite element (FE) package ABAQUS $^{\mathrm{TM}}$ with a user subroutine developed in-house, the temperature and stress fields were obtained for various casting conditions. Three post-processing programs were developed to analyze and present the FE simulation results. The first program, CONVERT, processes data files from ABAQUS ${ }^{\mathrm{TM}}$ and then determines the normalized stresses in the ingot. The magnitude, location of maximum stress level, and the directions of maximum principal stresses are determined to assess the mechanism of ingot cracking. The second program, REGRESS, is used for statistical regression analysis, which involves casting parameters such as casting speed, water flow rate, ingot aspect ratio, and corner radius. Results of REGRESS are input to a program, PREDICTION, which provides visualization of the temperature and stress fields on a PC monitor. Further, the user can choose desired casting parameters in PREDICTION to predict temperature and stress fields at selected ingot lengths during casting. Validity of the program PREDICTION is checked with additional simulation results from ABAQUS ${ }^{\mathrm{TM}}$ and good agreement is noted.
\end{abstract}




\section{ACKNOWLEDGMENTS}

I would like to thank and dedicate this work to my husband and my son, Paul and Yidong. Thanks for their loves and patience so that I could finish my graduate education.

I would like to acknowledge my research advisor, Dr. Bruce Kang, for his continuous financial assistance, guidance, and encouragement on my graduate studies and research work. I would also like to express my appreciation to the thesis committee, Professor Keh-Minn Chang and Professor Kenneth Means for their helpful comments and suggestions concerning this research work.

Some very dear friends have encouraged me in my research efforts. I thank Dr. Yi Luo for his encouragement on my research that I set out and was able to accomplish. I thank Dr. Wanhong Yang and Mrs. Jian Mao Yang, the " coolest couple" I have ever known, for their continued interest in the progress of my research. I also thank my friend Ed Wen for improving my writing skill. I thank Eric Saunders who helped me on using the Silicon Graphic Station. Tanks also extend to my friends Liyun and Wenbo for their kind help that I have such a memorable time in Morgantown. 


\section{TABLE OF CONTENTS}

$\begin{array}{lll}\text { ABASTRACT } & \text { ii }\end{array}$

ACKNOWLEDGEMENTS iii

TABLE OF CONTENTS IV iv

LIST OF TABLES vii

LIST OF FIGURES viii

$\begin{array}{ll}\text { CHAPTER 1. INTRODUCTION } & 1\end{array}$

$\begin{array}{ll}\text { 1.1 Direct chill Casting Process } & 1\end{array}$

1.2 Statement of Problem 2

1.3 Research Objectives and Methodology 5

1.4 Thesis Outline $\quad 6$

CHAPTER 2. LITERATURE REVIEW

CHAPTER 3. NUMERICAL MODELING OF D. C. CASTING 11

$\begin{array}{ll}\text { 3.1 Geometry model } & 11\end{array}$

$\begin{array}{lc}\text { 3.2 Material Model } & 13\end{array}$

$\begin{array}{ll}\text { 3.3 Boundary conditions } & 15\end{array}$

$\begin{array}{ll}\text { 3.4 Loading conditions } & 19\end{array}$

3.5 Heat-Flow Water Direct-Chill Model 20

$\begin{array}{ll}\text { 3.6 Numerical procedure } & 23\end{array}$

CHAPTER 4. ANALYSIS OF RESULTS 26

$\begin{array}{ll}\text { 4.1 Temperature Field } & 26\end{array}$

$\begin{array}{ll}\text { 4.2 Displacement Field } & 28\end{array}$ 
$\begin{array}{lc}\text { 4.3 Stress Field } & 30\end{array}$

4.4 Normalized Maximum Principal Stress Field 31

CHAPTER 5. PARAMETRIC STUDIES 4

5.1 Effect of Drop Rate $\quad 40$

5.2 Effect of Water Flow Rate

5.3 Effect of Corner Radius $\quad 44$

5.4 Effect of Aspect Ratio

5.5 Effect of Ingot Size

CHAPTER 6. DATA REDUCTION AND PREDICTION 64

$\begin{array}{lr}\text { 6.1 Program CONVERT } & 64\end{array}$

$\begin{array}{lr}\text { 6.1.1 File Format Conversion } & 64\end{array}$

$\begin{array}{lr}\text { 6.1.2 Stress Level calculation } & 65\end{array}$

$\begin{array}{lr}\text { 6.1.3 Data Reduction } & 67\end{array}$

6.2 Program REGRESS

6.2.1 Regression Model and Multi-Linear Regression $\quad 70$

6.2.2 Implementation of Program REGRESS 73

$\begin{array}{ll}\text { 6.3 Program PREDICTION } & 74\end{array}$

6.3.1 The Function Features of PREDICTION 75

$\begin{array}{ll}\text { 6.3.2 Interpolation model } & 75\end{array}$

$\begin{array}{ll}\text { 6.3.3 The Structure of PREDICTION } & 77\end{array}$

6.4 PREDICTION Results and Comparison with ABAQUS Results $\quad 78$ 
CHAPTER 7. SUMMARY AND FUTURE WORK 82

$\begin{array}{ll}\text { 7.1 Summary } & 82\end{array}$

$\begin{array}{ll}\text { 7.2 Suggestions for Future Work } & 85\end{array}$

$\begin{array}{lr}\text { REFRENCES } & \mathbf{8 6}\end{array}$

$\begin{array}{lr}\text { APPENDIXES } & 90\end{array}$

APPENDIX A: Program Operating Procedure $\quad 90$

$\begin{array}{ll}\text { APPENDIX B: Program CONVERT } & 101\end{array}$

$\begin{array}{ll}\text { APPENDIX C: Program REGRESS } & 107\end{array}$

APPENDIX D: Program PREDICTION 111 


\section{LIST OF TABLES}

Page

TABLE 3.1: Thermal Properties of Al-7050 Used in Simulation 14

TABLE 3.2: Properties of Steel Bottom Block Used in Simulation 16

$\begin{array}{ll}\text { TABLE 5.1: } \text { Maximum Stress Level } 2 & 47\end{array}$

TABLE 5.2: Maximum Stress Level 2 Locations (56"x16" ingots) 48

TABLE 5.3: Normalized Maximum Principle Stresses for Different Water Flow Rate 57

TABLE 5.4: Locations of Maximum Stress Level 2 in the Ingots

for Three Water Flow Rates $\quad 58$

TABLE 5.5: Normalized Maximum Principle Stresses for Corner Radius 59

TABLE 5.6: Locations of Maximum Stress Level 2 for Corner Radius 59

TABLE 5.7: Normalized Maximum Principle Stresses for Three Aspect Ratios $\quad 60$

TABLE 5.8: Locations of Maximum Stress Level for Different Aspect Ratios 61

TABLE 5.9: Maximum Stress Level 2 ( 58"x19" ingot) 61

TABLE 5.10: Locations of the Maximum Stress Level 2 in the Ingots

for Five Drop Rates (58"x19" ingots) 63

TABLE 6.1: Comparison of PREDITION and ABAQUS Results for 56" x 16" Ingot 80

TABLE 6.2: Comparison of PREDITION and ABAQUS Results for 58" x 19" Ingot 81 


\section{LIST OF FIGURES}

Page

FIGURE 1.1: Direct Chill Casting $\quad 2$

FIGURE 1.2: Typical Fracture Modes of Casting Ingot 4

FIGURE 2.1: An Idealized Heat Flux vs. Surface Temperature for Water Cooling 8

FIGURE 3.1: Simulation Model of Ingot and Bottom Block 12

FIGURE 3.2: Finite Element Mesh of Ingot and Bottom Block 13

FIGURE 3.3: Measured As -Cast Stress-Strain Curves of Alloy Al-7xxxx 15

FIGURE 3.4: Heat Transfer Coefficient of the Interface between Ingot Butt and Bottom Block

FIGURE 3.5: Heat Flux Density vs. Surface Temperature of On-Cooling Ingot 21

FIGURE 3.6: Maximum Heat Flux Density vs. Hole Spacing 22

FIGURE 3.7: Water Flow Pattern along Rolling Face of Ingot $\quad 24$

$\begin{array}{ll}\text { FIGURE 3.8: Ingot Dimensions } & 24\end{array}$

FIGURE 4.1: Temperature Contour of Inner Face

(base case, ingot length: 20 inches) 27

FIGURE 4.2: Temperature Contour of Outside Face

(base case, ingot length: 20 inches) 27

FIGURE 4.3: Butt Curl Deformation (ingot length: 10 in) 28

FIGURE 4.4: Vertical Displacement of Butt Curl at Different Ingot Length 29

FIGURE 4.5: Vertical Displacement of Corner Point $\quad 29$

FIGURE 4.6: Maximum Principal Stress in Base Case, outside view

(Ingot length is 5 inches) 33

FIGURE 4.7: Maximum Principal Stress in Base Case, inside view

(Ingot length is 5 inches) 
FIGURE 4.8: Maximum Principal Stress in Base Case, outside view (Ingot length is $\mathbf{1 0}$ inches)

FIGURE 4.9: Maximum Principal Stress in Base Case, inside view

(Ingot length is 10 inches)

FIGURE 4.10: Maximum Principal Stress in Base Case, outside view (Ingot length is 20 inches)

FIGURE 4.11: Maximum Principal Stress in Base Case, inside view (Ingot length is $\mathbf{2 0}$ inches)

FIGURE 4.12: Maximum Principal Stress in Base Case, outside view (Ingot length is $\mathbf{3 0}$ inches)

FIGURE 4.13: Maximum Principal Stress in Base Case, inside view (Ingot length is $\mathbf{3 0}$ inches)

FIGURE 4.14: Quenching Stress Directions in Base Case (Ingot Length: 40 in)

FIGURE 4.15: Stress Level 2 Locations in Base Case (Ingot Length: 5 in)

FIGURE 4.16: Stress Level 2 Locations in Base Case (Ingot Length: 10 in)

FIGURE 4.17: Stress Level 2 Locations in Base Case (Ingot Length: 20 in)

FIGURE 4.18: Stress Level 2 Locations in Base Case (Ingot Length: 30 in)

FIGURE 5.1: Drop Rate Effect

FIGURE 5.2: Principal Stress Directions (Drop Rate:1.0 in/min, L=30", Y=30")

FIGURE 5.3: Principal Stress Directions (Drop Rate: 1.9 in/min, L=5", Y=1")

FIGURE 5.4: Principal Stress Directions (Drop Rate: 1.9in/min, L=20", Y=1")

FIGURE 5.5: Principal Stress Directions (Drop Rate: 1.9in/min, L=30", Y=8.7")

FIGURE 5.6: Principal Stress Directions (Drop Rate: $1.9 \mathrm{in} / \mathrm{min}, \mathrm{L}=30$ ", $X=0$ ")

FIGURE 5.7: Principal Stress Directions (Drop Rate: $1.5 \mathrm{in} / \mathrm{min}, \mathrm{L}=10$ ", Y=9.7") 
FIGURE 5.8: Principal Stress Directions (Drop Rate: 1.9in/min, L=30", Y=9.7") 52

FIGURE 5.9: Principal Stress Directions (Drop Rate: $1.5 \mathrm{in} / \mathrm{min}, \mathrm{L}=30$ ", $X=0$ ") $\quad 53$

FIGURE 5.10: Principal Stress Directions (Drop Rate: 2.4 in/min, L=30", Y=8.7") 54

FIGURE 5.11: Principal Stress Directions (Drop Rate: 3.0in/min, L=30", Y=7.7") 54

FIGURE 5.12: Principal Stress Directions (Drop Rate: 2.4 in/min, L=30", X=0") 55

FIGURE 5.13: Principal Stress Directions (Drop Rate: $3.0 \mathrm{in} / \mathrm{min}, \mathrm{L}=30 "$ ", X=0") $\quad 56$

$\begin{array}{ll}\text { FIGURE 5.14: Water Flow Rate Effect } & 57\end{array}$

FIGURE 5.15: Effect of Corner Radius $\quad 58$

FIGURE 5.16: Effect of Ingot Aspect Ratio $\quad 60$

FIGURE 5.17: Effect of Drop Rate, 58"x19" Ingot 62

FIGURE 6.1: Relation Ships Between Temperature and Yield and Tensile Strength 66

FIGURE 6.2: Output File from ABAQUS

FIGURE 6.3: The First Output Data File from CONVERT $\quad 67$

FIGURE 6.4: Division of Sub-Zones in the Model $\quad 68$

FIGURE 6.5: Second Output Data File Generated by CONVERT 69

$\begin{array}{ll}\text { FIGURE 6.6: Job Control File } & 73\end{array}$

$\begin{array}{ll}\text { FIGURE 6.7: Regression Output File } & 74\end{array}$

FIGURE 6.8: Weighting Function Used in Time Interpolation 76

FIGURE A.1: Maximum Principal Stress File before Moving Break Line 91

FIGURE A.2: Maximum Principal Stress File after Moving Break Lines 92

FIGURE A.3: Main Menu of PREDICTION 95

FIGURE A.4: Input Interface of PREDICTION 96 
Page

FIGURE A.5: Independent Variable Panel of PREDICTION 97

FIGURE A.6: Computation Menu of PREDICTION 98

FIGURE A.7: Distribution Menu of PREDICTION 99

FIGURE A.8: Curve and Its Input Menu of PREDICTION 100 


\section{CHAPTER 1}

\section{INTRODUCTION}

\subsection{Direct chill Casting Process}

Direct chill semi-continuous casting is an efficient method to produce large aluminum ingots. This method was established in the late 1930s, and has been proved to be robust and well adopted in the industry because it permits large dimension casting, yields high production rate and requires relatively simple mold design $[1,2]$.

A schematic representation of the direct chill semi-continuous casting process is shown in Figure 1.1. In the initial stage of the casting process, the bottom block is lift up to form a cavity with the mold and the cooling water switched on. Liquid metal is poured into the mold over the bottom block. As it contacts the mold and bottom block, the liquid metal cools and solidifies along the surface of the cavity. After the liquid metal has reached to a predefined height in the mold, the bottom block starts to move downward. The solidified surfaces are then directly exposed to the cooling water sprayed onto the ingot. The bottom and side surfaces of the ingot solidify first and form a shell. This shell becomes the mold itself for the remaining liquid metal. The molten metal is continuously supplied from the top as the bottom block moves downward resulting in more metal being solidified.

The direct chill casting process consists of three main stages [3]. The first one is transient stage or starting phase. In this stage, temperature field, solidification front, and shape of the ingot are all time-dependent. The second stage is steady state or pseudo-stationary phase featuring the 
establishment of a nearly steady-state regime. The third is the end stage or post drop phase. In this final stage, the pouring of the liquid metal is discontinued and the ingot is left for further cooling.

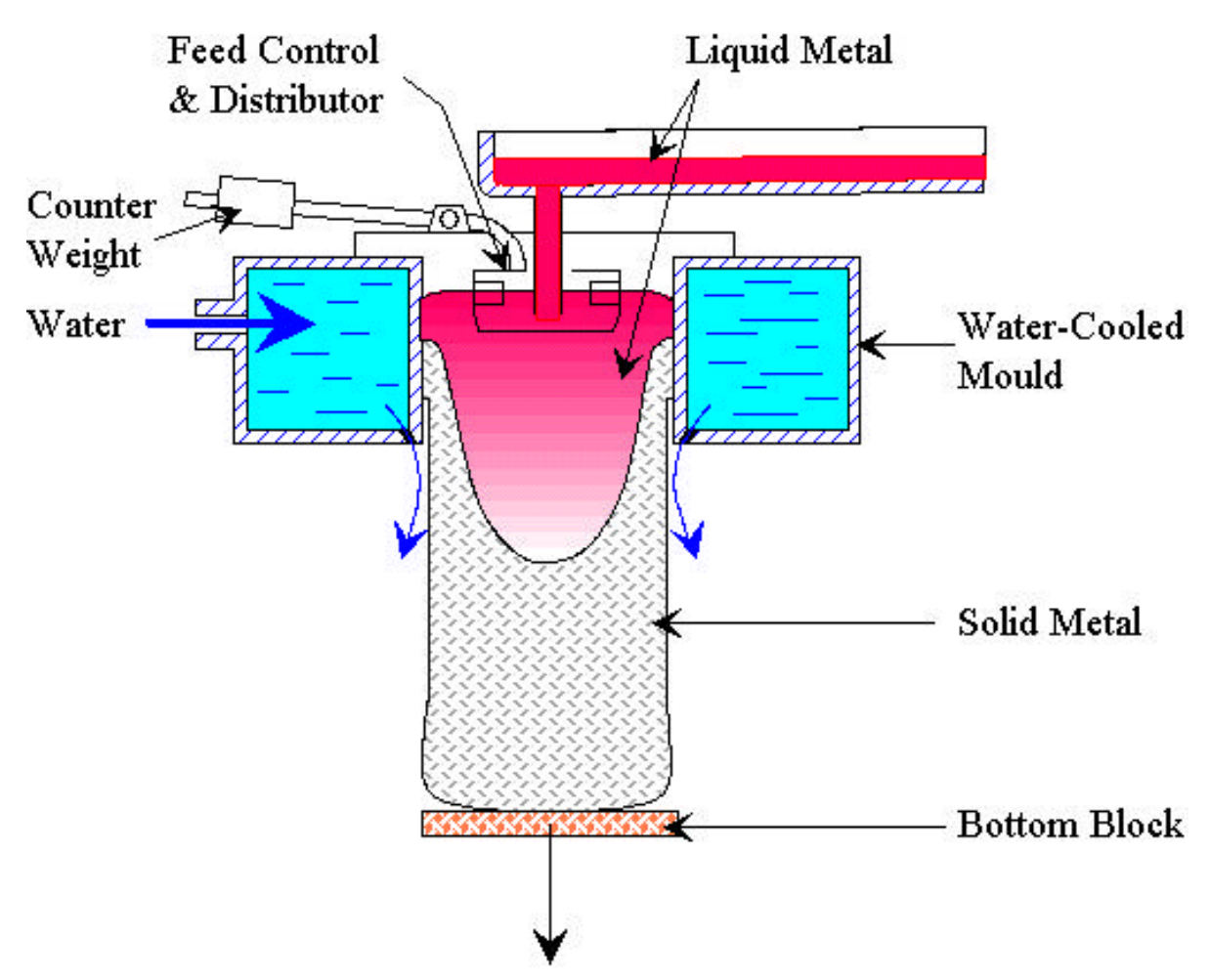

Figure 1.1 Direct Chill Casting

\subsection{Statement of Problem}

During transient stage of the direct chill process, the ingot experiences much higher cooling rate than the later two stages. As the bottom block begins to drop, the ingot is chilled by both the bottom block and the mold. When the bottom block is moved further downward, the ingot is also chilled by the cooling water. The high heat transfer by bottom block, mold and cooling water generates large thermal gradients in the ingot, which has relatively small volume at this 
stage. The bottom and the side surfaces of the ingot are cooled down while the center of the ingot remains hot molten phase. The large temperature gradient near ingot surface will make the bottom section of the ingot to bow that is often called "butt curl".

"Butt swell" is another phenomenon associated with a thick section of the butt of the ingot as compared with the remaining height of the ingot [4]. Because of the butt curl, a small gap exists between the bottom block and the bottom of the ingot. The cooling water can enter this gap and change the cooling rate of the ingot resulting in the reduction of ingot contraction. In the transient stage, the ingot has nearly the same nominal dimensions as the mold. However, once this transient stage is over, the depth of the liquid phase is bigger than that in the transient stage and the associated contraction will increase. The result is that the central portion of the ingot is pulled inward creating a deception that the butt of the final ingot had swollen.

In steady state stage, the solidified shell contracts toward the liquid pool. This contraction is not uniform throughout the ingot cross section. The lateral faces of the ingot are curved inward, i.e. pulling-in of the rolling faces.

Butt curl, Butt swell, and pulling of the rolling faces requires additional scalping before rolling the ingot. They decrease productivity and increase production cost. A major problem however is the formation of residual stresses, which can cause micro-cracks or even lead to ingot fracture. There are three kinds of fracture modes, which are schematically shown in Figure 1.2 [5]. Furthermore the induced stresses can lead to defect or ingot cracking during casting, especially in the area near the liquid zone. This may cause hot tearing, which is a serious safety problem. 

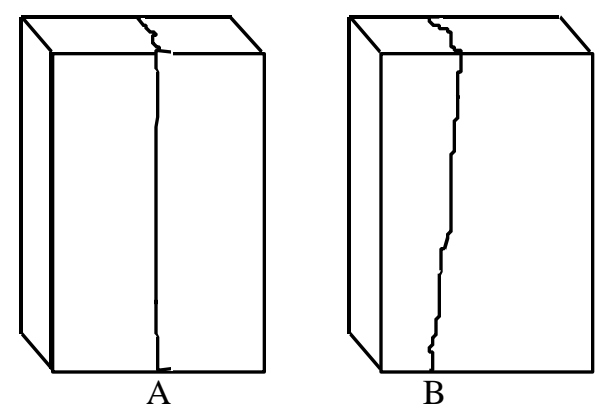

Center Crack

Quarter-point Crack

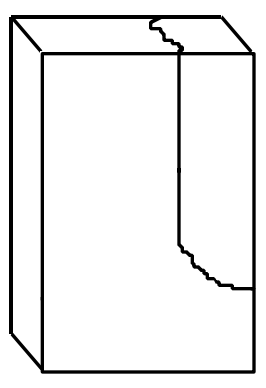

J Crack

Figure 1.2 Typical fracture modes of casting ingot.

Great efforts have been made to reduce the cooling rate in the start-up stage to reduce the thermal stresses during casting. Typical approaches include: (1) adjusting the casting parameters (i.e., drop rate, water flow rate, water purity and water flow pattern), (2) "top wiper" to prevent cooling water from flowing down along the ingot surfaces and (3) placing insulation pads between the ingot and the bottom block to reduce heat exchange there. Insulation tape has also been used occasionally along bottom periphery of the ingot to reduce heat extraction.

In recent years, research on numerical simulations of metal casting process has gained ground [6]. However, most of the research has focused on the heat-flow-based analysis for bottom block design. Some important aspects of the DC ingot casting, such as the mechanism of ingot cracking, crack initiation sites, and process optimization remain largely unresolved. 


\subsection{Research Objectives and Methodology}

This research is aimed to develop a practical tool for the evaluation of possible ingot cracking initiation locations during DC ingot casting and to study the effect of individual relevant casting parameter to the build-up of ingot stress. The research effort can be divided into the following three phases.

1. Finite element (FE) simulations of the thermal stress field at the transient stage. The numerical calculations are based on a transient model [5] developed in 1997, using the commercial finite element analysis package ABAQUS $^{\mathrm{TM}}$ with a user subroutine developed in-house. The FE simulations generate temperature, displacement and stress fields in the ingot for different casting conditions. This information enables researchers to understand the curling effect and locate the high stress zones. It should be noted that the amount of output data for each simulation is large and post data analysis is needed to fully evaluate the FE results.

2. Data interpolation and reduction. In this step, two PC programs (CONVERT and REGRESS) are developed to aid the analyses of FE results and to reduce the amount of the output data to a manageable level without losing accuracy. Using these in-house developed programs, the time-dependent normalized maximum principal stresses and their locations in the ingot can be easily identified. The magnitude, location and directions of the normalized maximum principal stresses revealed the mechanism of the cracking formation. The entire ingot is divided into a manageable number of sub-zones. Statistical analysis is then performed on the dependent variables (i.e., principal stress, temperature, and normalized stresses) in each of the sub-zones. Regression analysis is also conducted 
on the dependent variables with reference to the casting parameters (i.e., casting speed, water flow rate, aspect ratio, and corner radius).

3. Representation and interpolation of the simulation results. Base on the results of the regression analysis, a PC program (PREDICTION) is developed to visualize the results in a user-friendly format. Users of this program can easily visualize the distributions of the temperature, principal stress and stress level in the ingot at different casting stages. The tendency of dependent variable for each and every zone is also given as ingot grows.

\subsection{Thesis Outline}

This thesis includes seven chapters and four appendixes. A brief literature review of the research and development on the DC ingot casting process is given in chapter 2. Chapter 3 describes numerical modeling of transient DC ingot casting. It details the geometry model, heat flow model, types of elements, finite element mesh, material model, displacement boundary, heat transfer boundary, and the loading conditions. In chapter 4 , a rational mechanism to explain the crack formation is proposed based on the FE and CONVERT results. The distribution of temperature, displacement and the maximum principal stress fields are shown. Chapter 5 discusses effect of casting parameters in relation to the normalized maximum principal stresses. Through parametric study, a better understanding for optimizing casting parameters is established. Chapter 6 briefly introduces the methodology and algorithm used in the data reduction, regression and representation of the FE results. The predicted results from the PC package are compared with the ABAQUS $^{\mathrm{TM}}$ results and relative errors are also examined. Chapter 7 summarizes the research work and suggests future work. Operating procedure of the three programs and their codes is given in the Appendix. 


\section{CHAPTER 2}

\section{LITERATURE REVIEW}

Numerical analysis methods have been frequently applied to study the DC casting process in recent years as reviewed by Thomas [6]. These studies fall in three categories: (1) heat-flow, water-cooling model, (2) thermal stress simulation of DC casting, and (3) optimization on the shape of bottom block.

The first study on the modeling of heat flow in water-cooling was made by Weckman and Niessen [7]. Using theories of nucleate boiling with forced convection and film cooling, they developed a method to calculate boundary conditions in the submold region of the ingot and the method was implemented in a two-dimensional finite element code. Wiskel and Cockcroft [1] developed a method for determining the heat flux versus temperature curve on the ingot surface using an inverse heat transfer analysis of temperature data measured from an embedded thermal couple. In this method, four heat transfer regimes were defined as shown in Figure 2.1. In the descending order of the surface temperature, forms of the heat flux in the four regimes are film boiling, transition boiling, nucleate boiling, and natural or forced convection. Kraushaar et al. [8] correlated the heat transfer coefficient to the measured ingot surface temperature. A more comprehensive study on this subject has been reported recently by Maenner et al. [9]. A newly developed technique for quantifying the heat transfer coefficients and the heat fluxes for DC water sprays has been reported. The results on the effect of composition, temperature, and flow rate of cooling water have been published by Grandfield et al. $[10,11]$. 


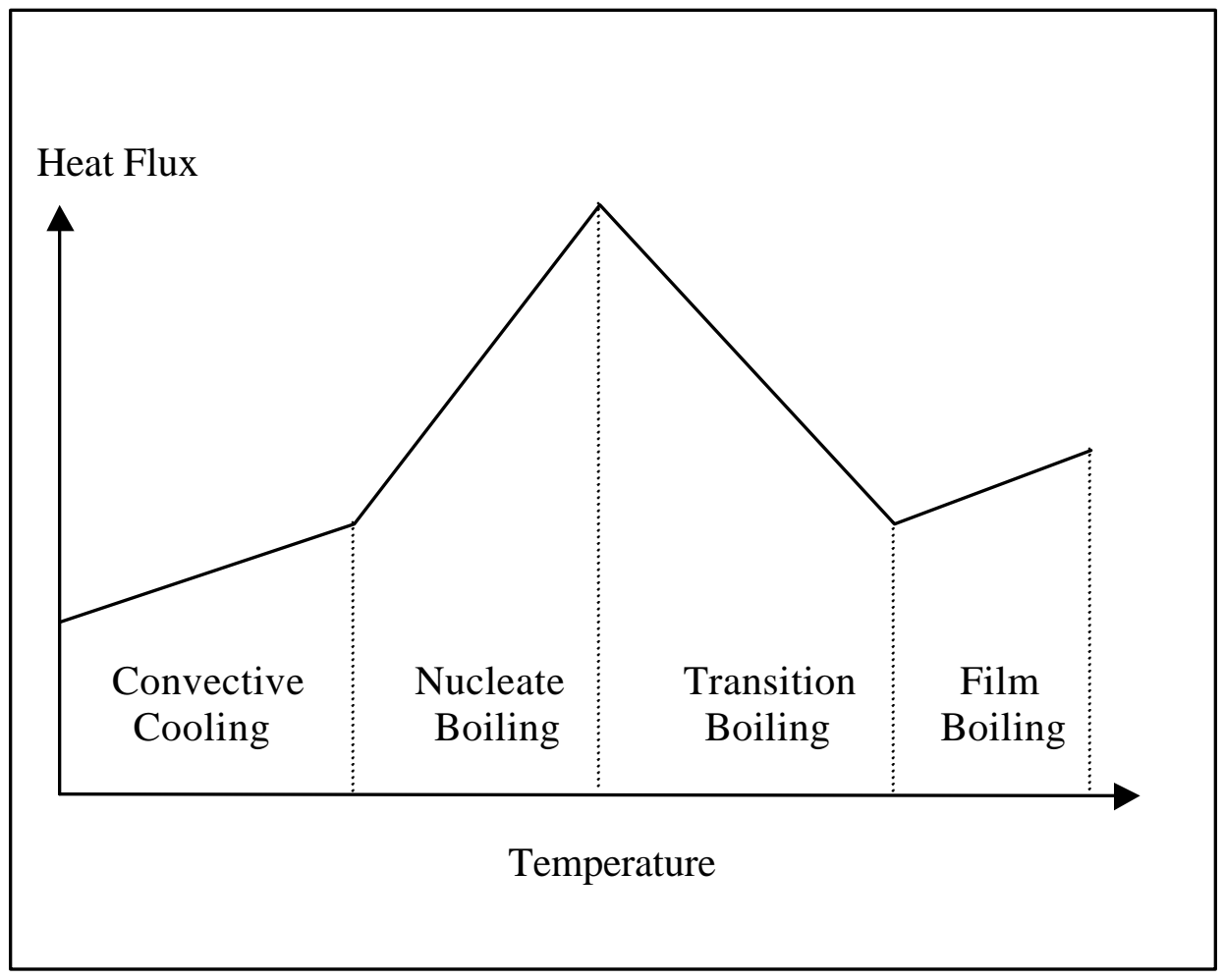

Figure 2.1 An Idealized Heat Flux vs. Surface Temperature for Water Cooling

Modeling of thermal stresses during D.C. casting was performed by Fjaer and Mo for aluminum billets [12]. In their analysis, the material was assumed to be isotropic elastoviscoplastic with the material properties, which are strongly temperature-dependent. Inoue and $\mathrm{Ju}$ [13] formulated a method to simulate solidification process, temperature and stress distributions in casting billets. A modified Perzyna viscoplastic constitutive relation, reflecting the actual liquid-solid phase transformation during the casting process, was proposed. Janin [14] conducted DC casting simulation of aluminum billets with sequentially coupled temperature and stress. Hannart et al. [15] calculated the thermal stresses in DC casting of aluminum slabs using a commercial code MARC $^{\mathrm{TM}}$ with special emphasis on the 
induced stresses which play a major role in the initiation of cracks. Li and Ruan [16] developed an integrated finite element model for transient fluid flow and thermal stresses during continuous casting with a particular reference to aluminum casting. Drezet and Rappaz investigated the thermal-mechanical effect during DC casting of aluminum alloys experimentally [17] and numerically $[18,19]$. In their numerical procedure, the fully coupled simultaneous heat transfer and stress analysis was performed using ABAQUS ${ }^{\mathrm{TM}}$. The nonlinear material properties, such as creep and latent heat, are treated by Newton-Raphson integration. Three-dimensional models of DC casting of aluminum ingot were developed by Devadas and Grandfield [20] and Watanabe and Hayashi [21]. Sequentially coupled temperature and stress simulation of three-dimensional ingot was also performed by Rogers et al. [22]. Since their analysis is not fully coupled, gap formation between the ingot bottom and the bottom block can not be included in the simulation.

Since the most possible location for crack initiation is at the ingot bottom, optimizations on the shape of the bottom block have been studied extensively. Droste and Schneider [23] experimentally investigated effects of water volume and casting speed on the formation of the butt curl and swell. They found that the butt curl increased with the casting speed and could be reduced by using low water volume with high casting speed to promote film boiling. Schneider et al. [24] and Jensen et al. [25] have developed a new starting block shape. They found that using the special starting block could reduce butt curl. Fjaer and Jensen [26] constructed a mathematical model to analyze butt curl deformation of sheet ingots associated with different starting block shapes. 
Although significant knowledge of DC casting process has been gained from the studies mentioned before, to this date, the mechanisms involved in both the direct water cooling model and crack formation are still not well understood to this date. 


\section{CHAPTER 3}

\section{NUMERICAL MODELING OF DC CASTING [5]}

A numerical simulation model of transient D.C. casting of aluminum ingot has been developed and implemented in a general purpose finite element code ABAQUS $^{\mathrm{TM}}$ to determine the timedependent temperature and thermal stress fields in the ingot during casting. Details of the model have been described in an annual report [5]. Since this simulation model and its simulation results have been used in this research, it is necessary to recite some details of the model in this chapter.

The model consists of six components, that is, geometry model, material model, boundary conditions, loading conditions, water heat-flow model and numerical procedures. These components are the input to ABAQUS ${ }^{\mathrm{TM}}$ for DC casting simulation.

\subsection{Geometry model}

Figure 3.1 shows the geometry of a ingot. Due to the symmetrical nature about the vertical center line, it is only necessary to simulate one quarter of the ingot as shown in Fig. 3.1. The bottom block is also included in the model in order to simulate the heat transfer across the ingot bottom surface. Based on the actual design from Century Aluminum of West Virginia, this bottom block has curved faces and is made of steel. The model is also capable of simulating the thermal insulation pad placed at the center on the upper surface of the bottom block and the insulation tape around the corner peripheries of the ingot bottom. The pad and the tape are used to reduce the heat transfer at these locations. They are textiles made of 


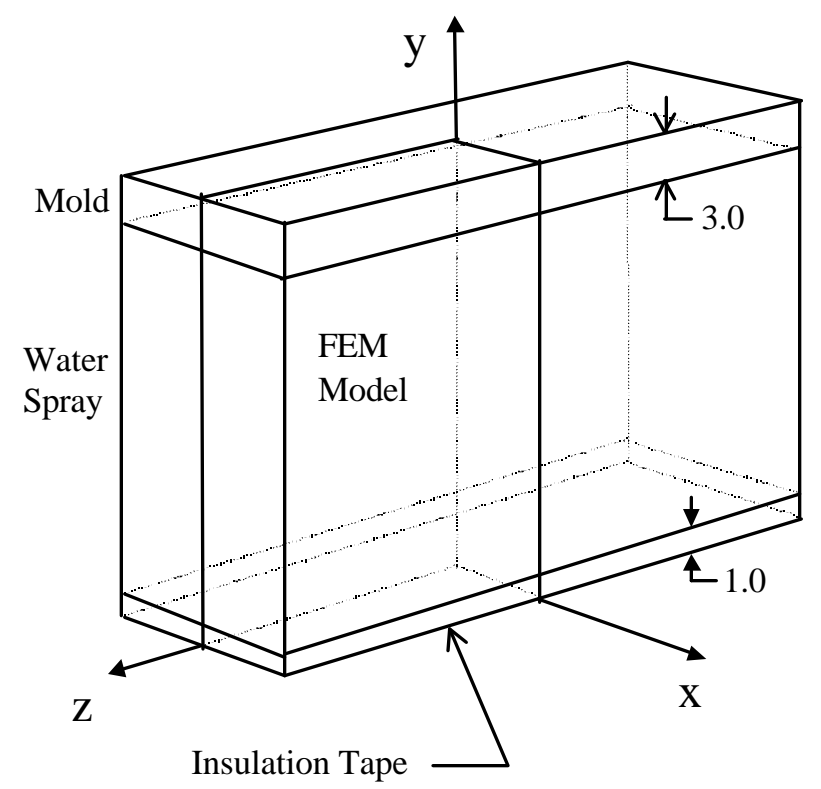

Location of Finite Element Model of the Ingot

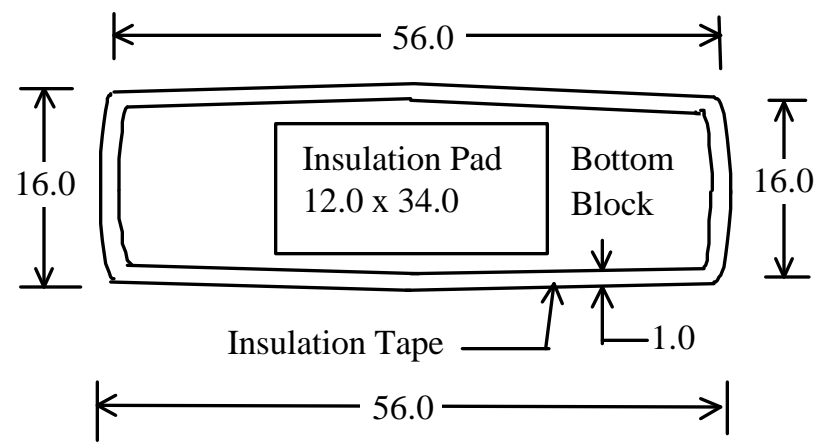

Top View of Bottom block, Unit: in

Figure 3.1. Simulation Model of Ingot and Bottom Block [5]

fiber glass. The ingot width and thickness change with cases. Most of FE simulations were carried out up to 30 inches ingot length where steady state is reached. 
The finite element mesh of quarter ingot and bottom block is shown in Figure 3.2. This model consists of 6,048 eight-node brick elements. Fully coupled temperature and displacement elements are used to the simulation studies. The thermal insulation pad and tape are modeled with interface elements of zero-thickness. The contacting face between the ingot and the bottom block is simulated by the fully coupled temperature-displacement interface elements.

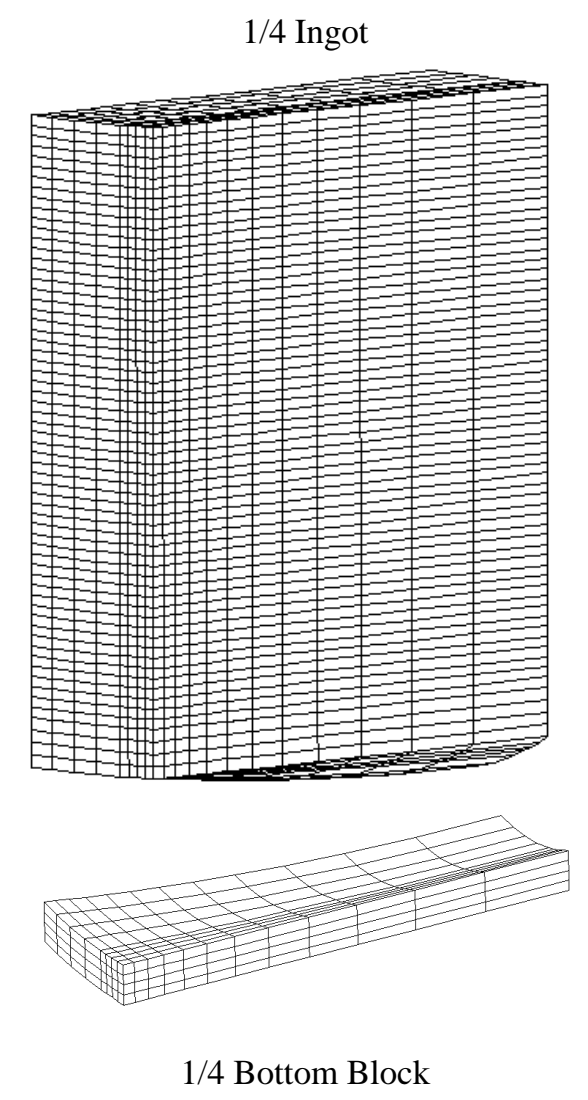

Figure 3.2. Finite Element Mesh of Ingot and Bottom Block.

\subsection{Material Model}

The aluminum ingot is modeled as a continuous isotropic thermal elasto-plastic material with a constant coefficient of thermal expansion but phase dependent conductivity and specific heat. The solid part of the ingot is assumed to be elastic-plastic and isotropic hardening with 
temperature dependent elastic properties and strain hardening curves. The liquid part is assumed to be an ideal fluid. The latent heat of fusion released during the liquid to solid phase change is also included in the model.

Thermal properties such as thermal conductivity, specific heat, densities of both solid and liquid phases were obtained from available literature data. The thermal properties of the mushy zone were determined through linear interpolation between those of the solidus and liquidus. The latent heat of the material is calculated according to the composition of the alloy. The data used in the simulation studies are listed in Table 3.1.

Table 3.1 Thermal Properties of Al-7050 Used in Simulation [5]

\begin{tabular}{|c|c|}
\hline Liquid Density $\left(\mathrm{lb} / \mathrm{in}^{3}\right)$ & 0.087 \\
\hline Solid density $\left(\mathrm{lb} / \mathrm{in}^{3}\right)$ & 0.102 \\
\hline Latent Heat $(\mathrm{Btu} / \mathrm{lb})$ & 164.0 \\
\hline Liquid Specific Heat $\left(\mathrm{Btu} / \mathrm{lb} /{ }^{0} \mathrm{~F}\right)$ & 0.243 \\
\hline Solid Specific Heat $\left(\mathrm{Btu} / \mathrm{lb} /{ }^{0} \mathrm{~F}\right)$ & 0.230 \\
\hline Liquid Conductivity $\left(\mathrm{Btu} / \mathrm{in} / \mathrm{hr} /{ }^{0} \mathrm{~F}\right)$ & 4.592 \\
\hline Solid Conductivity $\left(\mathrm{Btu} / \mathrm{in} / \mathrm{hr} /{ }^{0} \mathrm{~F}\right)$ & 8.667 \\
\hline
\end{tabular}

The mechanical properties of the as-cast Al-705 ingot were measured under on-cooling condition using coupon specimens cut from the as-cast ingot as reported by Lu et al. [27]. Figure 3.3 shows the stress-strain curve. 


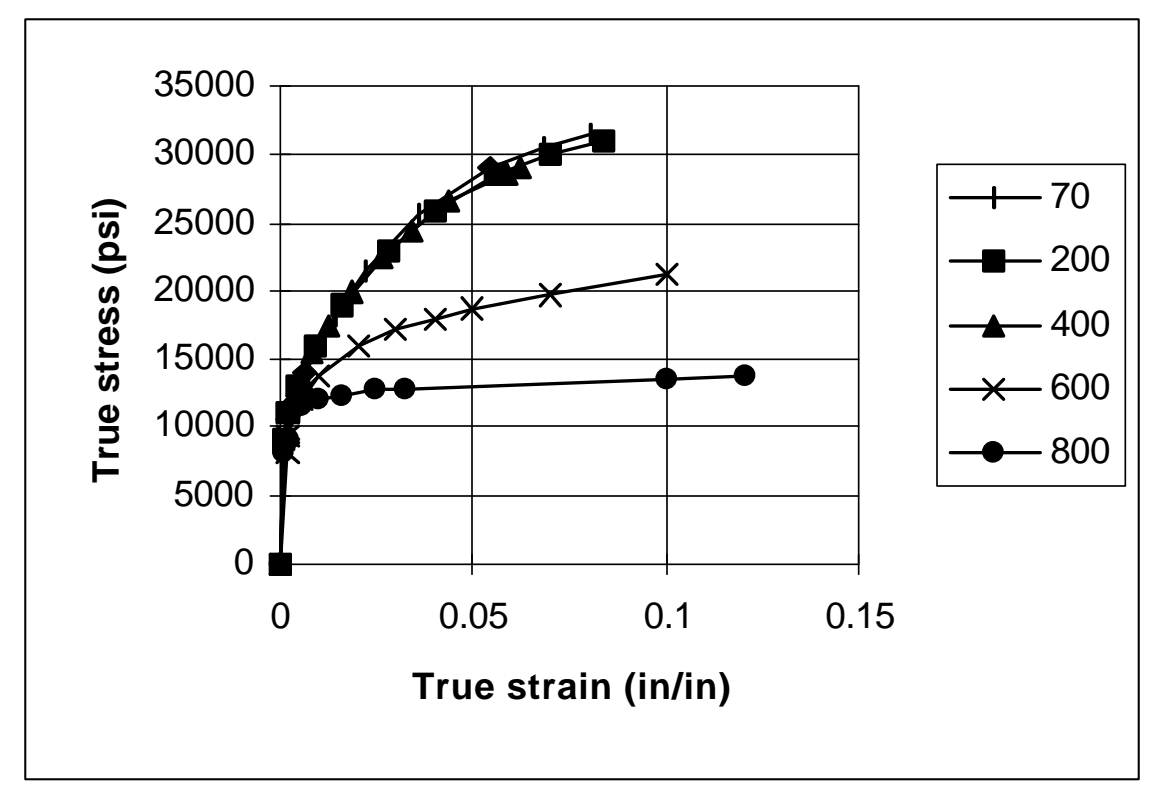

Figure 3.3 Measured As-Cast Stress-Strain Curves of Alloy Al-7050 [27]

For the liquid portion of the ingot, the elastic modulus is assumed to be zero, i.e. no stress in it. The mechanical properties of the mushy zone were also determined through linear interpolation between those of the solid and liquid metal.

The thermal and mechanical properties, which were used in the simulation of the steel bottom block, are listed in Table 3.2.

\subsection{Boundary conditions}

For this coupled thermal-stress model, there are three types of boundary conditions imposed on the different locations of the domain of the finite element model. These boundary conditions include: (1) thermal boundary condition, (2) mechanical boundary condition, and (3) coupled boundary condition. 
Table 3.2 Properties of Steel Bottom Block Used in Simulation [5]

\begin{tabular}{|l|c|}
\hline Density $\left(\mathrm{lb} / \mathrm{in}^{3}\right)$ & 0.28 \\
\hline Specific Heat $\left(\mathrm{Btu} / \mathrm{lb} /{ }^{0} \mathrm{~F}\right)$ & 0.11 \\
\hline Conductivity $\left(\mathrm{Btu} / \mathrm{in} / \mathrm{hr} /{ }^{0} \mathrm{~F}\right)$ & 2.20 \\
\hline Elastic Modulus (Msi) & 30.0 \\
\hline Poisson's Ratio & 0.29 \\
\hline
\end{tabular}

The thermal boundary conditions are assumed as follows:

1. At the top of the casting ingot, temperature of the liquid metal is initially set to $1200^{\circ} \mathrm{F}$ by adding a flat layer of brick elements set at $1200^{\circ} \mathrm{F}$ at the beginning of each simulation step.

2. On the planes of symmetry, $x=0$ and $z=0$, there is no heat flux in the direction normal to these planes.

3. At the interface between ingot and water containing mold the heat transfer coefficient is estimated to be $3.0 \mathrm{Btu} /\left(\mathrm{in}^{2} . \mathrm{hr} .{ }^{\circ} \mathrm{F}\right)$ according to the thermal conductivity of the mold material and mold thickness and also verified by the steady-state temperature measurement conducted at Century Aluminum of West Virginia.

4. At the bottom of the model, $y=0$, the heat transfer is simulated by interface elements in order to account for the coupling effect of gap opening due to the butt curl as well as heat insulation pad and tape.

5. At the water-contacting surface of the ingot, a relationship between the heat flux density running out of the ingot surface and the surface temperature is established. 
This relationship is also depending on the water flow rate and will be discussed in details in the later part of this chapter.

The mechanical boundary conditions imposed on the model are:

1. It is assumed that there is no friction or other constraint between the casting ingot and the mold.

2. On the planes of symmetry, $x=0$ and $z=0$, there is no displacement in the directions normal to these planes.

3. The ingot bottom surface is constrained in the vertical direction only in the area where the lower surface of the ingot and the upper surface of the bottom block are still in contact. Since a gap is usually formed due to the butt curl, these surfaces are modeled by interface elements.

For the bottom block, the thermal boundary condition of its side surface is assumed to be the same as that of ingot direct cooling face. At the bottom surface, it is thermally insulated. The mechanical boundary conditions of bottom block are:

1. On the planes of symmetry, $\mathrm{x}=0$ and $\mathrm{z}=0$, there is no displacement in the direction normal to these planes.

2. The block is firmly supported at its bottom surface in the vertical direction. The weight of the casting material is included in the model.

The coupled thermal-mechanical boundary conditions are described below. At the contacting face between ingot and bottom block, the heat transfer and mechanical deformation are cou- 
pled, which is modeled as a functional relation between heat transfer coefficient and interfacial gap opening. It is assumed that the gap is always filled with water. The thermal conductivity of water is $\mathrm{k}_{\mathrm{water}}=0.03274 \mathrm{Btu} /\left(\mathrm{in} . \mathrm{hr} .{ }^{\circ} \mathrm{F}\right)$. The heat transfer coefficient of the interface between the ingot bottom and the bottom block due to oxide layer is estimated as $\mathrm{h}_{\text {oxide }}=$ 2.445 Btu/(in $\left.{ }^{2} . \mathrm{hr}^{\circ}{ }^{\circ} \mathrm{F}\right)[4,28]$. The combined heat transfer coefficient across the interface is calculated according to the equation

$$
h_{\text {water }}+\text { oxide }=\frac{1}{\frac{d}{k_{\text {water }}}+\frac{1}{h_{\text {oxide }}}}
$$

where $\mathrm{d}$ is the gap opening displacement and is a time dependent variable.

Similarly, the combined heat transfer coefficients at the interfacial areas between the ingot and insulation pad or tape are

$$
\begin{aligned}
& h_{\text {water }}+\text { pad }+ \text { oxide }=\frac{1}{\frac{d}{k_{\text {water }}}+\frac{t_{\text {pad }}}{k_{\text {pad }}}+\frac{1}{h_{\text {oxide }}}} \\
& h_{\text {water }}+\text { tape }+ \text { oxide }=\frac{1}{\frac{d}{k_{\text {water }}}+\frac{t_{\text {tape }}}{k_{\text {tape }}}+\frac{1}{h_{\text {oxide }}}}
\end{aligned}
$$

where $\mathrm{k}_{\mathrm{pad}}=\mathrm{k}_{\mathrm{tape}}=0.04815 \mathrm{Btu} /\left(\mathrm{in} . \mathrm{hr} .{ }^{\circ} \mathrm{F}\right)$ is the thermal conductivity of the insulation material. Thickness of the pad is $t_{\mathrm{pad}}=0.025$ inch and thickness of the tape is $\mathrm{t}_{\text {tape }}=0.015$ inch. These relations are also shown in Figure 3.4. 


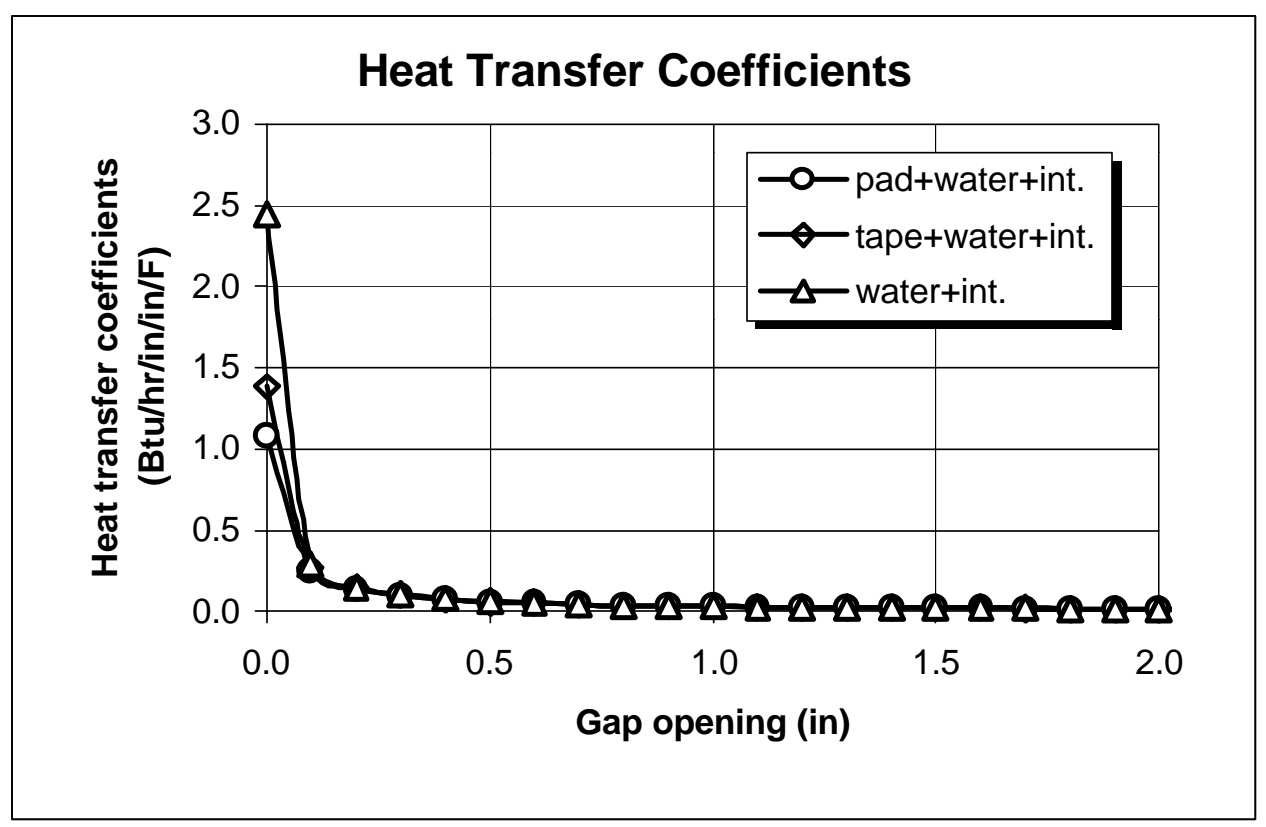

Figure 3.4 Heat Transfer Coefficient of the Interface
between Ingot Butt and Bottom Block

\subsection{Loading conditions}

The thermal loading condition is to add hot liquid metal layers to the top of the casting ingot. The temperature of the liquid metal is $1200^{\circ} \mathrm{F}$. Another thermal loading is the latent heat generated during the phase change of the alloy. Thus, it is applied over the area of the mushy zone at the temperature between $975^{\circ} \mathrm{F}$ and $1175^{\circ} \mathrm{F}$.

There is no external mechanical load applied to the ingot except its own weight. The weight of the casting material is included in the model as distributed load. Since the ingot accelerates slowly when it start to move and then is dropping down in a constant -speed the inertial effect is not considered in the simulation. 


\subsection{Heat-Flow Water Direct-Chill Model}

From the frozen-in thermal couple measurement of a casting ingot (which was conducted at Century Aluminum of West Virginia), temperature distributions inside the casting ingot during transient stage as well as steady-state stage were obtained. By analyzing these data, the surface temperature and the corresponding normal temperature gradient to the surface are estimated. The surface heat flux density is then determined by multiplying the heat conductivity value (which is assumed to be a constant for the solid metal), to the local temperature gradient.

Thus, relationships between the heat flux density and the surface temperature are established for water flow rate corresponding to 4 holes/in and 2 holes/in at outlet water velocity of 60 in/sec from the mold and hole diameter of $1 / 8$ inch. The mathematical expressions for the established relationships are shown in Equation (3.4) and plotted in Figure 3.5.

$$
F(T)= \begin{cases}F_{m}\left[e^{-\left(\frac{T-150}{100 / 3}\right)^{2}}\right] & T \leq 300^{\circ} F \\ F_{m}\left[(0.9) e^{-\left(\frac{T-150}{200}\right)^{2}}+0.1\right] & T>300^{\circ} F\end{cases}
$$

where $F_{m}$ is the peak value of the heat flux density which depends on the water flow rate, and $T$ is the ingot surface temperature.

These relationships are sometimes called boiling curves in terms of heat flux density. The ascending part of the curve represents the increasing convective heat transfer with elevating temperature. In this stage, steam bubbles begin to form at the boiling temperature of $212^{\circ} \mathrm{F}$ 
and the formation of the bubbles absorbs heat and then carries away the heat. The higher the temperature is, the more heat the steam bubbles can carry away. However, as the temperature reaches about $300{ }^{\circ} \mathrm{F}$, the steam bubbles become too many. These bubbles form a steam film on the ingot surface to prevent most of the cooling water from directly contacting the ingot surface. As the temperature increases, the steam film becomes thicker reducing the ability of heat exchange between the cooling water and the ingot. This is the reason for the descending part of the boiling curve. As the temperature increases even higher, a stable film is formed and the heat flux becomes constant and this stage is called film boiling.

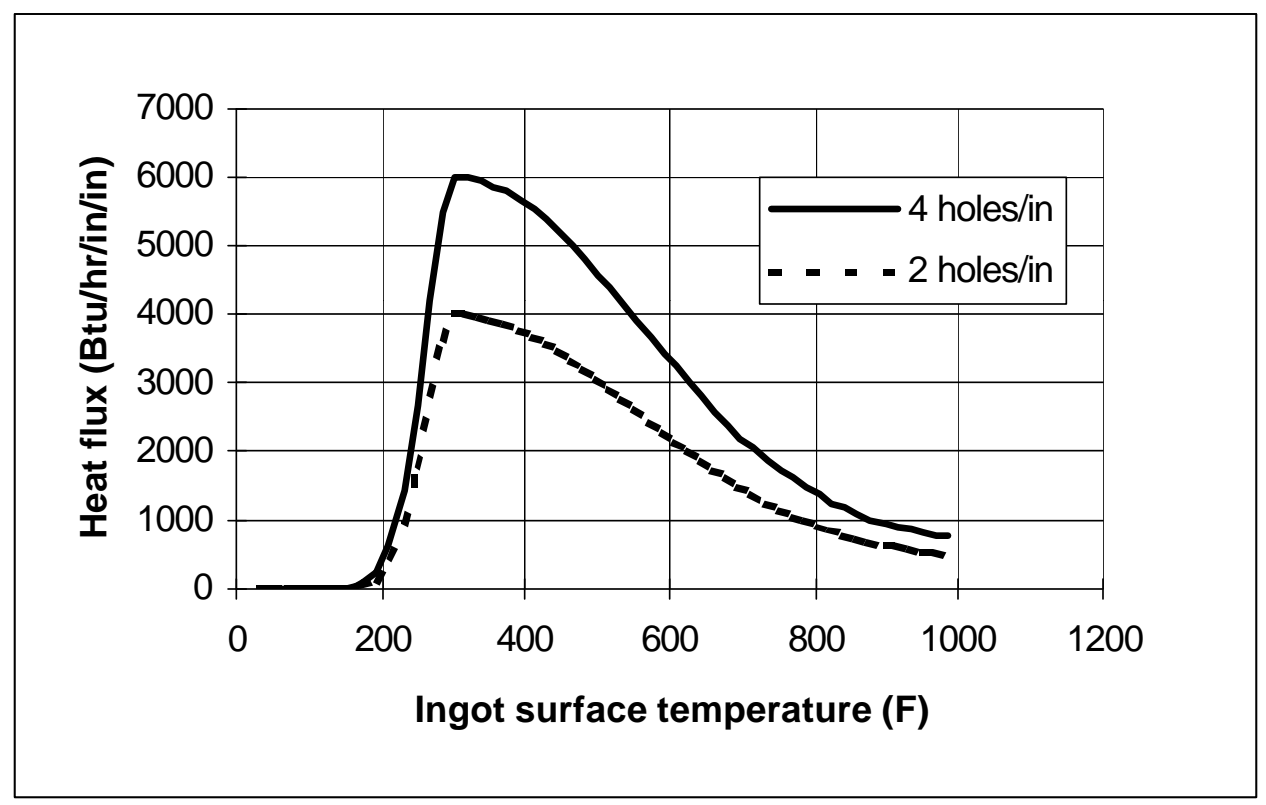

Figure 3.5 Heat Flux Density vs. Surface Temperature of On-Cooling Ingot [5]

Since the water hole spacing changes continuously, a second order polynomial (Equation $3.5)$ is selected to represent the relationship between the heat flux density and the water flow 
rate. This relationship is established from three experimental points for the water flow rates in the 4 holes/in and 2 holes/in arrangements as shown in Figure 3.6.

$$
F_{m}=-(3000) Q^{2}+(7500) Q
$$

where $\mathrm{Q}$ is the water flow rate. The values for $\mathrm{Q}$ are 1 and 0.5 for the 4 holes/in and 2 holes/in arrangements, respectively. Also, to account for the heat transfer reduction due to the heat insulation tape which is mounted around the corner of the ingot bottom as shown in Figure 3.1, twenty five percent less heat flux density is assumed in this area.

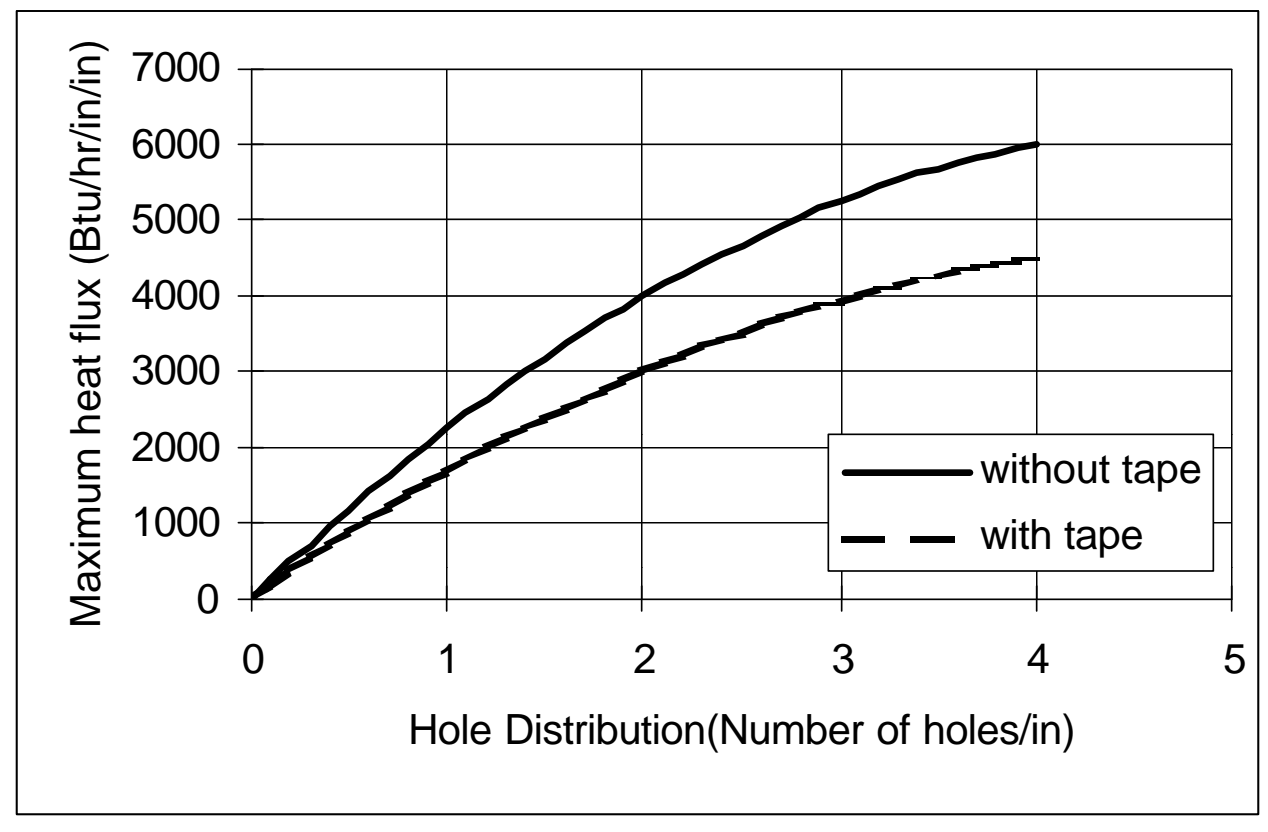

Figure 3.6 Maximum Heat Flux Density vs. Hole Spacing 


\subsection{Numerical procedure}

In the 3-D transient casting simulation, the mesh of the FE model is fixed on material. Since the ingot is dropping down at a constant rate during casting, the inverse modeling was used, i.e. the finite element model is growing in length by continuously adding half inch thick layer of elements at appropriate time interval on the upper surface of the ingot. In the numerical model, the ingot and the bottom block are fixed in space. Equivalently, the water-containing mold is moving up at a constant speed. This effect is simulated by the moving-up boundary condition of the mold and prescribing heat flux at the ingot side surface below the mold.

Fully coupled temperature and displacement elements are used in this analysis. The temperature-displacement coupling means that temperature change leads to thermal expansion/shrinkage and this rapid thermal straining will generate heat, which is small, compared to the latent heat of the alloy. This heat is, therefore, neglected in the current simulation studies. The latent heat of fusion of the material is important in the modeling analysis, which makes the numerical simulation highly nonlinear.

The fully coupled analysis is necessary to simulate the complicated process in the ingot and the bottom block. The reason is that the deformation of the ingot will form a gap between the ingot bottom surface and bottom block, and the gap will alter the heat transfer condition at that area. The interface is also simulated by fully coupled temperature-displacement interface elements, which are originally set at zero-thickness. They connect two opposite sides of the brick elements allowing the gap opening but not overlapping. They also allow heat transfer with variable heat transfer coefficients depending on the gap opening displacement. 
Water flow pattern II, as shown in Figure 3.7, was chosen for the FE simulations. Figure 3.8 shows the dimension and the actual shape of the ingot. The water flow rate along the narrow side is one half of that at the center of the wider side.

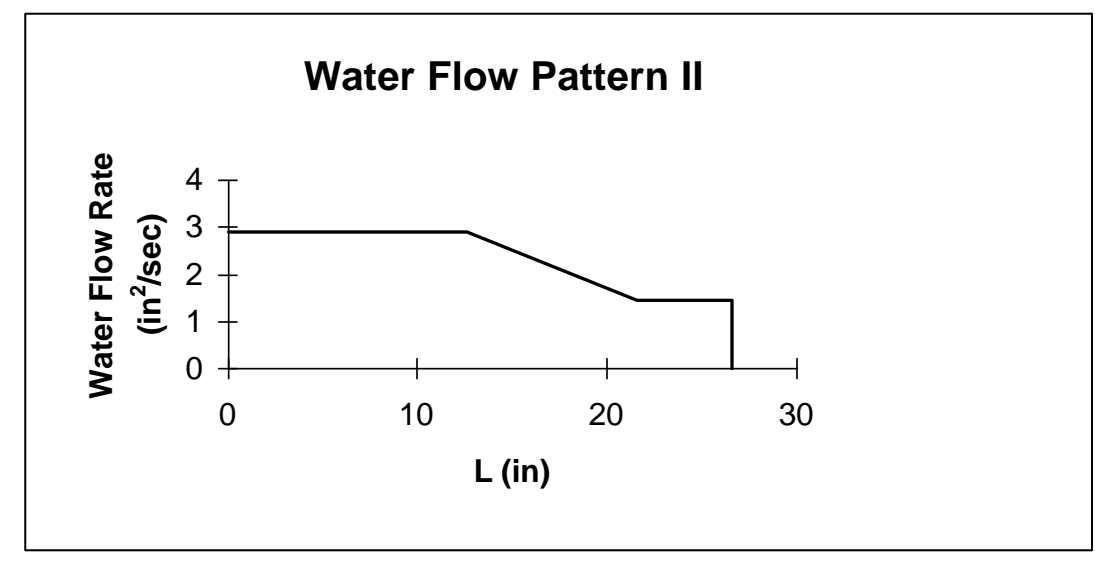

Figure 3.7 Water Flow Pattern along Rolling Face of Ingot

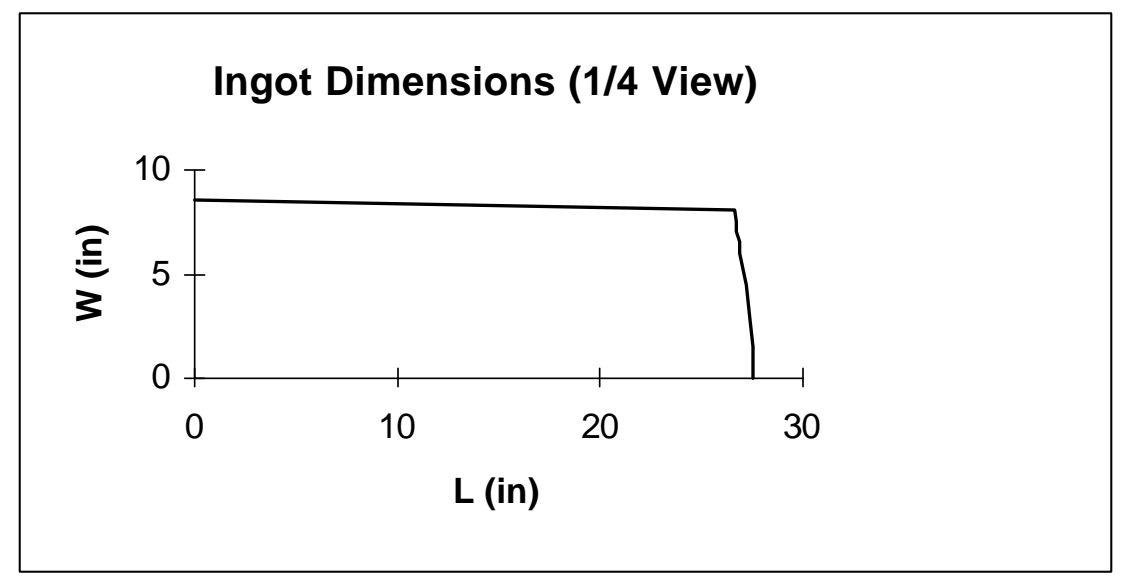

Figure 3.8 Ingot Dimensions

In order to increase the computational efficiency, elements of the whole model are inactivated at the beginning of simulation, and then addition of elemental layers are activated one 
by one. Since the analyses are highly nonlinear, difficulties have been encountered to achieve the necessary convergence in a number of cases. In such cases, some of the input parameters had to be adjusted to make the simulations successful.

The simulations are conducted on a Silicon Graphic Challenge Workstation. The average CPU time for each run is approximately 60 hours. The restarting procedure of ABAQUS ${ }^{\mathrm{TM}}$ was used if an analysis requires the continuation in computation based on the results from a previous run. 


\section{CHAPTER 4}

\section{ANALYSIS OF RESULTS}

A computer simulation model of transient DC casting of aluminum ingot has been developed [5]. A general-purpose finite element package $\mathrm{ABAQUS}^{\mathrm{TM}}$ is used to simulate the transient state of casting process. The temperature, displacement and stress distribution fields determined by ABAQUS ${ }^{\mathrm{TM}}$ facilitate the understanding of the mechanism of solidification cracking and the curling action of ingot. The following analysis is based on an ingot cross section of 56"x16", which is referred to as the base case. Each DC casting simulation was carried out from initial transient stage to the beginning of steady state stage (at ingot length of 30 inches). The casting speed is $1.9 \mathrm{in} / \mathrm{min}$ with ingot corner radius of $1.0 \mathrm{inch}$.

\subsection{Temperature Field}

Figures 4.1 and 4.2 show the temperature contours on the ingot inner and outer faces. The lowest temperature is on the ingot surface below mold. This is the cooling water impinging area. The outside surface is cooled first resulting in solidification of a surface skin but the ingot inner region is still in hot liquid state. The solidifying region, which is the mushy zone between liquid (at $\left.1,165^{\circ} \mathrm{F}\right)$ and solid $\left(910^{\circ} \mathrm{F}\right)$, can be identified by the temperature contours, which are useful information for metallurgist to correlate the temperature field and ingot microstructure since the solidification rate determines grain formation of the alloy. As shown in Figure 4.1, the unevenness in temperature distribution generates thermal stresses and may induce micro-cracks, which will be discussed later. 


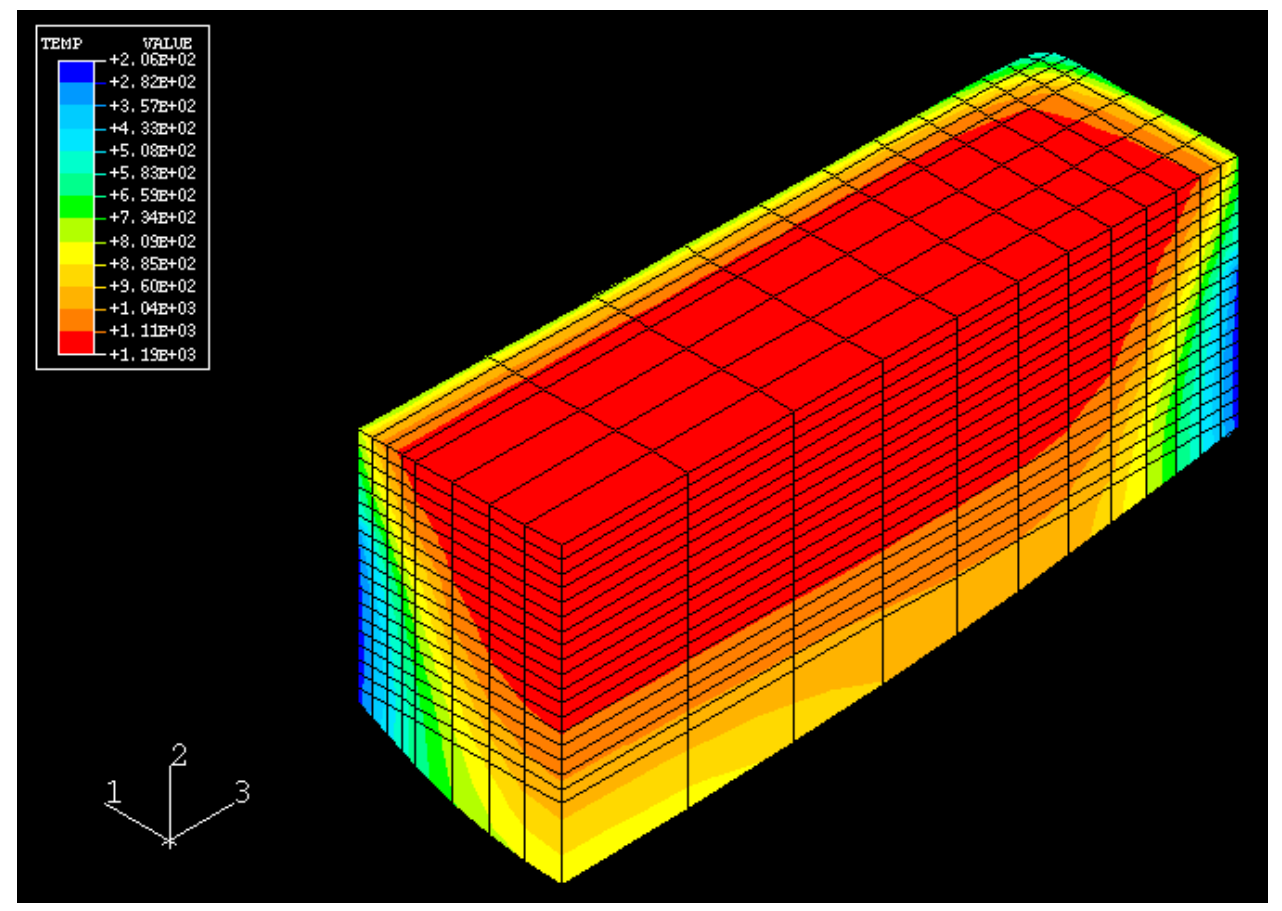

Figure 4.1 Temperature Contour of Inner Face (base case, ingot length: 20 inches)

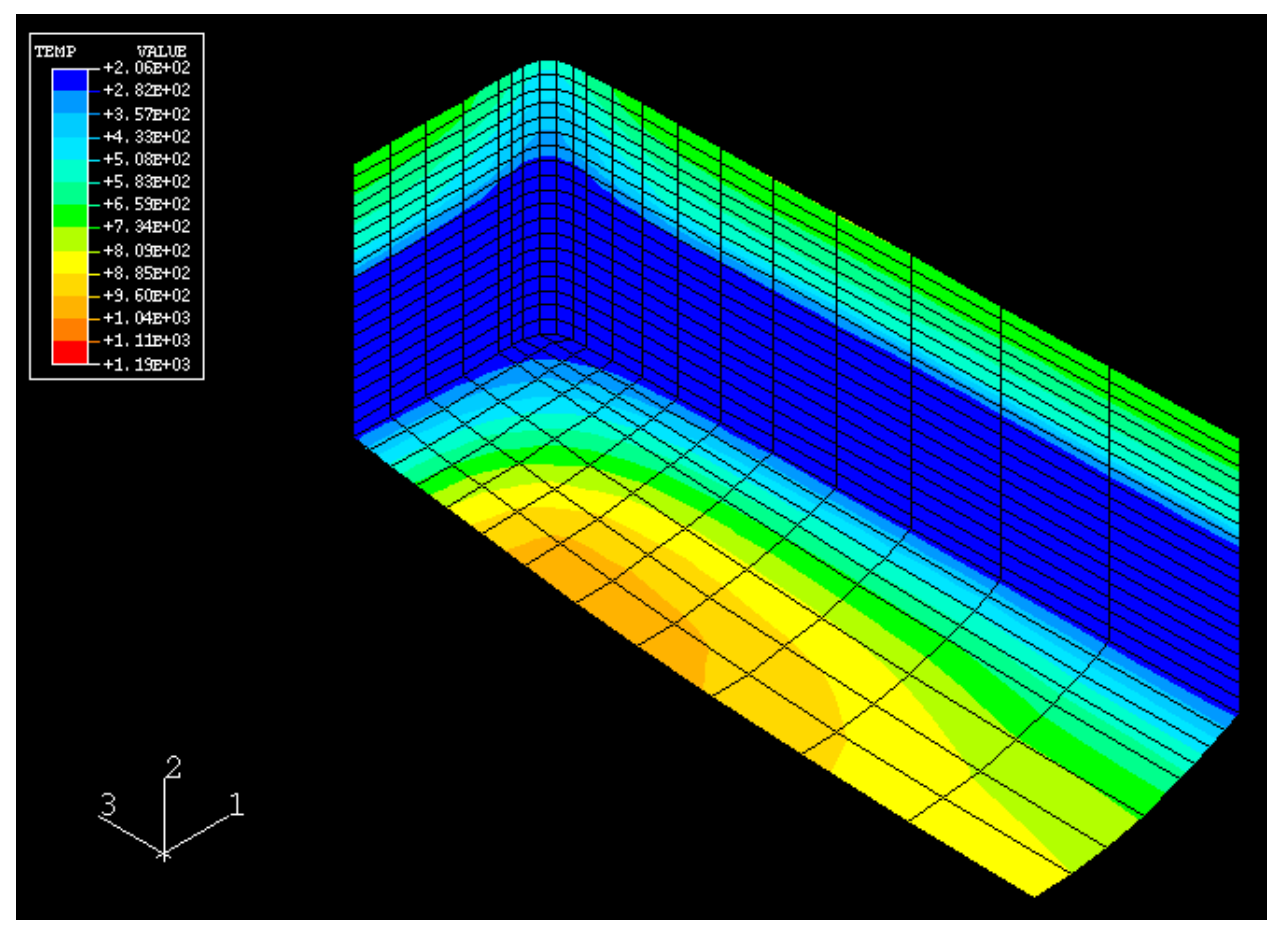

Figure 4.2 Temperature Contour of Outside Face (base case, ingot length: 20 inches) 


\subsection{Displacement Field}

Figure 4.3 shows the ingot butt deformation at 10 inches long. At the beginning of the DC casting, the ingot bottom is chilled both by the bottom block and by the mold. As the block moves downward, the ingot is also cooled by the lateral water spray. This rapid chilling generates the excessive uneven contraction that causes butt curl. Butt curl reduces the rigid standing of the ingot on the bottom block and causes portion of the ingot bottom surface to lose contact with the bottom block. Water can enter the gap between bottom block and underside of the ingot. Ingot butt curl is also simulated in the FE DC casting simulation model.

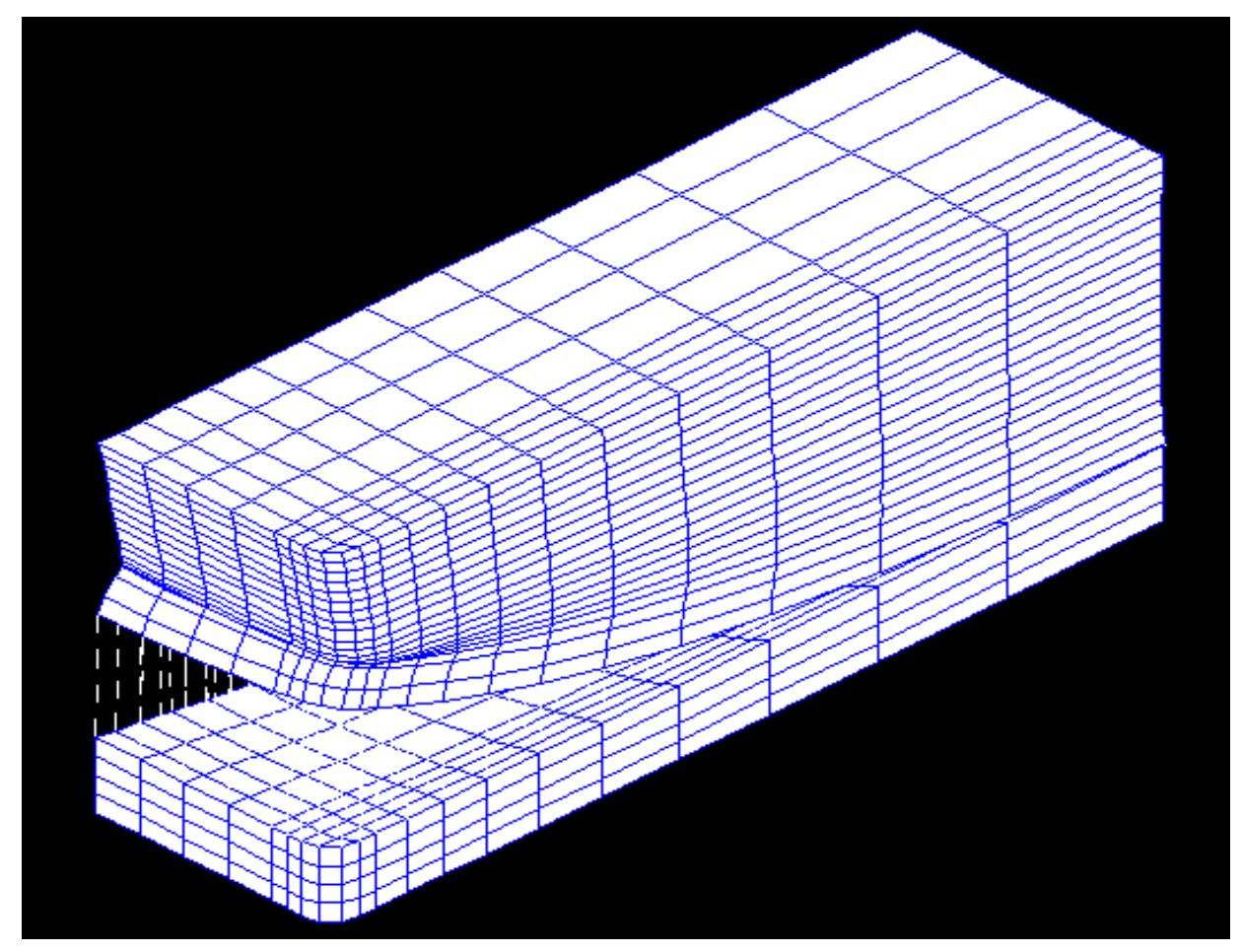

Figure 4.3 Butt Curl Deformation (ingot length: 10 in) 


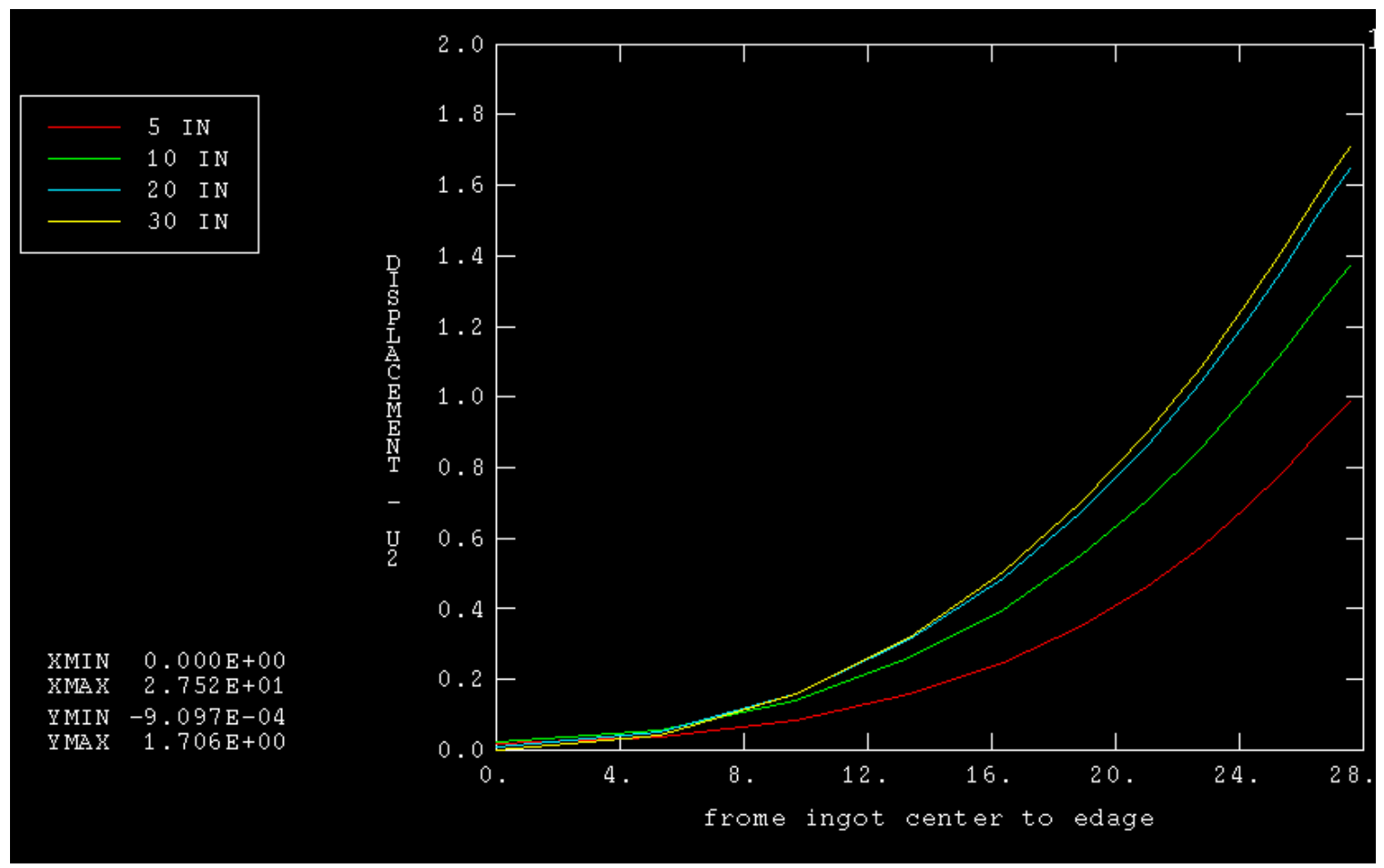

Figure 4.4 Vertical Displacement of Butt Curl at Different Ingot Lengths

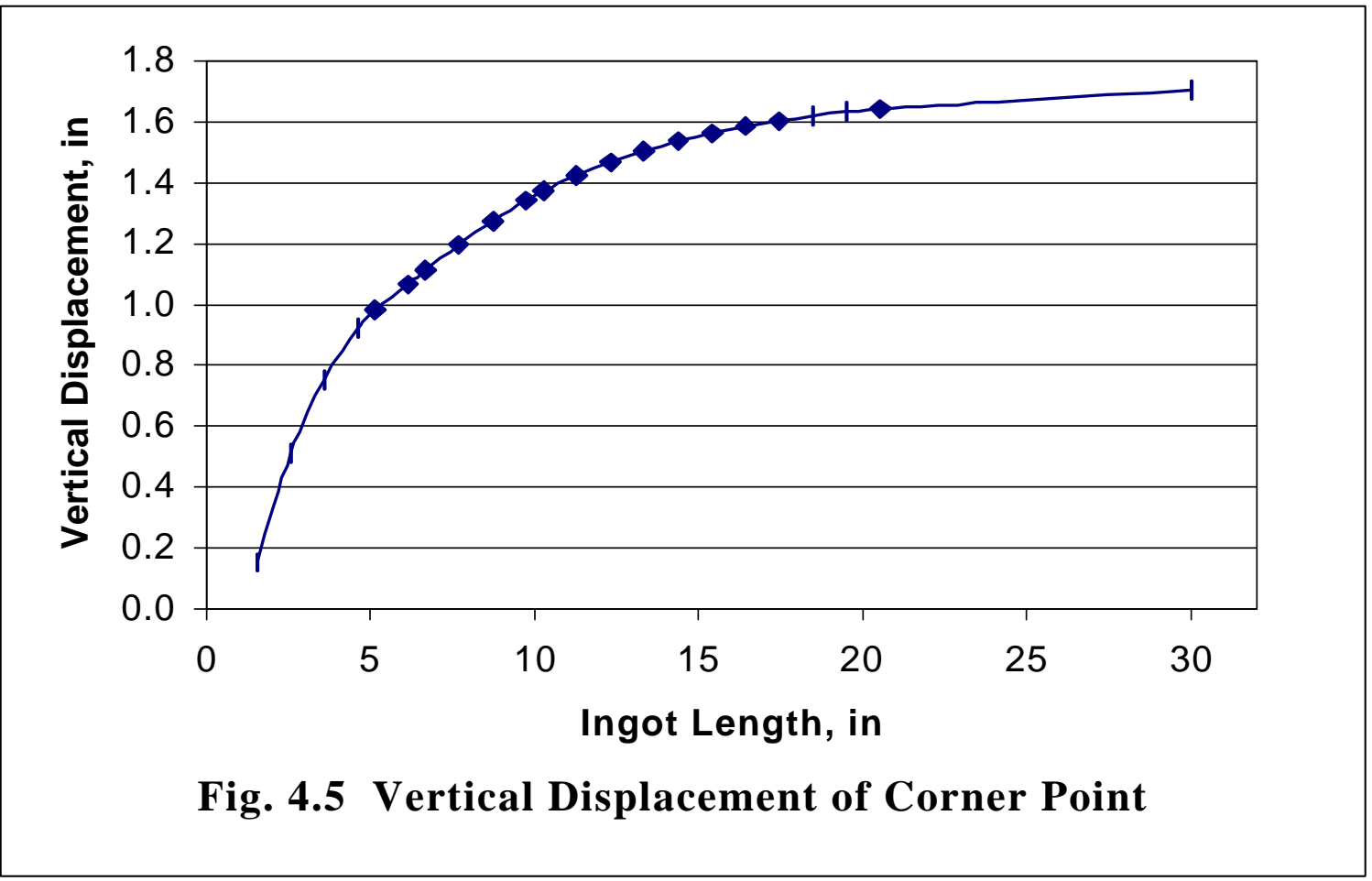


Figure 4.4 shows the vertical displacement of ingot butt edge for four casting steps that are corresponding to four different ingot lengths. The butt curl displacements increase as ingot length increases. The curling speed is not a constant; it is much faster at the beginning and decreases as ingot length increases. This can be clearly seen in Figure 4.5. The slope of the curve represents the curling speed of the ingot.

\subsection{Stress Field}

Figures 4.6 to 4.13 show contours of maximum principal stress for ingot lengths from 5 inches to 30 inches of the base case. The FE results show three types of high stresses in the ingot during DC casting: corner stress, quenching stress, and casting stress.

The corner stress is located along the vertical corner of the ingot. At first, corner stress is limited to a spot as shown in Figure 4.6 and then increases its size as the ingot length grows. The tensile corner stress is along the vertical direction as shown in Figure 4.14. The occurrence of the corner stress is caused by the fact that the corner region is colder than its surrounding.

The quenching stress is located in the first water contact region. It can be seen clearly from the outside view of the maximum principal stress contour plots. The quenching stress location moves up with respect to the ingot bottom and its magnitude remains the same as the ingot length increases.

The casting stress exists in the just solidified ingot region. The location of the high casting stress does not always stay in one place. As shown in Figure 4.7, the casting stress occurs first at the 
center of ingot wide side near the surface. As the ingot length increases, the maximum casting stress (principal stress) moved toward the center point of the ingot as shown in Figures 4.9 and Figure 4.11. This casting stress is referred to as center stress in this report. Another high casting stress zone is located inside the ingot near the quarter area. This high tensile stress zone is built after the ingot length is 20 inches or longer and its magnitude continues to increase until it reaches the steady state. This phenomenon can be seen from Figures 4.11 and 4.13.

\subsection{Normalized Maximum Principal Stress Field}

Since the strength of the alloy is temperature-dependent, the simulation results can be better presented by introducing two normalized stress levels. Either of the stress levels is defined to be the ratio of the stress to the strength of the material at the corresponding temperature. Stress level 1 is defined as the ratio of maximum principal stress to yield strength while stress level 2 is defined as the ratio of maximum principal stress to tensile strength. Due to the huge amount of output data from ABAQUS ${ }^{\mathrm{TM}}$, a PC program (CONVERT) is developed and used to process stress and temperature data of the FE results. This program will be described in details in Chapter 6. Since variance of the yield strength is relatively small and tensile strength may be correlated to ingot micro-cracks, stress level 2 was chosen as a criterion for predicting the possible occurrence of ingot cracking.

Figures 4.15 to 4.18 show the locations of the stress level 2 for four ingot lengths. Color codes of blue, yellow, orange and red color represent the values of stress level 2 in range $0.7-0.8,0.8$ $0.9,0.9-1.0$, and $1.0-1.1$, respectively. Quenching stress is not important in the base case because the value of stress level 2 is between 0.7 and 0.8 . The maximum stress level 2 is at the 
center of ingot wide side near surface when ingot length is 5 inches. This is a possible location for initiating center crack. When the ingot length is 10 inches, stress level 2 is decreased indicating that stress relaxation has occurred. After the ingot reaches 20 inches, the maximum stress level 2 is located in ingot central region moving toward quarter area until steady state is reached, which corresponds to ingot length longer than 30 inches, as shown in Figure 4.18. The possible cracking type is quarter crack or $\mathrm{J}$ crack depending on the direction of the maximum principal stress, which will be discussed in Chapter 5 . 


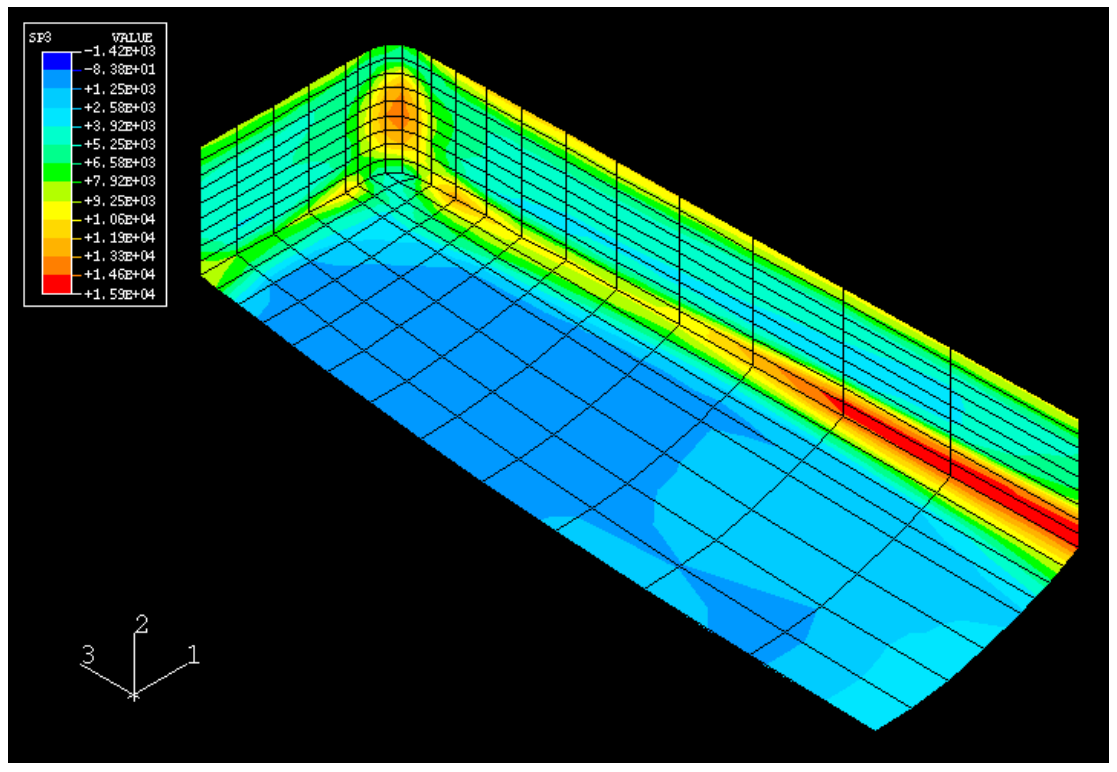

Figure 4.6 Maximum Principle Stress in Base Case, outside view (Ingot length is 5 inches)

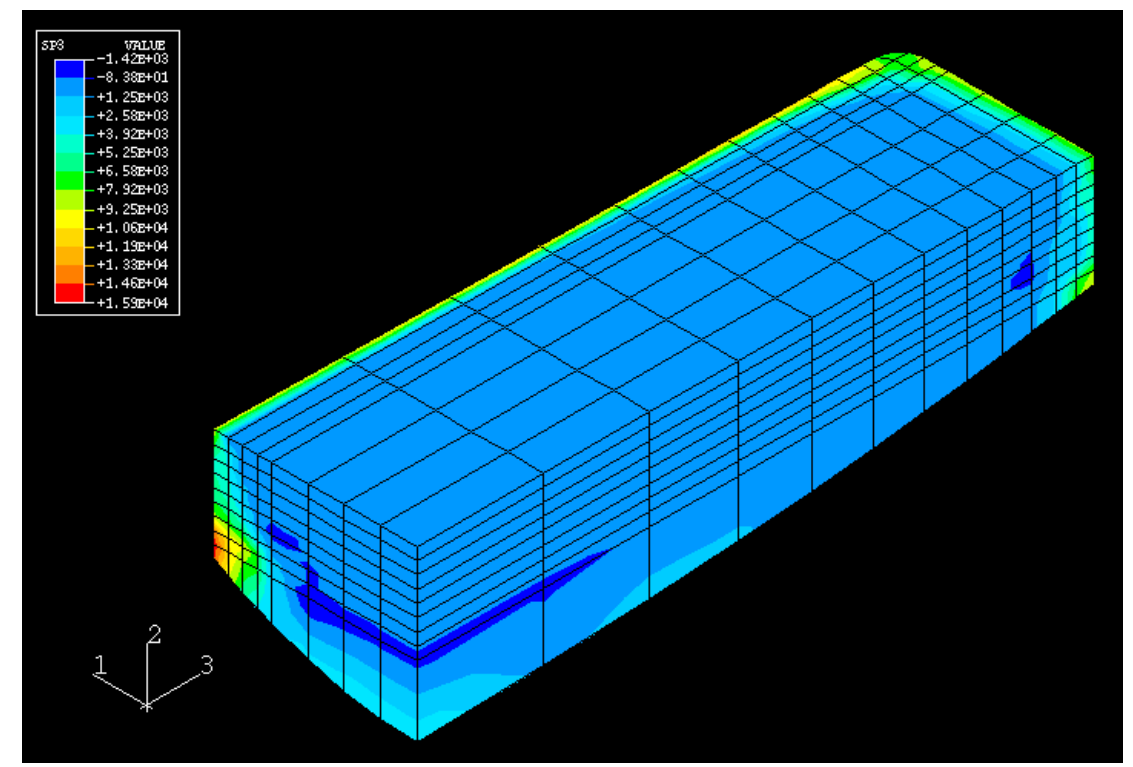

Figure 4.7 Maximum Principle Stress in Base Case, inside view (Ingot length is 5 inches) 


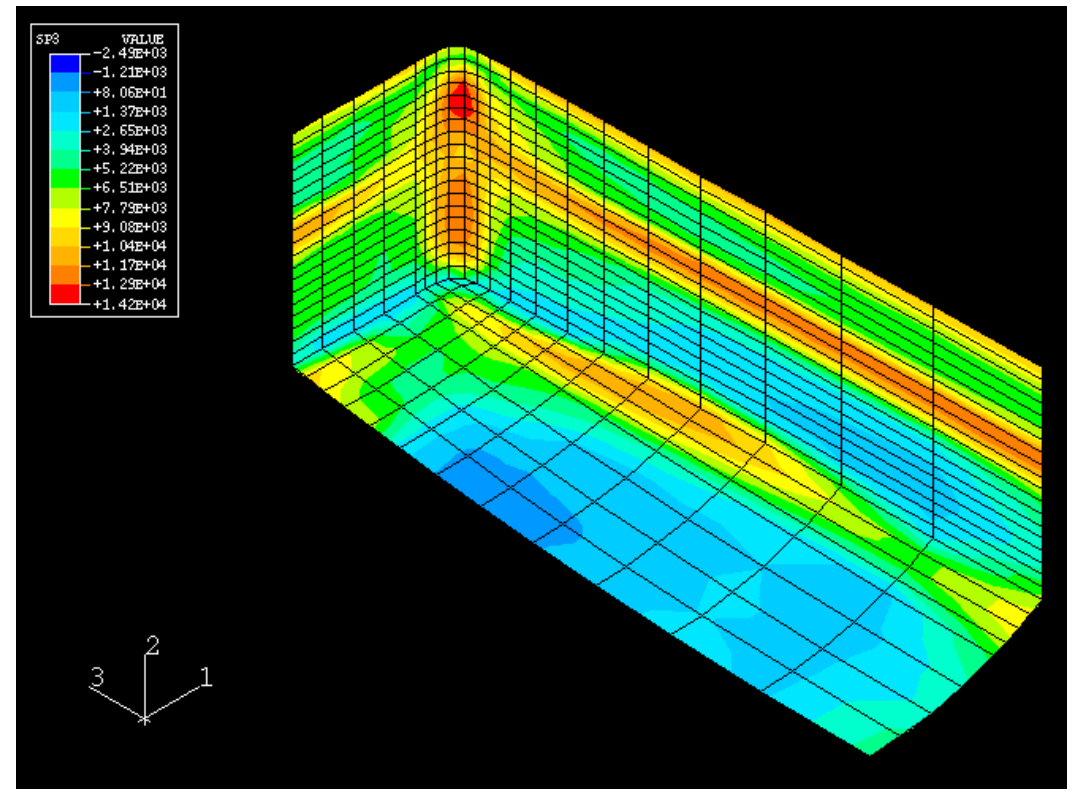

Figure 4.8 Maximum Principle Stress in Base Case, outside view (Ingot length is 10 inches)

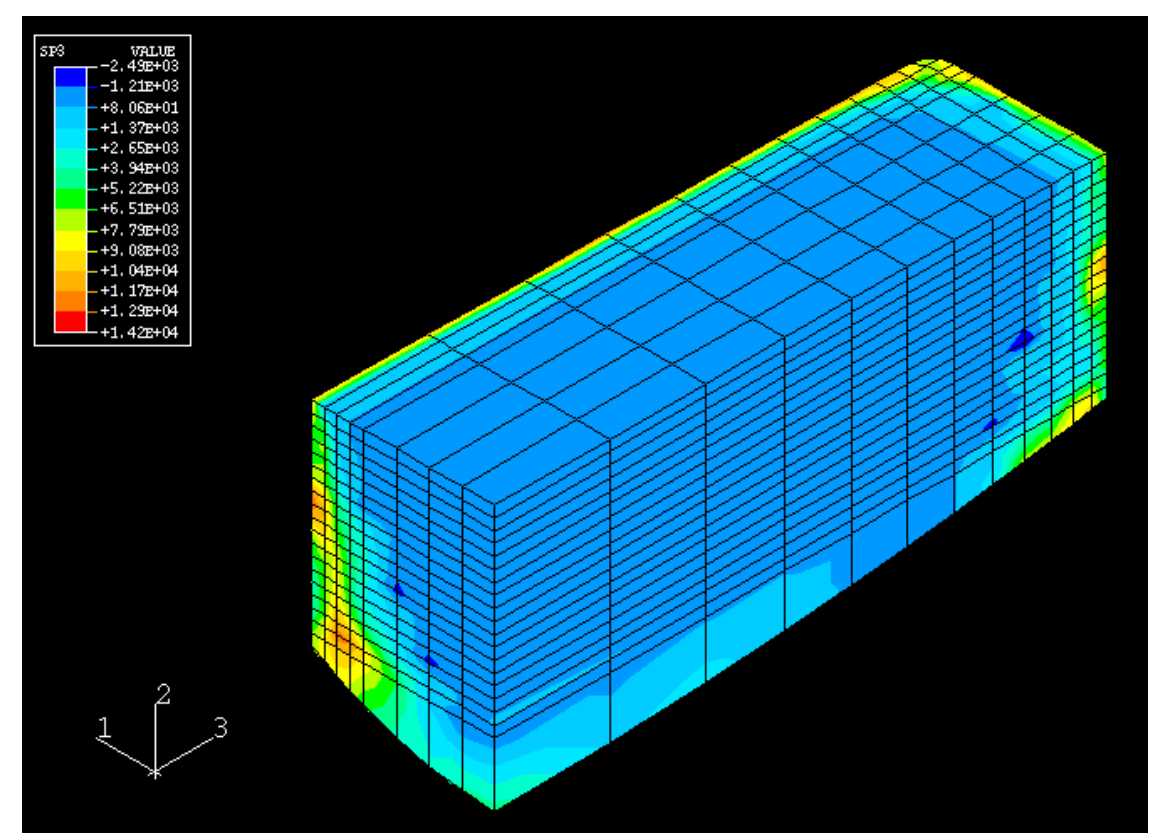

Figure 4.9 Maximum Principle Stress in Base Case, inside view (Ingot length is 10 inches) 


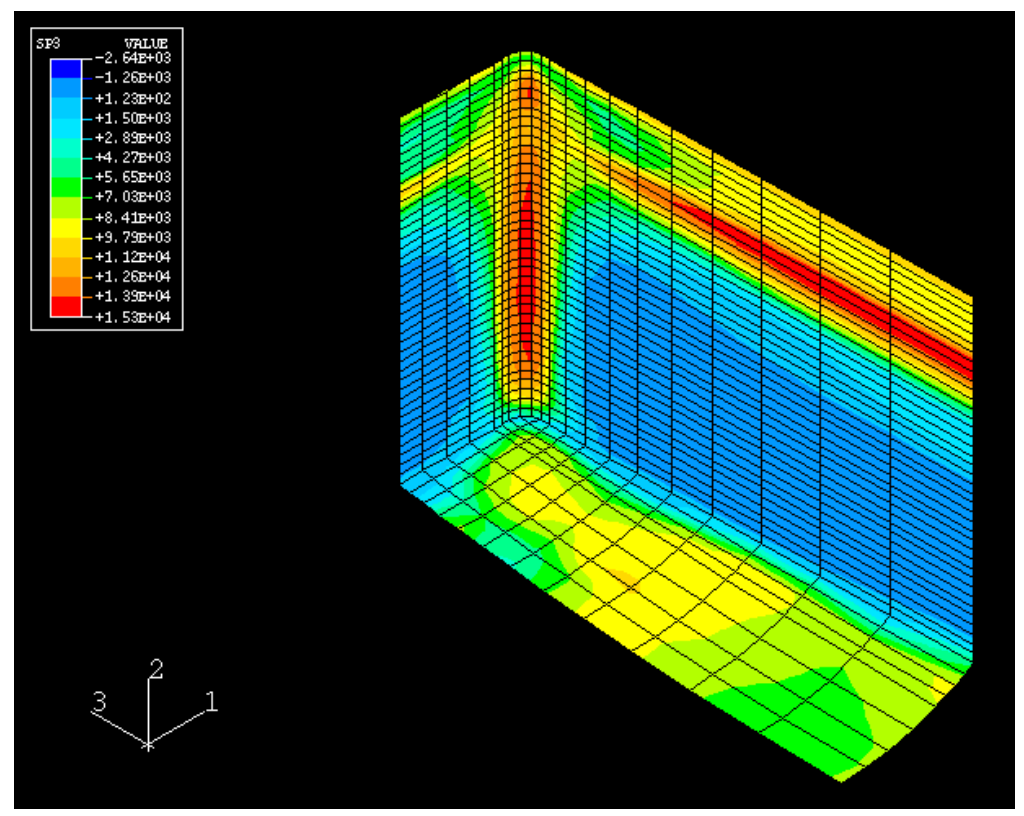

Figure 4.10 Maximum Principle Stress in Base Case, outside view (Ingot length is 20 inches)

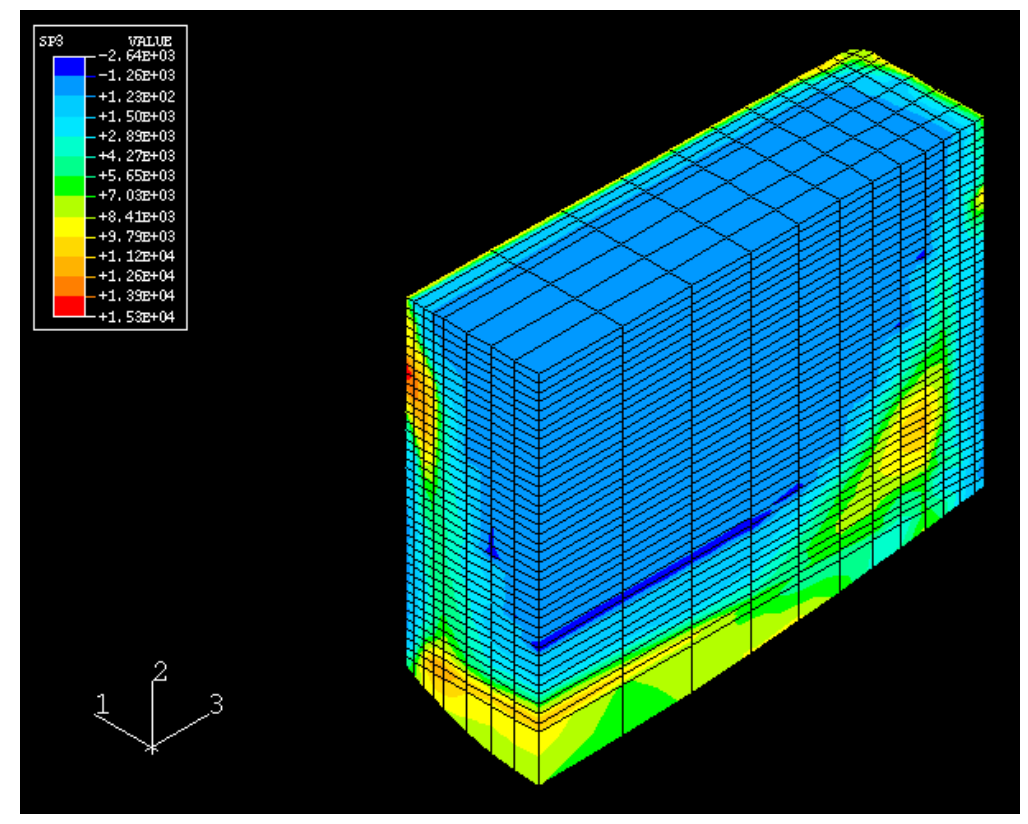

Figure 4.11 Maximum Principle Stress in Base Case, inside view (Ingot length is 20 inches) 


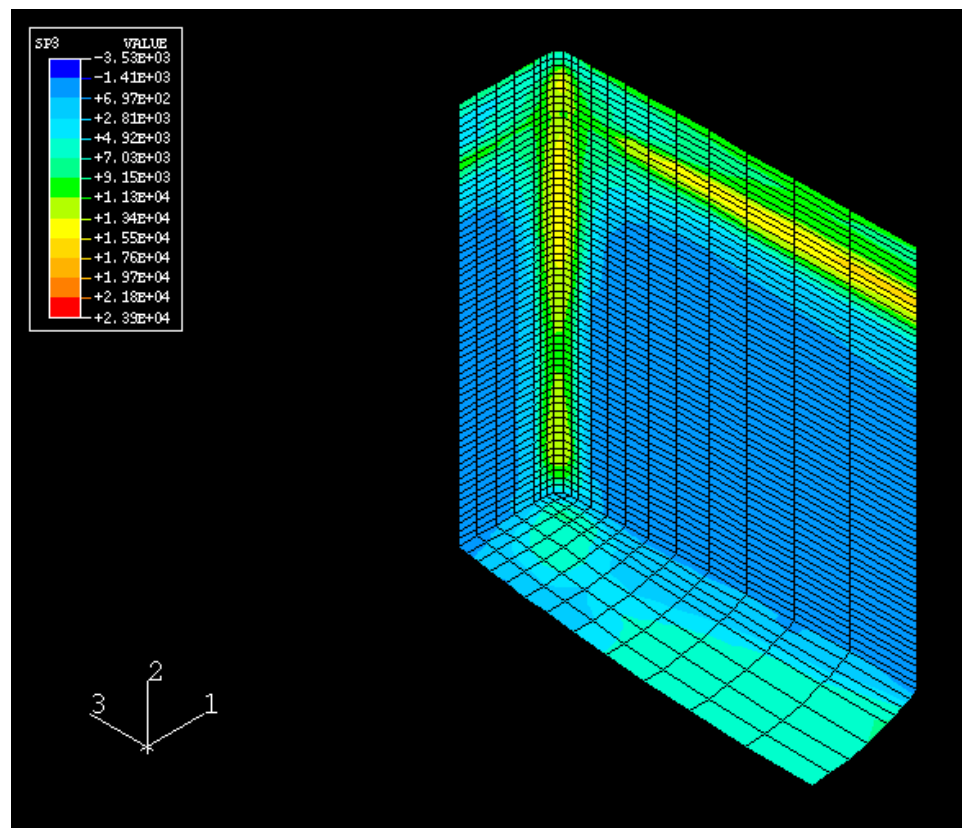

Figure 4.12 Maximum Principle Stress in Base Case, outside view (Ingot length is 30 inches)

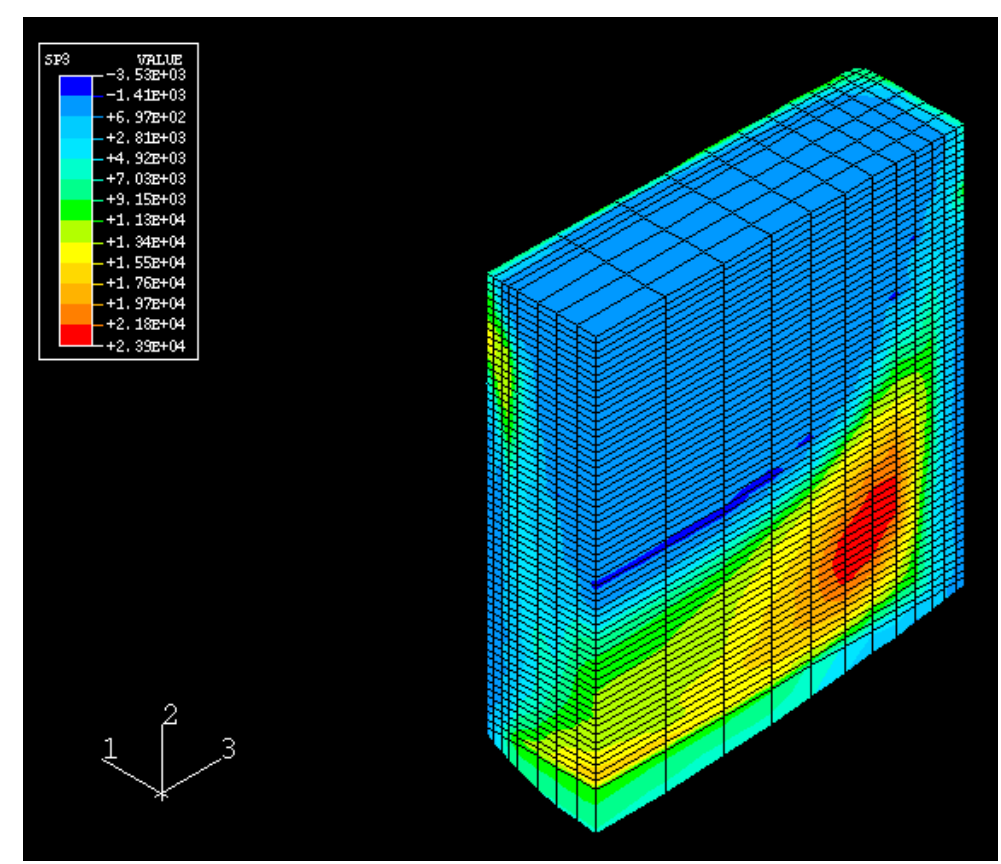

Figure 4.13 Maximum Principle Stress in Base Case, inside view (Ingot length is 30 inches) 


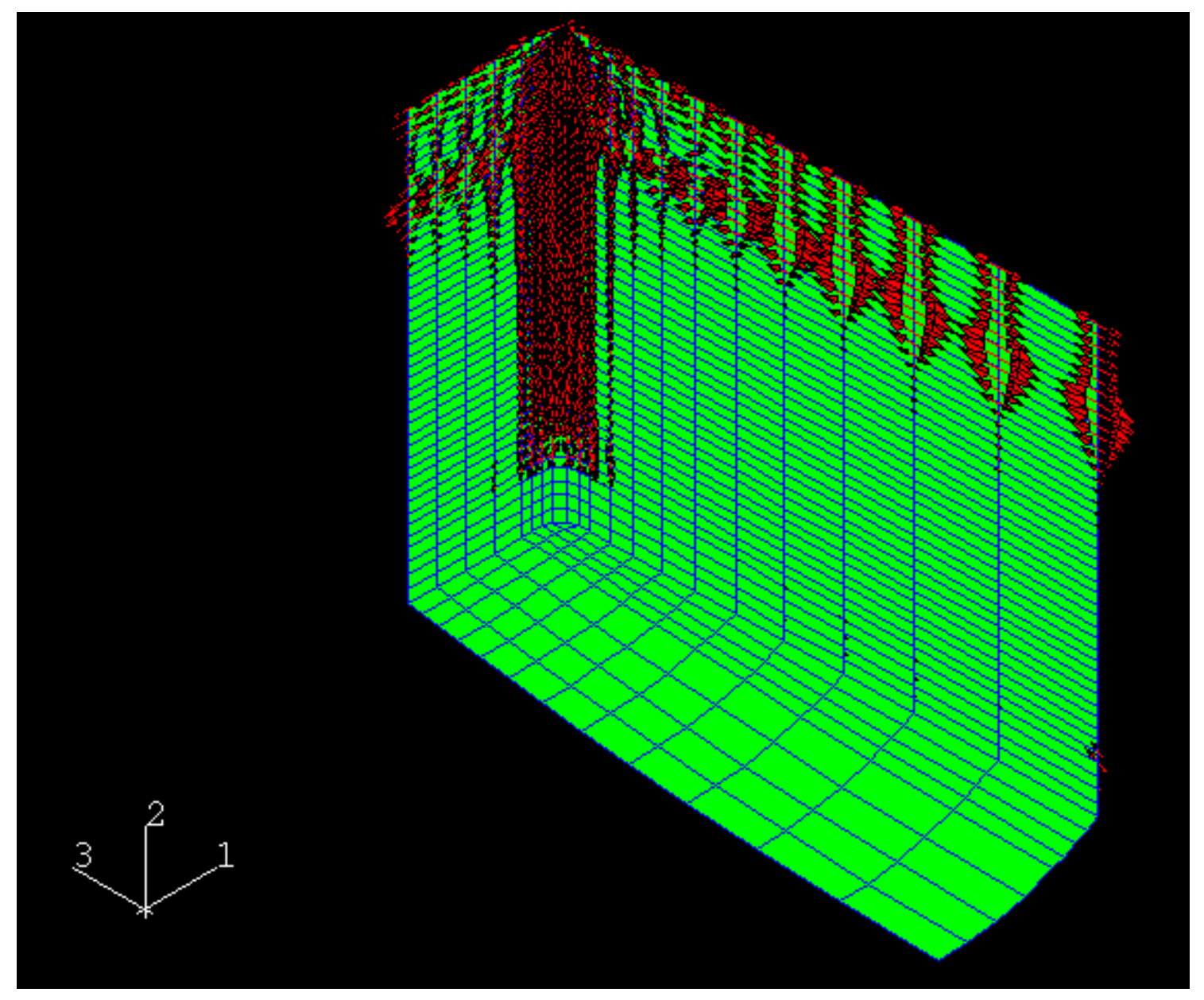

Figure 4.14 Quenching Stress Directions in Base Case (Ingot length: 20 in) 


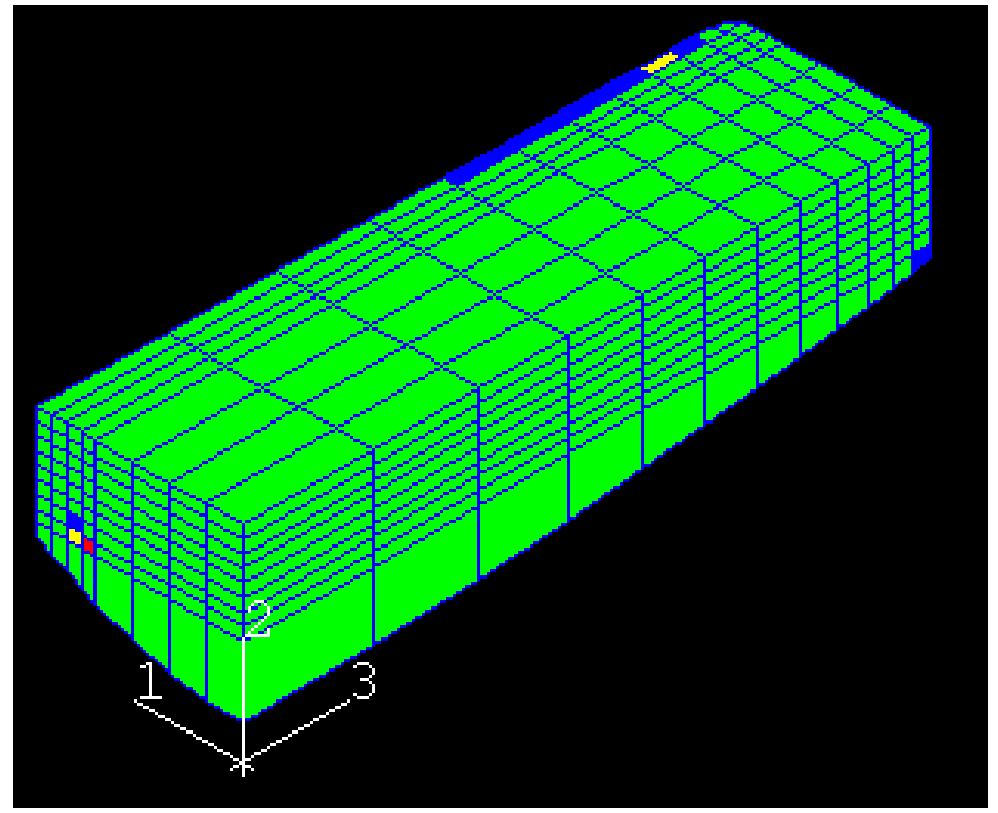

Figure 4.15 Stress Level 2 Locations in Base Case (Ingot length: 5 in)

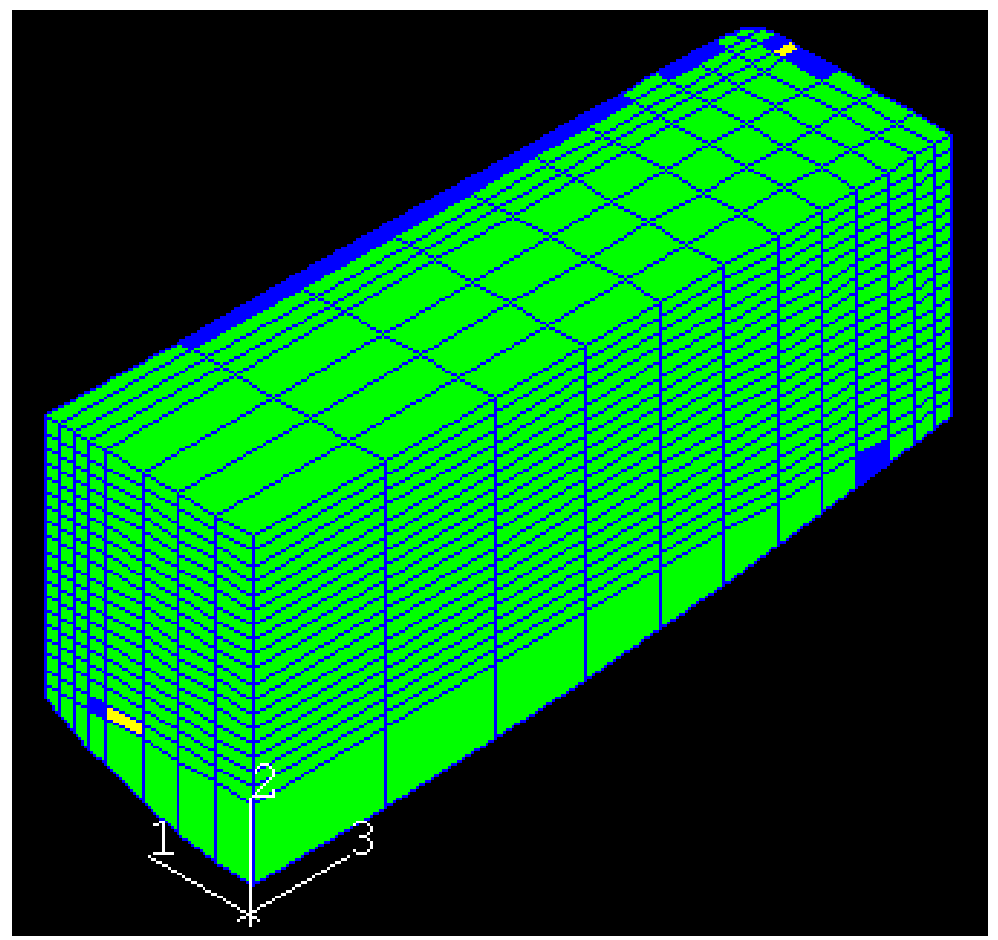

Figure 4.16 Stress Level 2 Locations in Base Case (Ingot length: 10 in) 


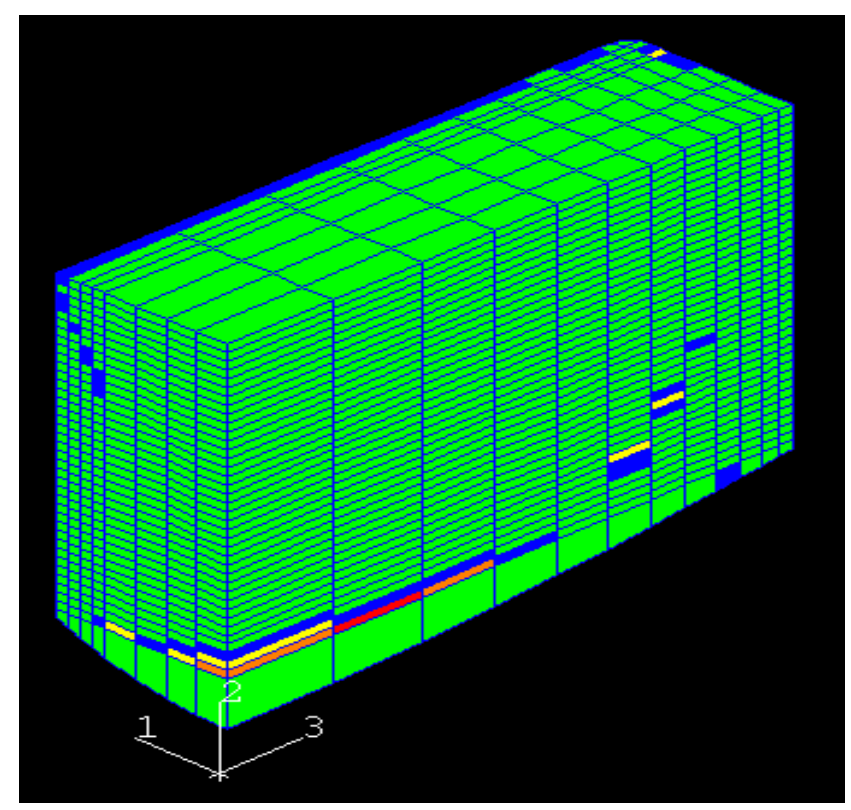

Figure 4.17 Stress Level 2 Locations in Base Case (Ingot length: 20 in)

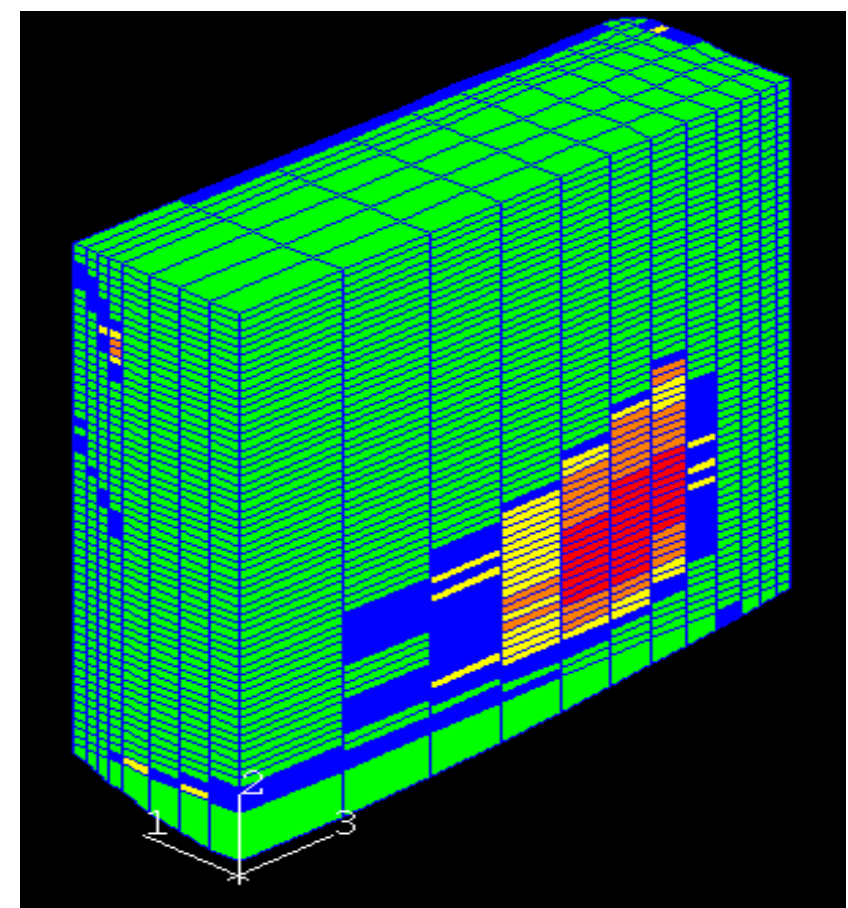

Figure 4.18 Stress Level 2 Locations in Base Case (Ingot length: 30 in) 


\section{CHAPTER 5}

\section{PARAMETRIC STUDIES}

There are many stress-reduction techniques, such as using wiper or altering the flow pattern of the cooling water $[5,29]$, each can be applied to improve the successful production rate of ingot casting. However, the emphasis of this chapter is focused on the effect of four casting parameters. Among them, the drop rate or casting speed is the most important parameter and will be discussed in details. The other three parameters (i.e., flow rate of cooling water, corner radius and ingot aspect ratio) will be discussed briefly. To study the effect of ingot size, simulation of larger ingot with five casting speeds are also conducted. The parametric studies are carried out with a total of sixteen simulations.

\subsection{Effect of Drop Rate}

A 56"x16" (width by thickness) ingot was chosen to study the effect of drop rate. For these simulations, water flow rate, corner radius and aspect ratio are fixed, they are 70 gallon per minute per mold, 1.0 inch and 7/2, respectively and five different casting drop rates are chosen. Again, the maximum principal stress level is used as the criterion for assessing the possibility of crack initiation. The temperature and stress from $\mathrm{ABAQUS}^{\mathrm{TM}}$ post are processed by a PC program CONVERT, developed in this research to quickly obtain/assess stress distributions in the ingots.

The maximum stress levels for four transient steps and five different drop rates are listed in Table 5.1 and plotted in Fig. 5.1. The term "Stress Level 2" is used to represent the ratio of 
principal stress to tensile strength at the point of interest. If stress level 2 at a point is above 1.0, micro crack is likely to initiate at this location. Table 5.2 shows the locations of maximum Stress Level 2 in four casting steps for five different drop rates. A special six-digit numbering system is used to identify the element locations in the ingot. The last two digits show the location of the element in the ingot along the $\mathrm{x}$ (thickness) direction. The range is from 01 to 08 with the central element to be 01 while the surface element to be 08 . The two digits in the middle indicate the element location along y direction (ingot length direction). The range is from 01 to 59 with 01 at the bottom and 59 on the top. The first two digits indicate the element location along $\mathrm{z}$ direction (ingot width direction) with a range from 01 to 12 (center to the surface). If the first two digits are less than 10 , the 0 on the left is dropped and the element number has only five digits. For example, an element numbered as 10101 indicates that it is located at bottom center of the ingot.

For drop rate of $1.0 \mathrm{in} / \mathrm{min}$, the maximum stress level 2 does not vary much with ingot length, as shown in Figure 5.1. The reason is that the maximum stress level 2 in this case is dominated by quenching stress throughout the casting steps with the exception at 5 inches ingot length. The locations of maximum stress level 2 are in quarter area and move up along as ingot drops down. The highest quenching stress location also moves from corner area to quarter area at ingot length of 20 in, and remains there. Thus for this case the likely crack initiation site is at the quarter area. The principal stress direction for a typical layer is shown in Figure 5.2. As shown, the maximum principal stress in quarter area is along $\mathrm{z}$ (or 3) axis, or crack propagation is along the y-axis, i.e. quarter crack. 
When ingot is 5 inches long and under $1.9 \mathrm{in} / \mathrm{min}$ drop rate, the maximum stress level 2 is in center out area (i.e. center width area near outside surface) and is above 1.0, which means the maximum principal stress reached ingot tensile strength and has high probability to cause crack initiation. Figure 5.3 shows principal stress direction for this step, which indicates that at center out area the crack initiation will be along the y-axis (i.e. center crack). When ingot length is longer than 5 inches, the results show no possibility for crack initiation until it reaches 20 inches long where the maximum stress level 2 reaches 1.02 and the location is inside the center area (center-in). Figure 5.4 shows maximum principal stress direction in that area, and indicates possible center crack growth. As the ingot length reaches 30 inches, it will approach steady state stage. The location of maximum stress level 2 moves from center-in position to the quarter-in area. The magnitude of stress level 2 increased to maximum. Figures 5.5 and 5.6 show the maximum principal stress direction from different viewpoint. As shown, it is noted that the maximum principal stress direction is not just alone one direction. Thus, either quarter crack or $\mathbf{J}$ crack may occur.

Notice that for $1.5 \mathrm{in} / \mathrm{min}$ drop rate, comparing to other drop rates, the maximum stress level 2 is relatively low throughout the casting steps and above 1.0 only when the ingot is in steady state. For ingot length of 10 inches, the maximum stress level 2 is in center-out area as shown in Figure 5.7. The cracking mechanism will be of center crack type. For ingot length of 30 inches, maximum stress level 2 moves to the quarter area inside the ingot. Figures 5.8 and 5.9 show vector plots of maximum principal stress directions for this step. Combining Table 2 and these two figures, the possible failure mode is quarter crack. 
For drop rates of $2.4 \mathrm{in} / \mathrm{min}$ and $3.0 \mathrm{in} / \mathrm{min}$, Figure 5.1 indicates that they are not likely to cause crack initiation as long as ingot length is below 22 inches. After which, high stress level will start to build up rapidly in quarter-in area (quarter area inside the ingot), where values of maximum stress level 2 are high. Figures 5.10 to 5.13 show maximum principal stress vector plots. Comparing these pictures to Figures 5.5, 5.6, 5.8, and 5.9, the maximum principal stress directions change to a bigger angle w.r.t. the z-axis and the high stress locations move away from the quarter area to corner area and the chance to have $\mathrm{J}$ crack is increased.

From above discussions, several conclusions can be made.

1. For $1.9 \mathrm{in} / \mathrm{min}$ drop rate, three types of ingot cracking may occur, i.e. center crack at the start-up stage, quarter crack or J crack at the steady state stage.

2. At steady state stage, the maximum stress level 2 increases with higher drop rate. For drop rate above $1.9 \mathrm{in} / \mathrm{min}$, it is more likely to have $\mathrm{J}$ crack, below $1.9 \mathrm{in} / \mathrm{min}$, it is likely to have quarter crack.

3. Quarter crack is the only cracking type when drop rate is slow (below $1.5 \mathrm{in} / \mathrm{min}$ ). As drop rate increase center and quarter cracks may occur. For high drop rate, the probable crack type is $\mathrm{J}$ crack and stress level 2 is high. High drop rates (above $2.4 \mathrm{in} / \mathrm{min}$ ) are not recommended for direct chill casting.

4. When drop rate is $1.5 \mathrm{in} / \mathrm{min}$ the possibility to have crack is lower comparing to other drop rates. This is the recommended drop rate. 


\subsection{Effect of Water Flow Rate}

Three cases of water flow rate were studied for 56"x 16" ingot with drop rate, corner radius, and aspect ratio fixed at $1.9 \mathrm{in} / \mathrm{min}, 1.0 \mathrm{in}$, and 7/2 respectively. The water flow rates are 50, 70, and 90 gallon per minute. The maximum values of stress level 2 for four steps are shown in Table 5.3 and Figure 5.14. Table 5.4 gives maximum stress level 2 locations. From these tables and figures, we can see that water flow rate does not affect stress level 2 values and locations after ingot reach 10 inches long. For ingot shorter than 10 inches, water flow rate does have effect to the magnitude of stress level 2 and it's location. For the low water flow rate of 50 gallon $/ \mathrm{min}$, which extract relatively less heat out of ingot, the slow heat exchange induces lower value of stress level 2 and thus reduces the possibility of crack formation in start-up stage. For water flow rate above certain level, there is no further increase/change of stress level 2 and its location.

\subsection{Effect of Corner Radius}

Figure 5.15 shows the results of corner radius effect for ingot size of 56"x16" with 1.9 in/min drop rate and aspect ratio of 7/2. Tables 5.5 and 5.6 show values of maximum stress level 2 and their locations for four steps. As shown, corner radius does not affect stress level 2 with the exception at 10 inches ingot length. It may be concluded that corner radius has little effect to the stress level 2 of the ingot.

\subsection{Effect of Aspect Ratio}

In order to study aspect ratio effect, three ingots with sizes of 54"x18", 56"x16", and 64"x16" were chosen. Aspect ratios for these three ingots are 3/1,7/2, and 4/1. The other casting conditions are $1.9 \mathrm{in} / \mathrm{min}$ drop rate and 70 gallon per minute water flow rate. Corner radius for 
three ingots is 1.0 inches. Tables 5.7 and 5.8 give the values and locations of maximum stress level 2. Figure 5.16 show plots of maximum stress level 2. As shown, the best case is for aspect ratio of $4 / 1$. The only possible failure mode is quarter crack for this aspect ratio. Aspect ratio $7 / 2$ is the worst case. It has high possibility to cause ingot cracking and failure modes include center, quarter, and J crack.

\subsection{Effect of Ingot Size}

A 58"x19" (width by thickness) ingot was chosen to study the difference of stress level 2 when comparing to the results of 56"x16" ingot. In the simulations, water flow rate and corner radius were fixed at 84 gallon per minute and 1.0 inch respectively. The simulation results for five different casting drop rates are shown in Tables 5.9 and 5.10, and Figure 5.17.

The results show that the locations of maximum stress level 2 are between quarter and corner area for drop rate of $1.0 \mathrm{in} / \mathrm{min}$. Also the magnitude of maximum stress level 2 will start to exceed 1.1 as ingot length is longer than 8 inches. Under this drop rate, quenching stresses are important for crack formation and the cracking behavior will be cold cracking. At steady state stage, the possible ingot cracking type is $\mathrm{J}$ or quarter crack.

When drop rate is $1.9 \mathrm{in} / \mathrm{min}$, crack formation is not likely to occur for ingot length shorter than 20 inches. After which, quarter stress will build up quickly, as shown in Table 5.10 and Figure 5.17. At ingot length of 30 inches, maximum stress level 2 is 1.27 , which is the highest among the drop rates. The locations of maximum stress level 2 for four steps are similar to 56"x16" ingot with deferent magnitude. 
For $2.4 \mathrm{in} / \mathrm{min}$ drop rate, cracking may occur after 20 inches ingot length. The location of maximum stress level 2 is in quarter-in area. Cracking type is either $\mathbf{J}$ or quarter crack depending on the directions of maximum principal stress in that area. The magnitude of stress level 2 is 1.21 , i.e. high possibility to fail.

Although the magnitude of stress level 2 for 1.0 and $3.0 \mathrm{in} / \mathrm{min}$ drop rates are similar at ingot length of 5 and 10 inches, their locations are different. For $3.0 \mathrm{in} / \mathrm{min}$ drop rate, in the start-up stage center crack may occur.

Again, among the five drop rates, the $1.5 \mathrm{in} / \mathrm{min}$ drop rate is the best choice to avoid ingot cracking. This casting speed is highly recommended for this ingot size. 
Table 5.1 Maximum Stress Level 2

\begin{tabular}{|c|c|c|c|c|}
\hline \multirow{2}{*}{$\begin{array}{c}\text { Drop rate } \\
\text { in/min }\end{array}$} & \multicolumn{4}{|c|}{ Ingot Length, inches } \\
\cline { 2 - 5 } & 5 & 10 & 20 & 30 \\
\hline 1.0 & 1.02 & 1.09 & 1.10 & 1.09 \\
\hline 1.5 & 0.92 & 1.00 & 0.97 & 1.04 \\
\hline 1.9 & 1.01 & 0.86 & 1.02 & 1.10 \\
\hline 2.4 & 0.87 & 0.82 & 0.95 & 1.30 \\
\hline 3.0 & 0.93 & 0.90 & 0.91 & 1.32 \\
\hline
\end{tabular}

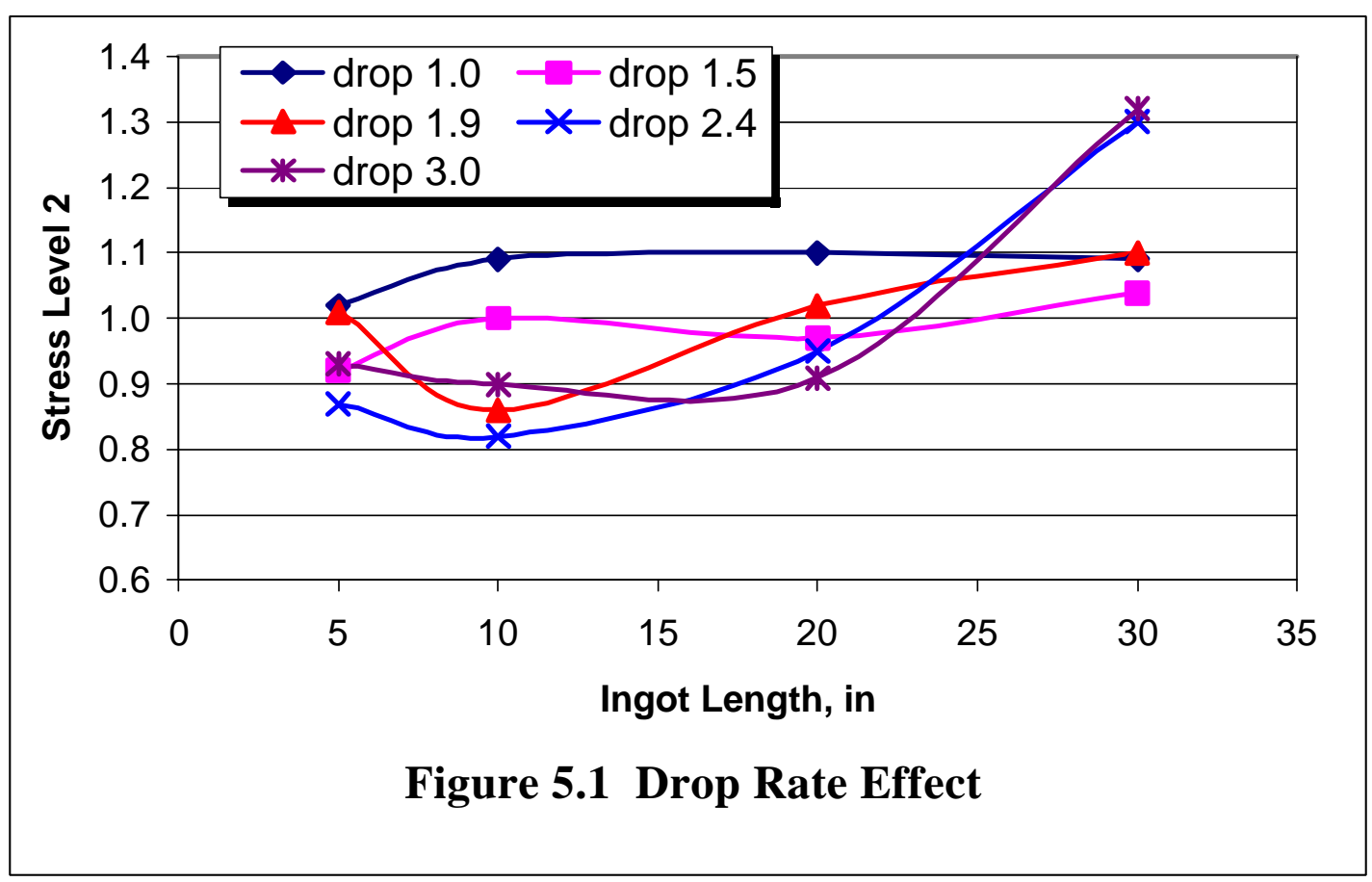


Table 5.2 Maximum Stress Level 2 Locations

(56"x16" ingots)

\begin{tabular}{|c|c|c|c|c|c|c|c|c|c|c|c|c|}
\hline \multirow{3}{*}{$\begin{array}{l}\text { Drop } \\
\text { Rate } \\
\text { in/min }\end{array}$} & \multicolumn{12}{|c|}{ Ingot Length, inches } \\
\hline & \multicolumn{3}{|c|}{5} & \multicolumn{3}{|c|}{10} & \multicolumn{3}{|c|}{20} & \multicolumn{3}{|c|}{30} \\
\hline & 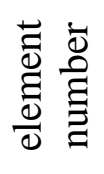 & 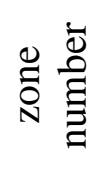 & 导 & 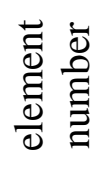 & 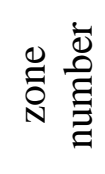 & 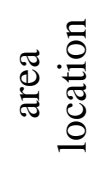 & 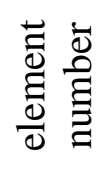 & 芯 & 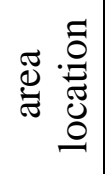 & 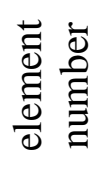 & 导 & 异: \\
\hline 1.0 & $\begin{array}{l}\text { ô } \\
\stackrel{8}{ᄋ} \\
=\end{array}$ & 19 & 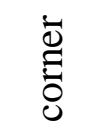 & $\frac{\gtrless}{2}$ & 38 & $\begin{array}{l}\overline{\mathrm{D}} \\
\stackrel{\vec{\sigma}}{\vec{\sigma}} \\
\vec{\sigma}\end{array}$ & $\begin{array}{l}\stackrel{2}{8} \\
\text { శె }\end{array}$ & 76 & 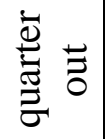 & 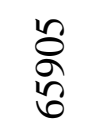 & 116 & 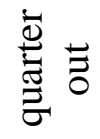 \\
\hline 1.5 & $\begin{array}{l}\infty \\
\stackrel{8}{\circ} \\
\stackrel{\infty}{0}\end{array}$ & 18 & $\begin{array}{l}\bar{\Phi} \\
\stackrel{\Xi}{0}\end{array}$ & $\begin{array}{l}\infty \\
\stackrel{\infty}{\sim} \\
\frac{2}{2}\end{array}$ & 32 & 离 & 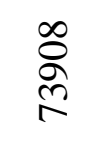 & 78 & $\begin{array}{l}\overrightarrow{\tilde{J}} \\
\stackrel{\vec{w}}{\vec{\sigma}} \\
\vec{\sigma}\end{array}$ & $\frac{\bar{a}}{\bar{n}}$ & 35 & 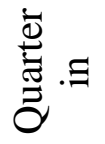 \\
\hline 1.9 & 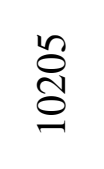 & 2 & 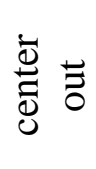 & 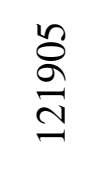 & 40 & $\begin{array}{l}\bar{\circlearrowright} \\
\bar{\Xi}\end{array}$ & 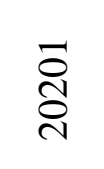 & 1 & 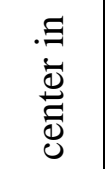 & $\frac{\overline{2}}{6}$ & 35 & $\begin{array}{l}\overrightarrow{\vec{E}} \\
\stackrel{\vec{E}}{\vec{a}} .\end{array}$ \\
\hline 2.4 & 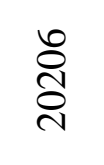 & 2 & 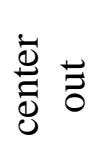 & 总 & 2 & 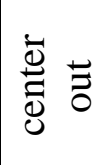 & $\begin{array}{l}\text { Ôे } \\
\text { Oे }\end{array}$ & 3 & 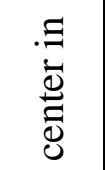 & $\bar{\sigma}$ & 35 & $\begin{array}{l}\stackrel{\overrightarrow{\tilde{E}}}{\vec{a}} . \\
\vec{a}\end{array}$ \\
\hline 3.0 & 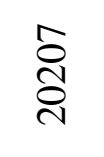 & 2 & $\stackrel{\bar{d}}{\stackrel{\vec{d}}{0}}$ & $\begin{array}{l}\text { ¿े } \\
\text { ठे }\end{array}$ & 2 & $\frac{\overrightarrow{\bar{m}}}{\overline{0}} \overline{0}$ & 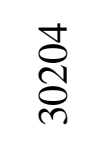 & 3 & 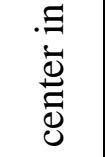 & $\begin{array}{l}\bar{\circ} \\
\stackrel{n}{n}\end{array}$ & 37 & $\begin{array}{l}\overrightarrow{\bar{U}} \\
\stackrel{\vec{a}}{\sigma} .\end{array}$ \\
\hline
\end{tabular}




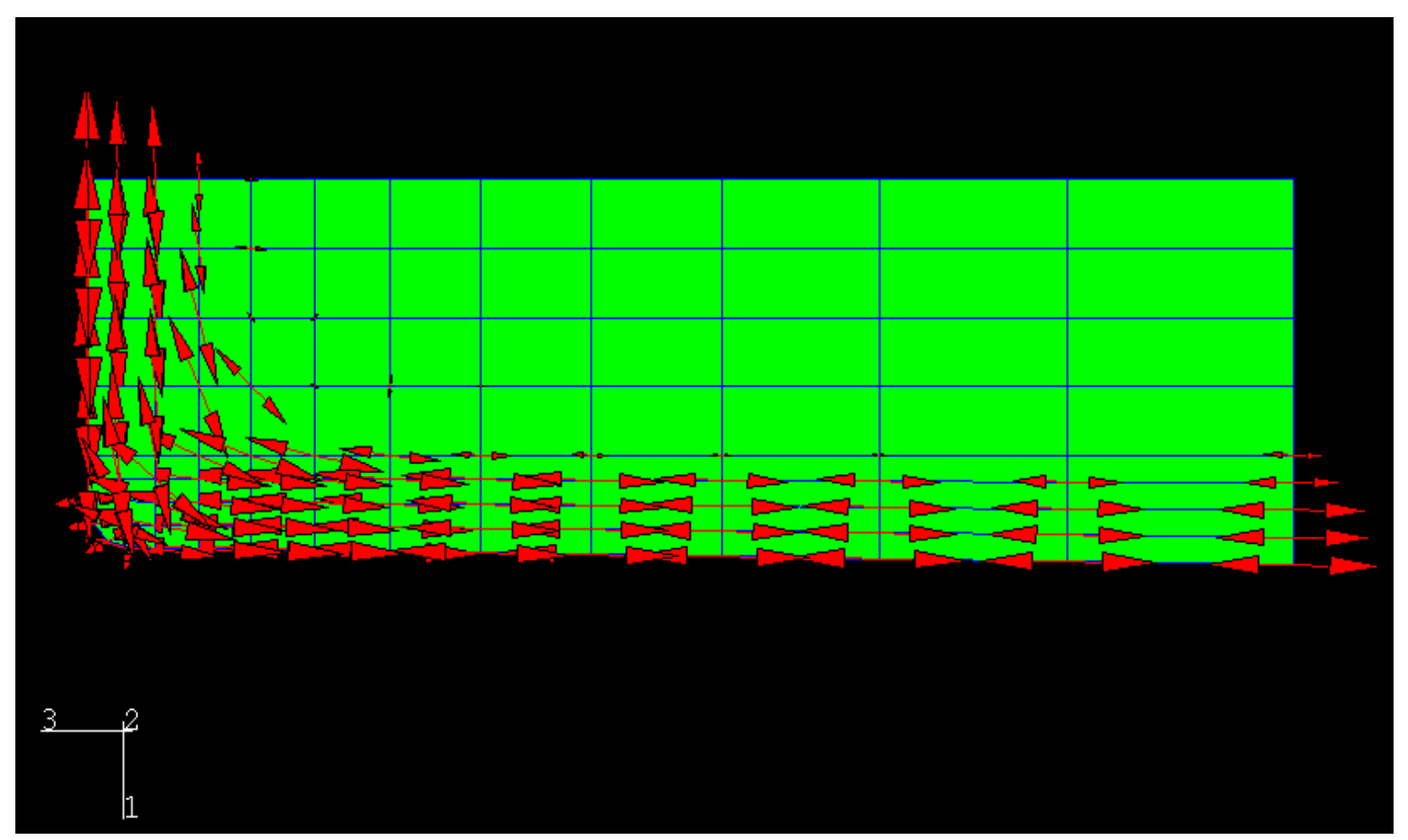

Figure 5.2 Principal Stress Directions (Drop Rate: 1.0 in/min, L=30", Y=30")

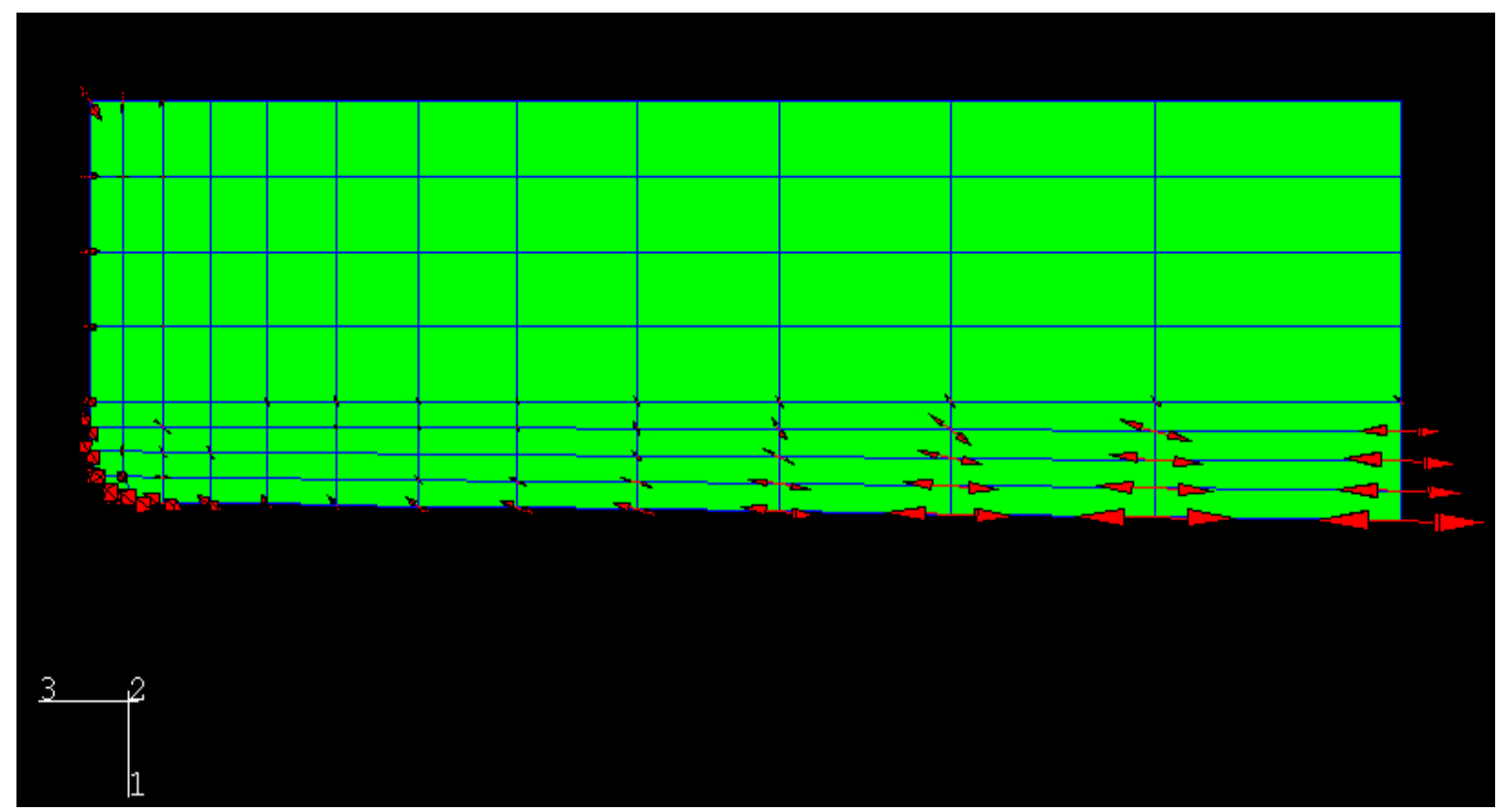

Figure 5.3 Principal Stress Directions (Drop Rate: 1.9 in/min, L=5", Y=1") 


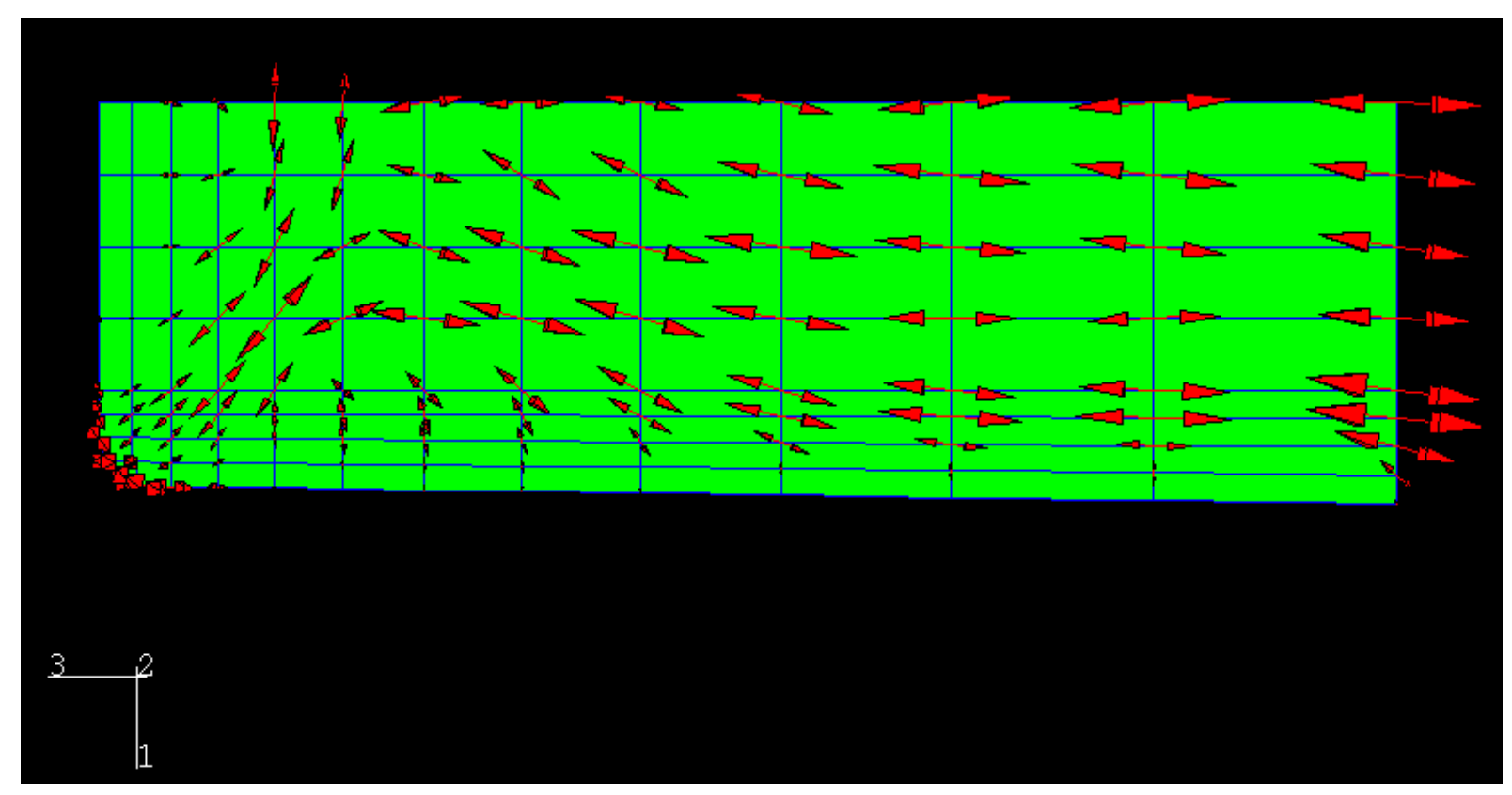

Figure 5.4 Principal Stress Directions (Drop Rate: $1.9 \mathrm{in} / \mathrm{min}, \mathrm{L}=20$ ", Y=1")

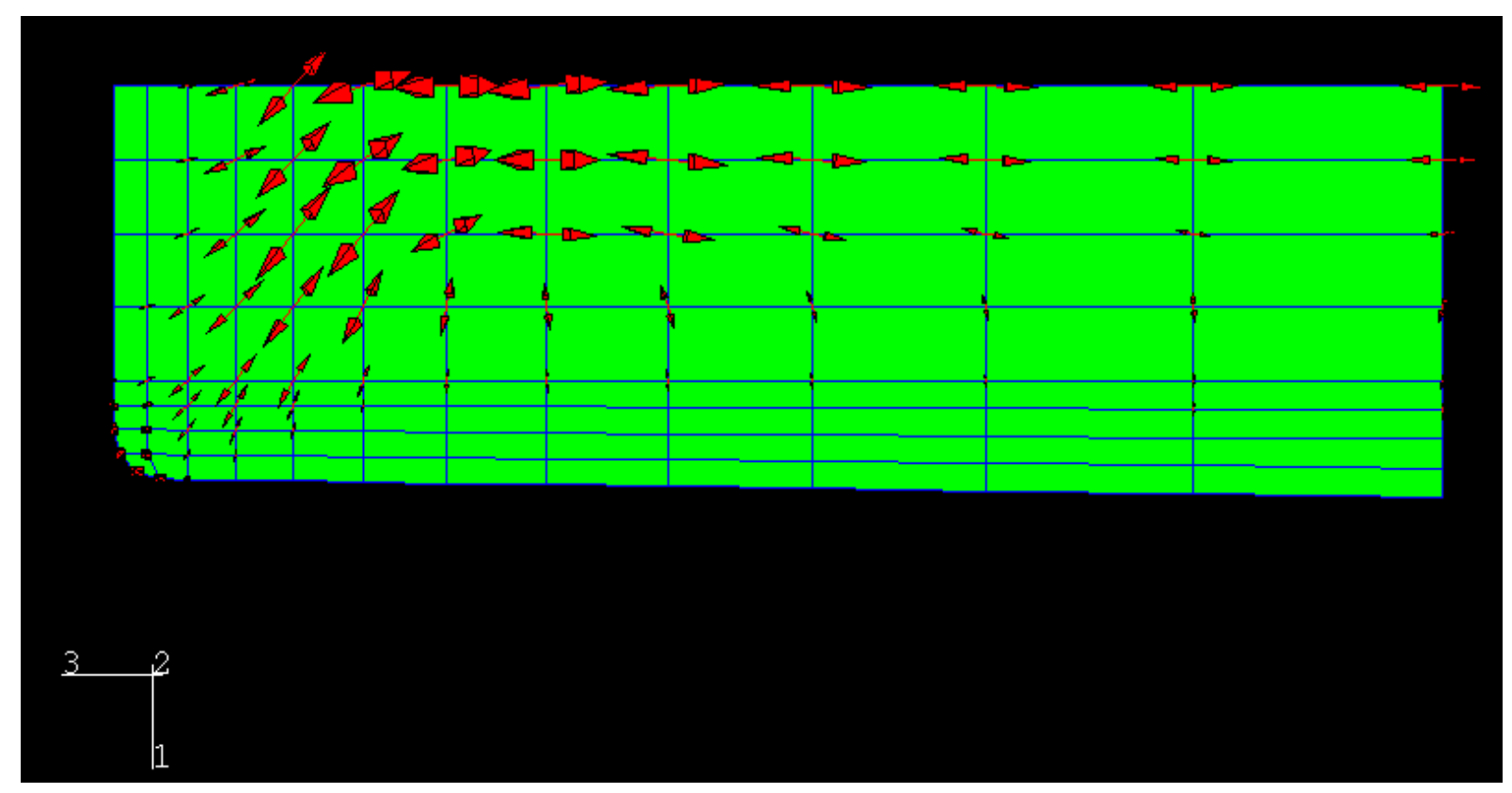

Figure 5.5 Principal Stress Directions (Drop Rate: 1.9 in/min, L=30", Y=8.7") 


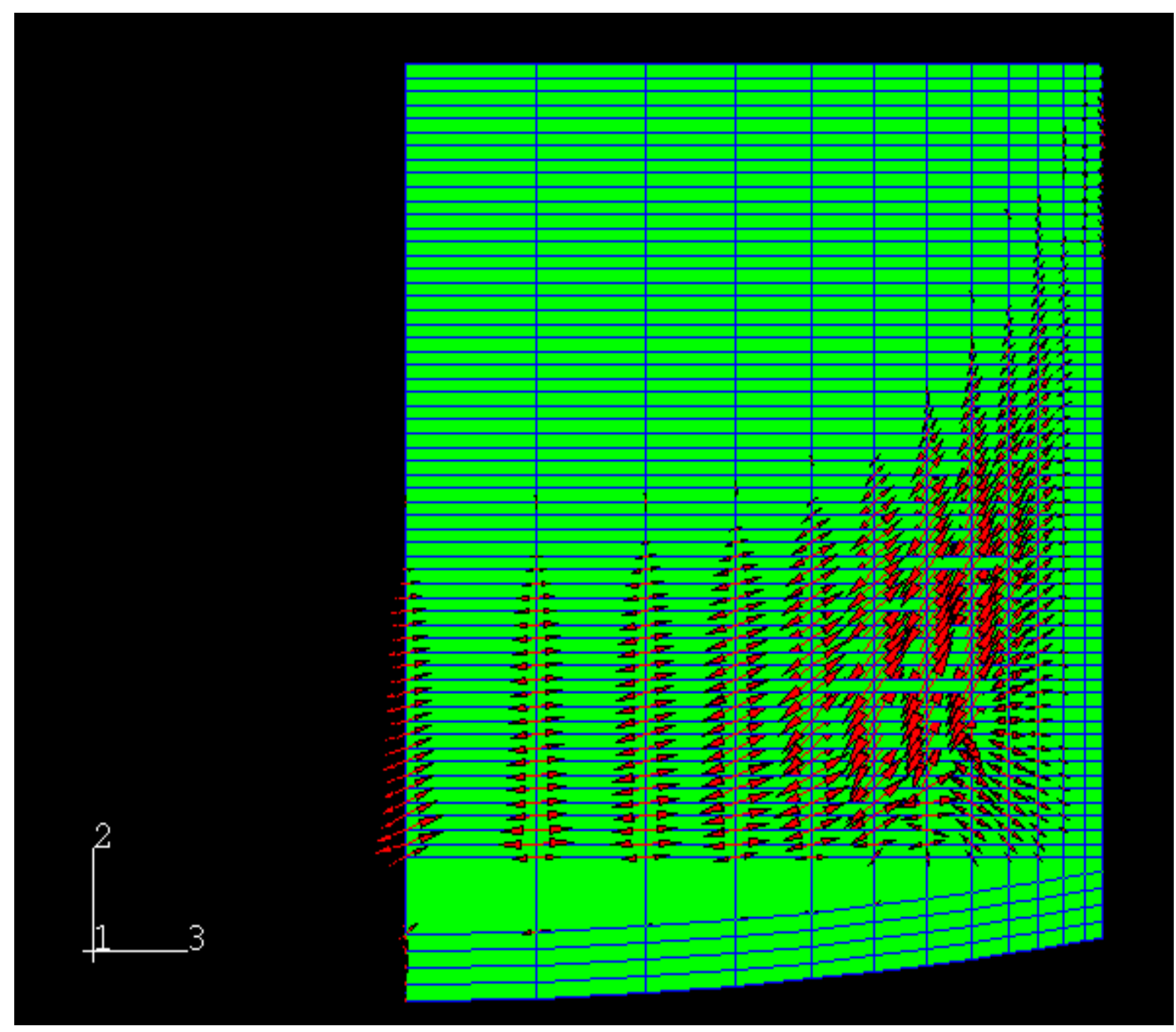

Figure 5.6 Principal Stress Directions

(Drop Rate: 1.9 in/min, $L=30 ", X=0$ ") 


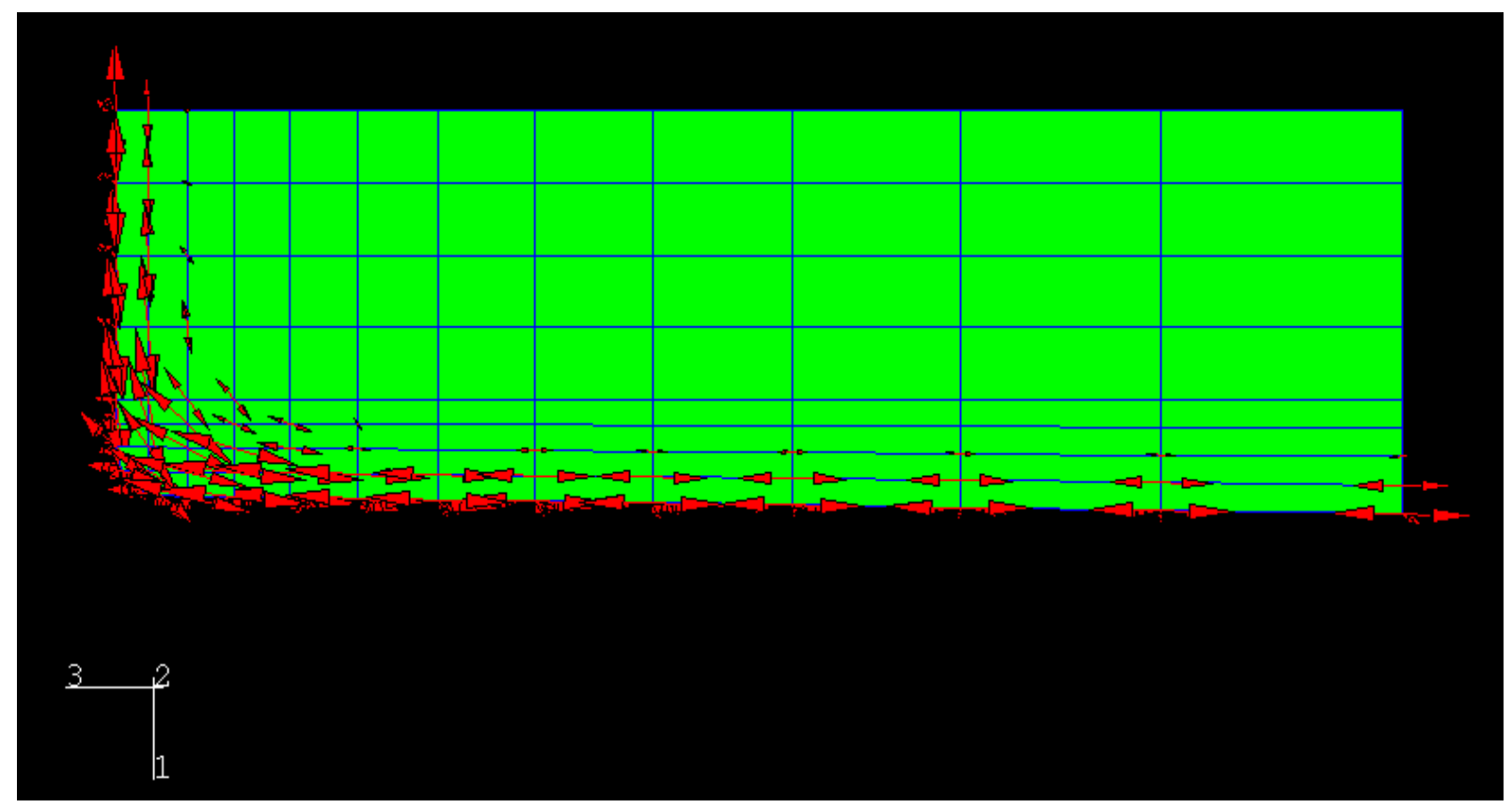

Figure 5.7 Principal Stress Directions (Drop Rate: 1.5 in/min, L=10", Y=9.7")

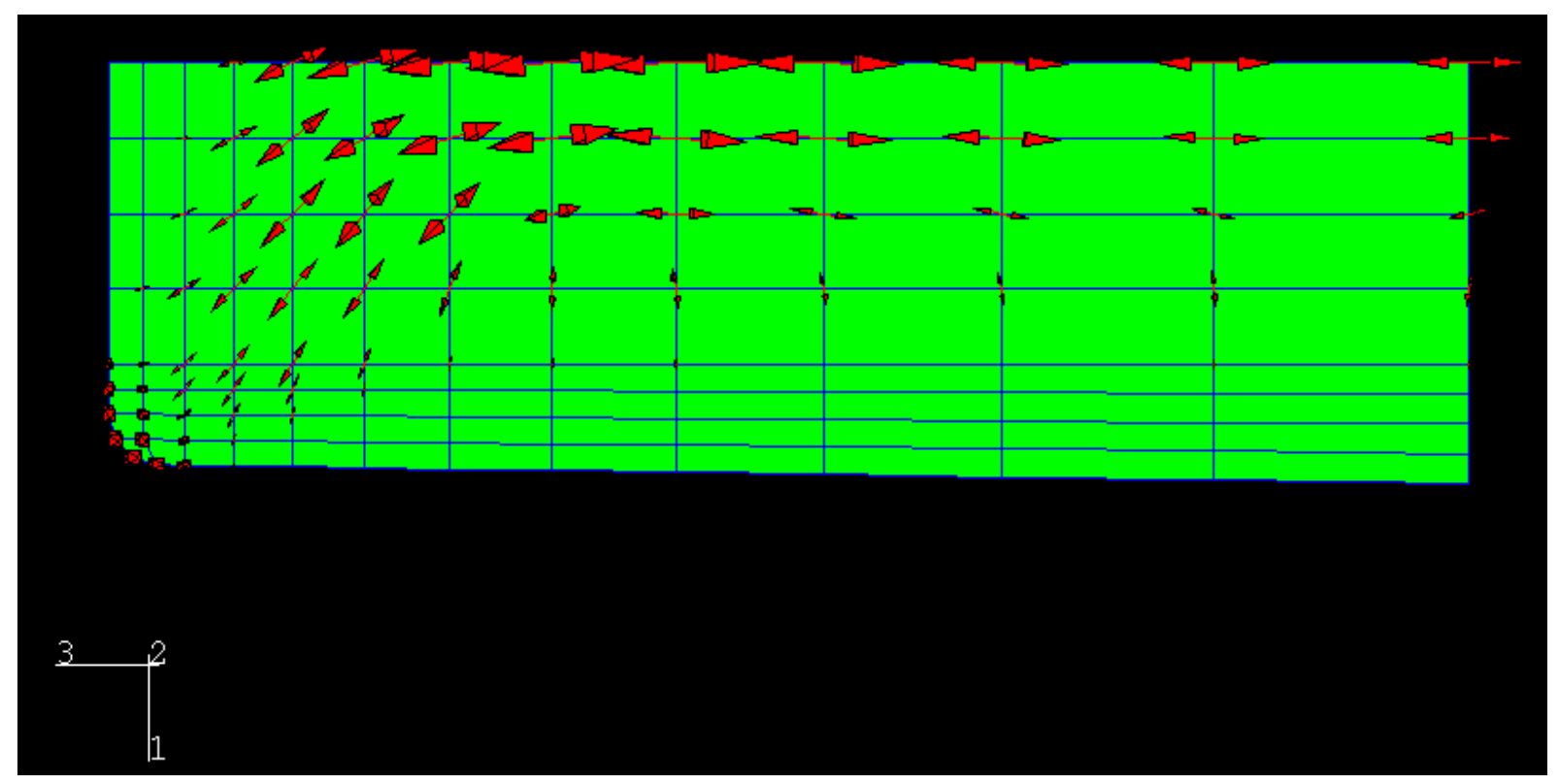

Figure 5.8 Principal Stress Directions (Drop Rate: 1.5 in/min, L=30", Y=9.7") 


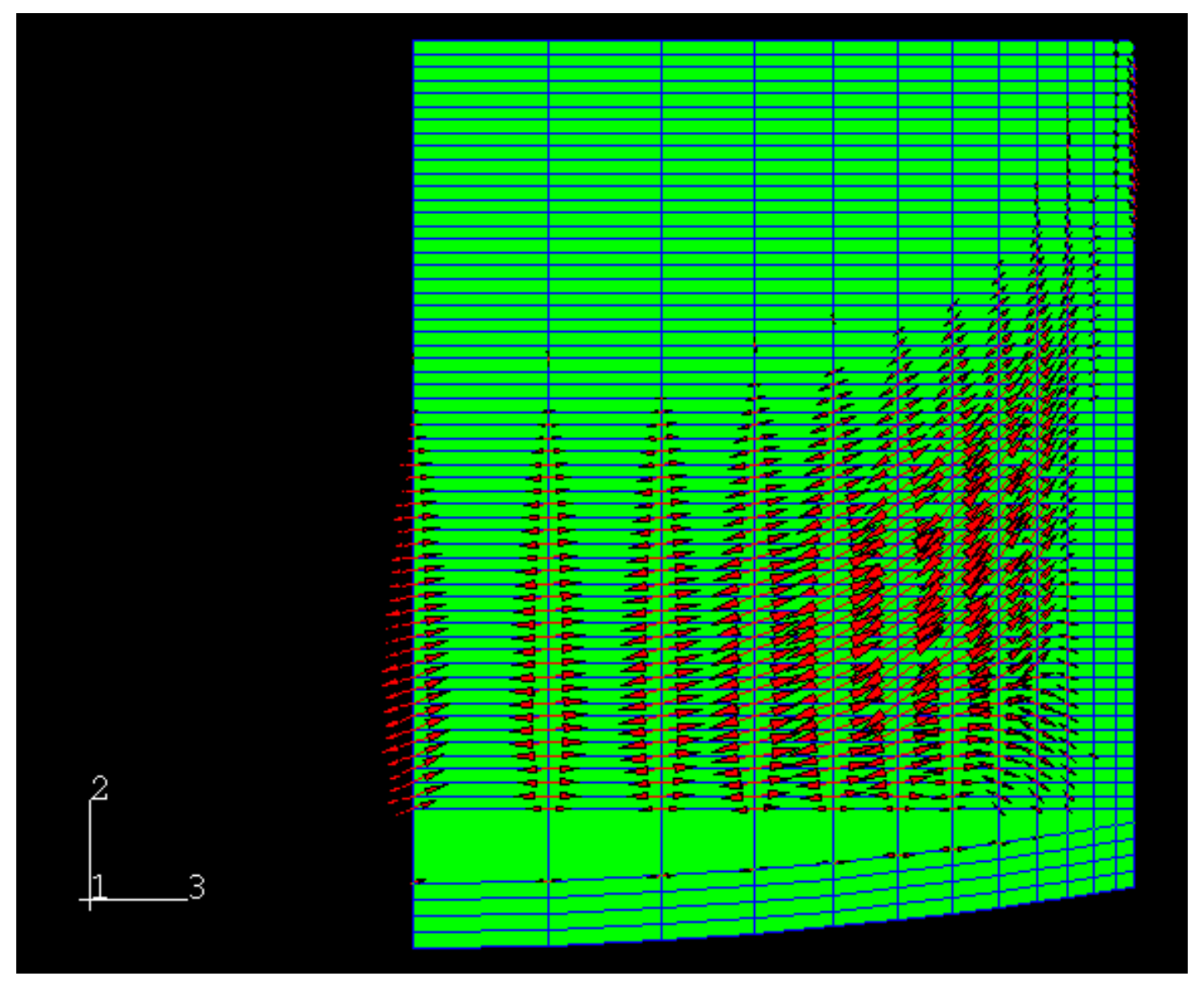

Figure 5.9 Principal Stress Directions

(Drop Rate: 1.5 in $/ \mathrm{min}, \mathbf{L}=30$ ", $X=0^{\prime \prime}$ ) 

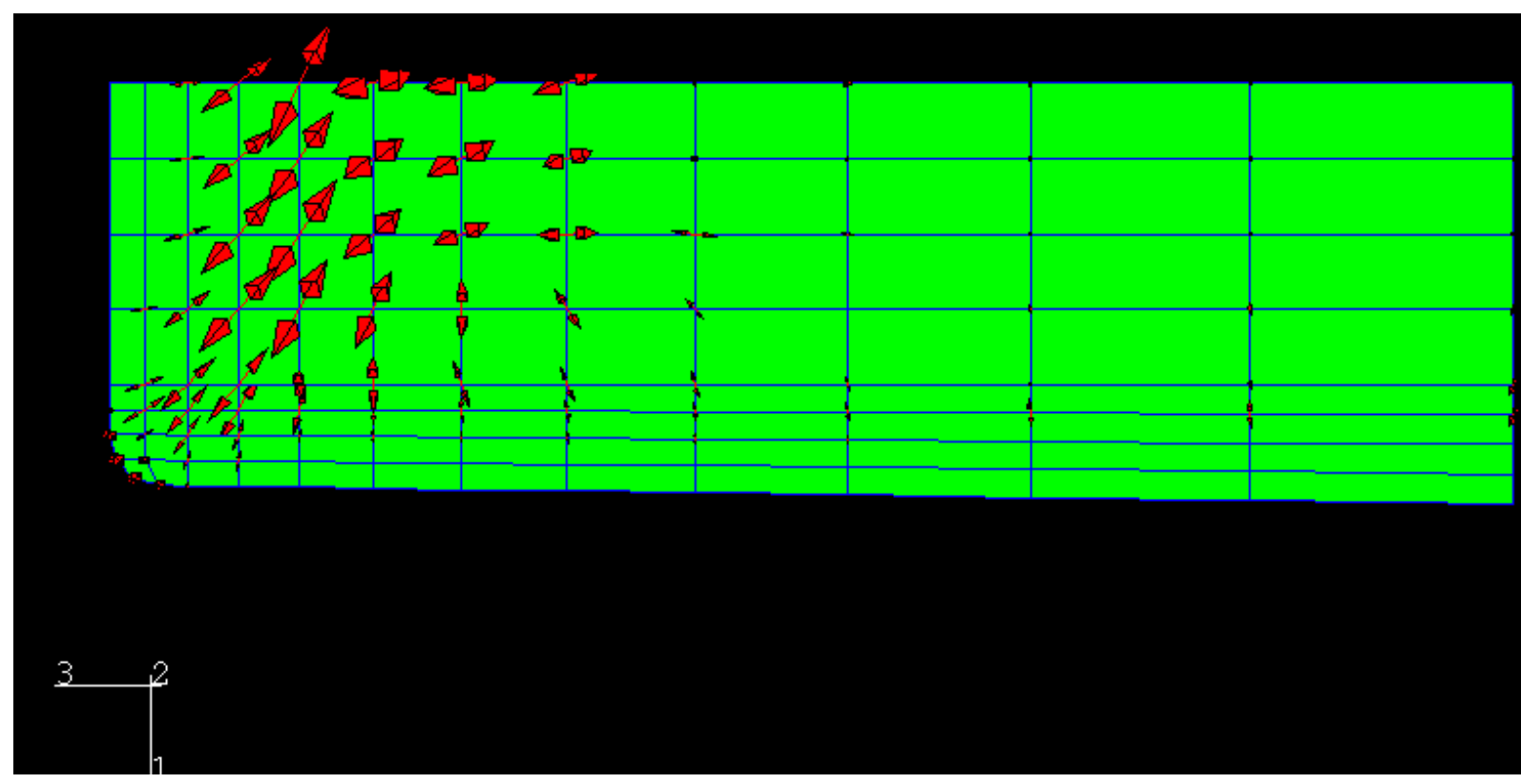

Figure 5.10 Principal Stress Directions (Drop Rate: 2.4 in/min, L=30", Y=8.7")

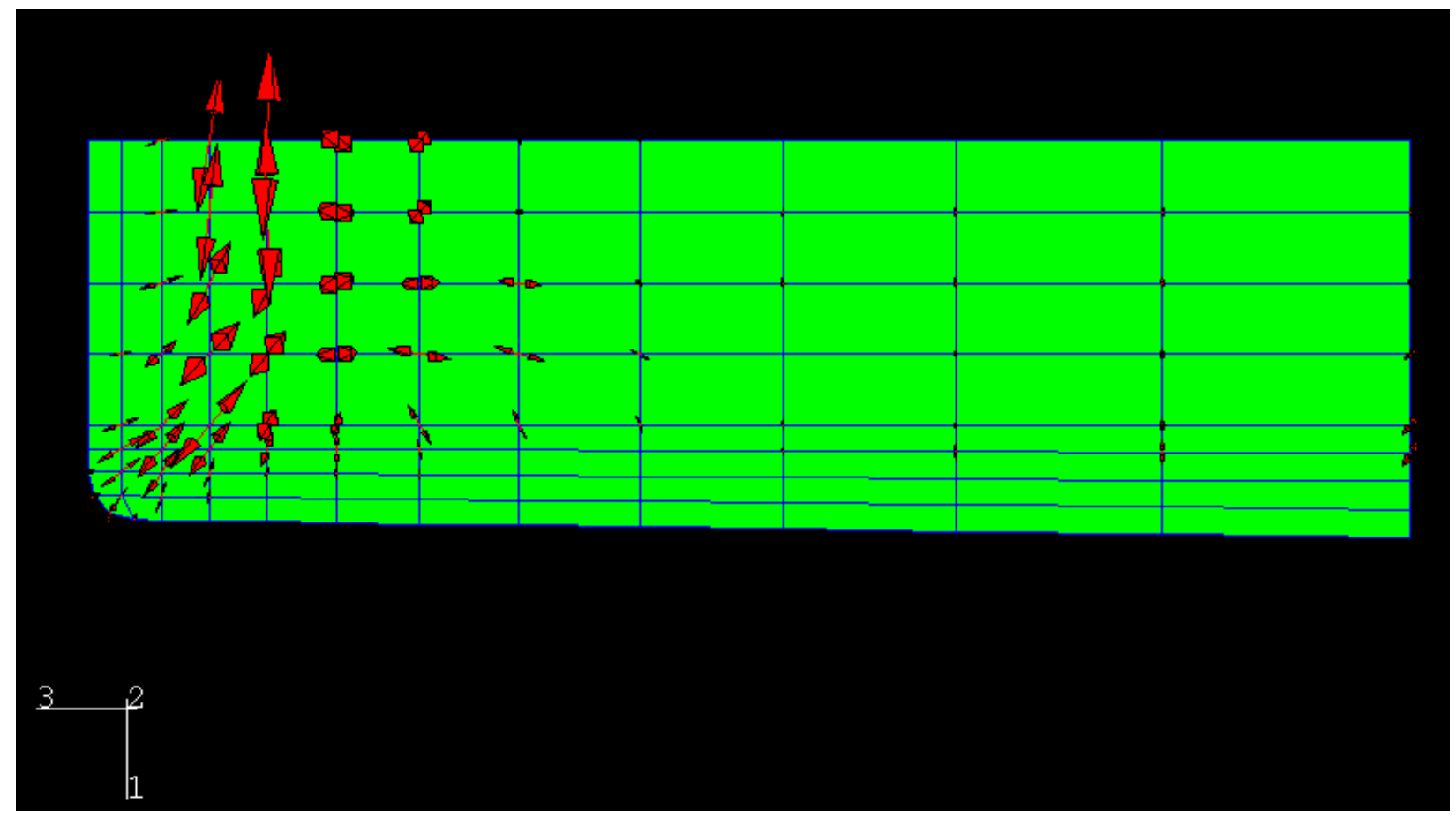

Figure 5.11 Principal Stress Direction (Drop Rate: 3.0 in/min, L=30", Y=7.7") 


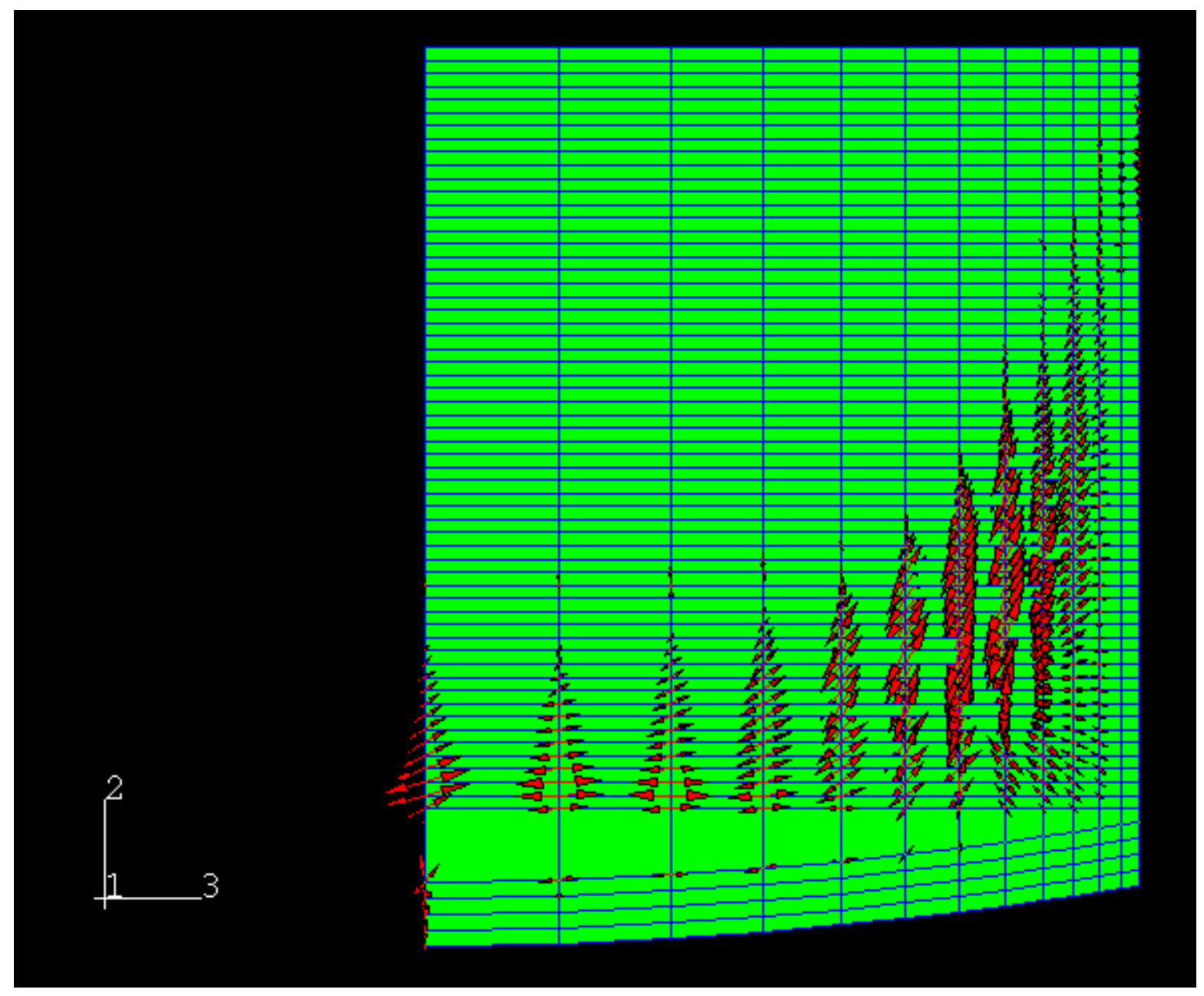

Figure 5.12 Principal Stress Directions

(Drop Rate: 2.4 in/min, L=30", $X=0 "$ ") 


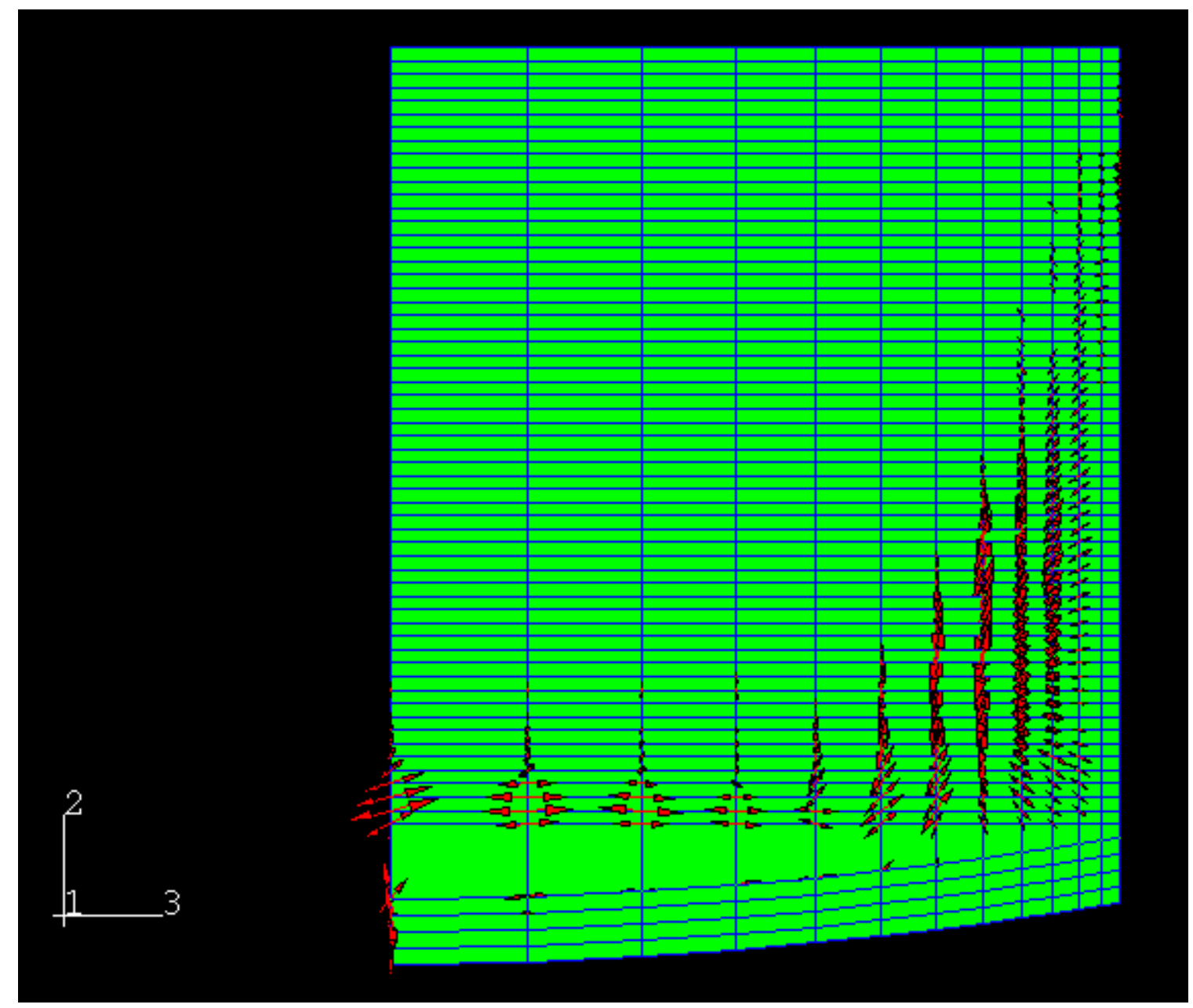

Figure 5.13 Principal Stress Directions

(Drop Rate: $3.0 \mathrm{in} / \mathrm{min}, \mathrm{L}=30$ ", $\mathrm{X}=\mathbf{0}^{\prime \prime}$ ) 
Table 5.3 Normalized Maximum Principle Stresses for Different Water Flow Rate

\begin{tabular}{|c|c|c|c|c|}
\hline \multirow{2}{*}{$\begin{array}{c}\text { Water flow } \\
\text { rate }\end{array}$} & \multicolumn{4}{|c|}{ Ingot length, inches } \\
\cline { 2 - 5 } gal/min & 5 & 10 & 20 & 30 \\
\hline 50 & 0.82 & 0.85 & 1.02 & 1.11 \\
\hline 70 & 1.01 & 0.86 & 1.02 & 1.10 \\
\hline 90 & 0.99 & 0.84 & 1.02 & 1.11 \\
\hline
\end{tabular}

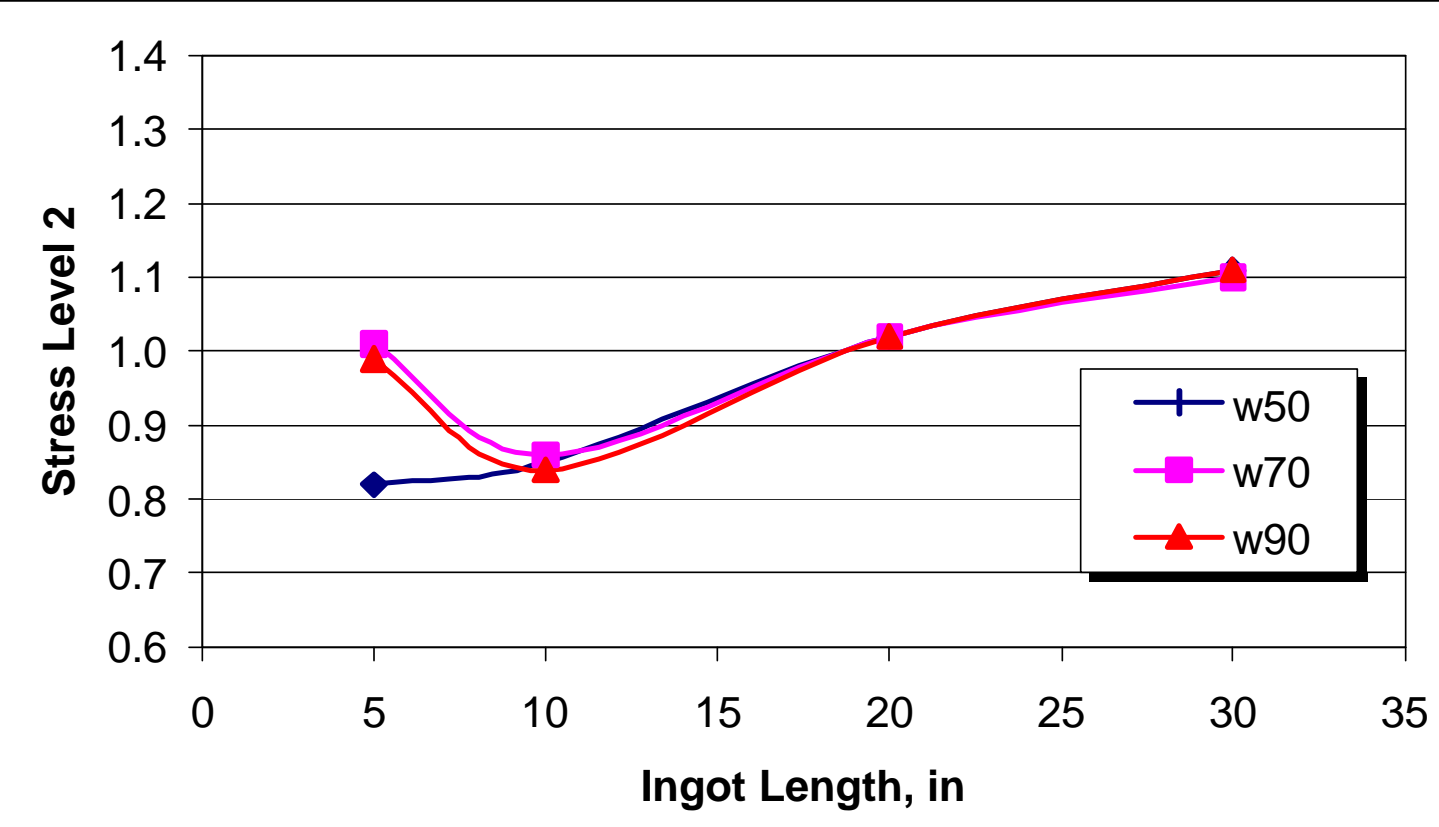

Figure 5.14 Water Flow Rate Effect 
Table 5.4 Locations of Maximum Stress Level 2 in the Ingots for Three Water Flow Rates

\begin{tabular}{|c|c|c|c|c|c|c|c|c|c|c|c|c|}
\hline \multirow{3}{*}{$\begin{array}{l}\text { Water } \\
\text { flow } \\
\text { rate } \\
\text { gal/min }\end{array}$} & \multicolumn{12}{|c|}{ Ingot Length, inches } \\
\hline & \multicolumn{3}{|c|}{5} & \multicolumn{3}{|c|}{10} & \multicolumn{3}{|c|}{20} & \multicolumn{3}{|c|}{30} \\
\hline & 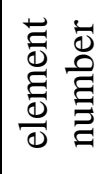 & 离 & 总 & 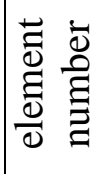 & 离 & 异. & 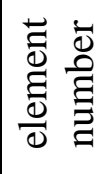 & 灾 & 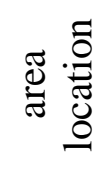 & 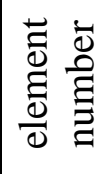 & 悹泀 & ฮี \\
\hline 50 & 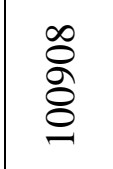 & 20 & $\begin{array}{l}\bar{\Xi} \\
\bar{\Xi}\end{array}$ & 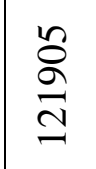 & 40 & $\begin{array}{l}\vec{\Phi} \\
\stackrel{0}{0}\end{array}$ & 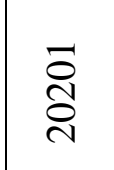 & 1 & 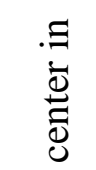 & $\frac{\bar{b}}{\sigma}$ & 35 & $\begin{array}{l}\stackrel{\bar{\Xi}}{\bar{\Xi}} . \Xi \\
\vec{\Xi}\end{array}$ \\
\hline 70 & 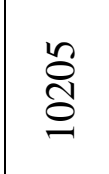 & 2 & 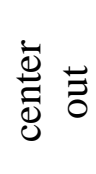 & $\begin{array}{l}\mathscr{\S} \\
\stackrel{\Xi}{\Xi}\end{array}$ & 40 & $\begin{array}{l}\vec{\Phi} \\
\vec{\Xi} \\
\stackrel{0}{0}\end{array}$ & 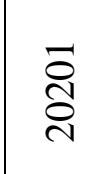 & 1 & 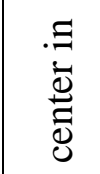 & $\frac{\overline{2}}{\sigma}$ & 35 & 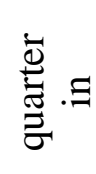 \\
\hline 90 & 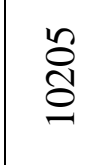 & 2 & 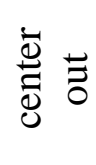 & $\frac{\stackrel{2}{\S}}{2}$ & 40 & $\begin{array}{l}\bar{\Xi} \\
\bar{\Xi} \\
\stackrel{0}{0}\end{array}$ & 苂 & 1 & 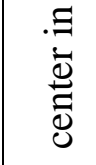 & $\frac{\bar{\delta}}{\sigma}$ & 35 & $\begin{array}{l}\frac{\bar{g}}{\bar{E}} . \Xi \\
\vec{\sigma}\end{array}$ \\
\hline
\end{tabular}

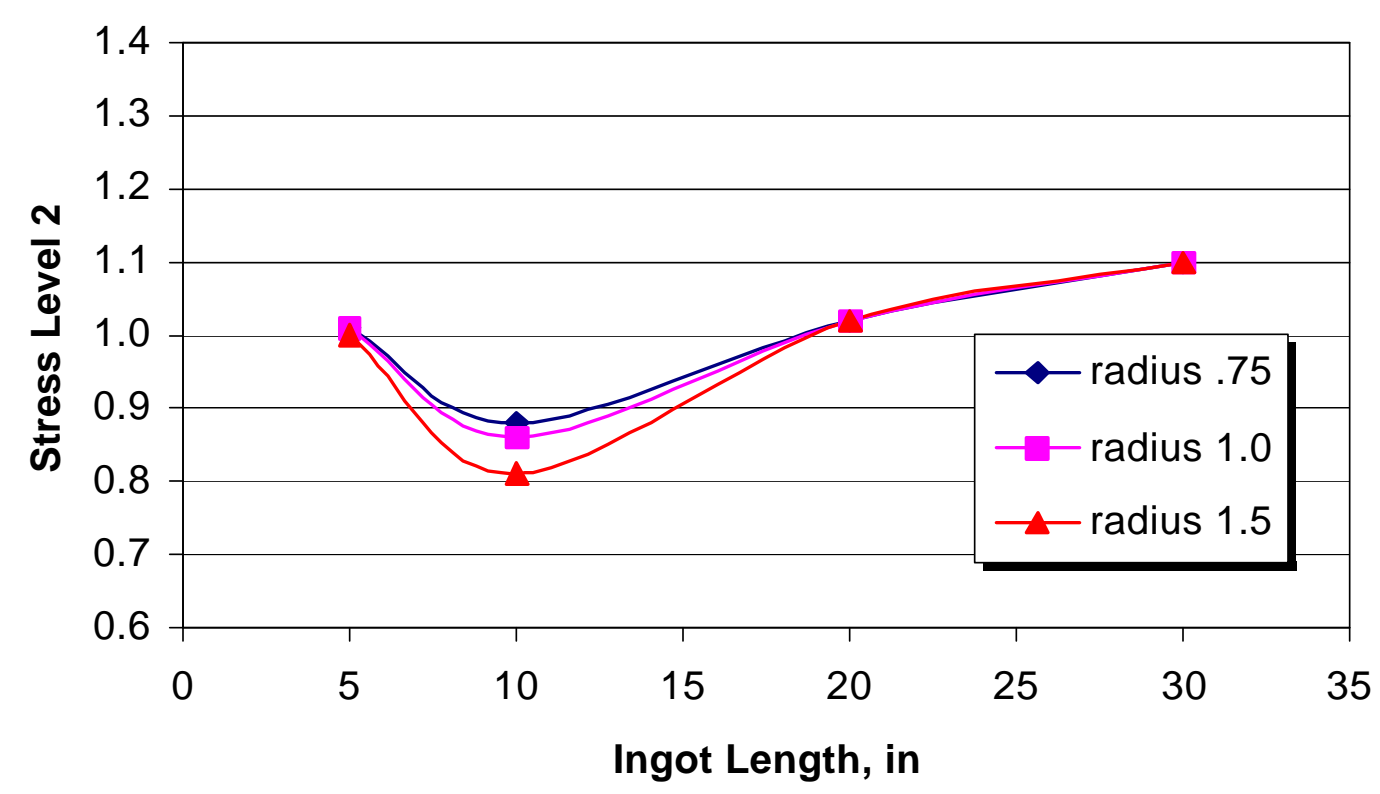

Figure 5.15 Effect of Corner Radius 
Table 5.5 Normalized Maximum Principle Stresses for Corner Radius

\begin{tabular}{|c|c|c|c|c|}
\hline Corner Radius & \multicolumn{4}{|c|}{ Ingot Length, inches } \\
\cline { 2 - 5 } inches & 5 & 10 & 20 & 30 \\
\hline 0.75 & 1.01 & 0.88 & 1.02 & 1.10 \\
\hline 1.00 & 1.01 & 0.86 & 1.02 & 1.10 \\
\hline 1.50 & 1.00 & 0.81 & 1.02 & 1.10 \\
\hline
\end{tabular}

Table 5.6 Locations of Maximum Stress Level 2 for Corner Radius

\begin{tabular}{|c|c|c|c|c|c|c|c|c|c|c|c|c|}
\hline \multirow{3}{*}{$\begin{array}{c}\text { Corner } \\
\text { Radius } \\
\text { inches }\end{array}$} & \multicolumn{12}{|c|}{ Ingot Length, inches } \\
\hline & \multicolumn{3}{|c|}{5} & \multicolumn{3}{|c|}{10} & \multicolumn{3}{|c|}{20} & \multicolumn{3}{|c|}{30} \\
\hline & 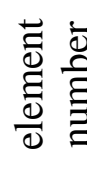 & 离 & ש̋ & 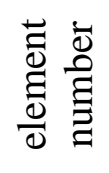 & 悹 & 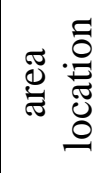 & 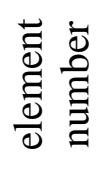 & 灾 & Ð & 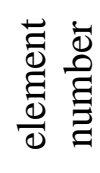 & 灾 离 & 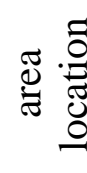 \\
\hline 0.75 & 苂 & 2 & $\stackrel{\overline{0}}{\stackrel{\overline{0}}{0}}$ & $\begin{array}{l}\stackrel{2}{8} \\
\stackrel{ి}{\beth}\end{array}$ & 40 & $\begin{array}{l}\dot{\bar{\Xi}} \\
\overline{0}\end{array}$ & 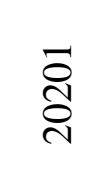 & 1 & $\begin{array}{l}\Xi \\
: \\
\stackrel{0}{0} \\
0\end{array}$ & $\frac{\overline{2}}{6}$ & 35 & 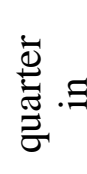 \\
\hline 1.00 & 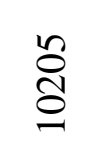 & 2 & $\stackrel{\bar{\Xi}}{\overline{0}}$ & $\frac{\check{\delta}}{\grave{\Xi}}$ & 40 & $\begin{array}{l}\bar{\Xi} \\
\stackrel{\Xi}{0}\end{array}$ & 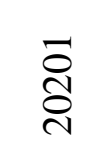 & 1 & 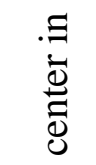 & $\frac{\overrightarrow{2}}{\sigma}$ & 35 & $\begin{array}{l}\stackrel{\dot{\vec{\Xi}}}{\vec{\Xi}} . \Xi \\
\vec{\sigma}\end{array}$ \\
\hline 1.50 & ڤి & 2 & $\stackrel{\overline{0}}{\overline{0}}$ & 总 & 1 & 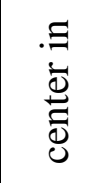 & 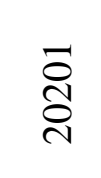 & 1 & 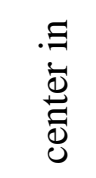 & $\frac{\mathfrak{2}}{\frac{2}{6}}$ & 35 & 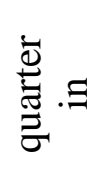 \\
\hline
\end{tabular}




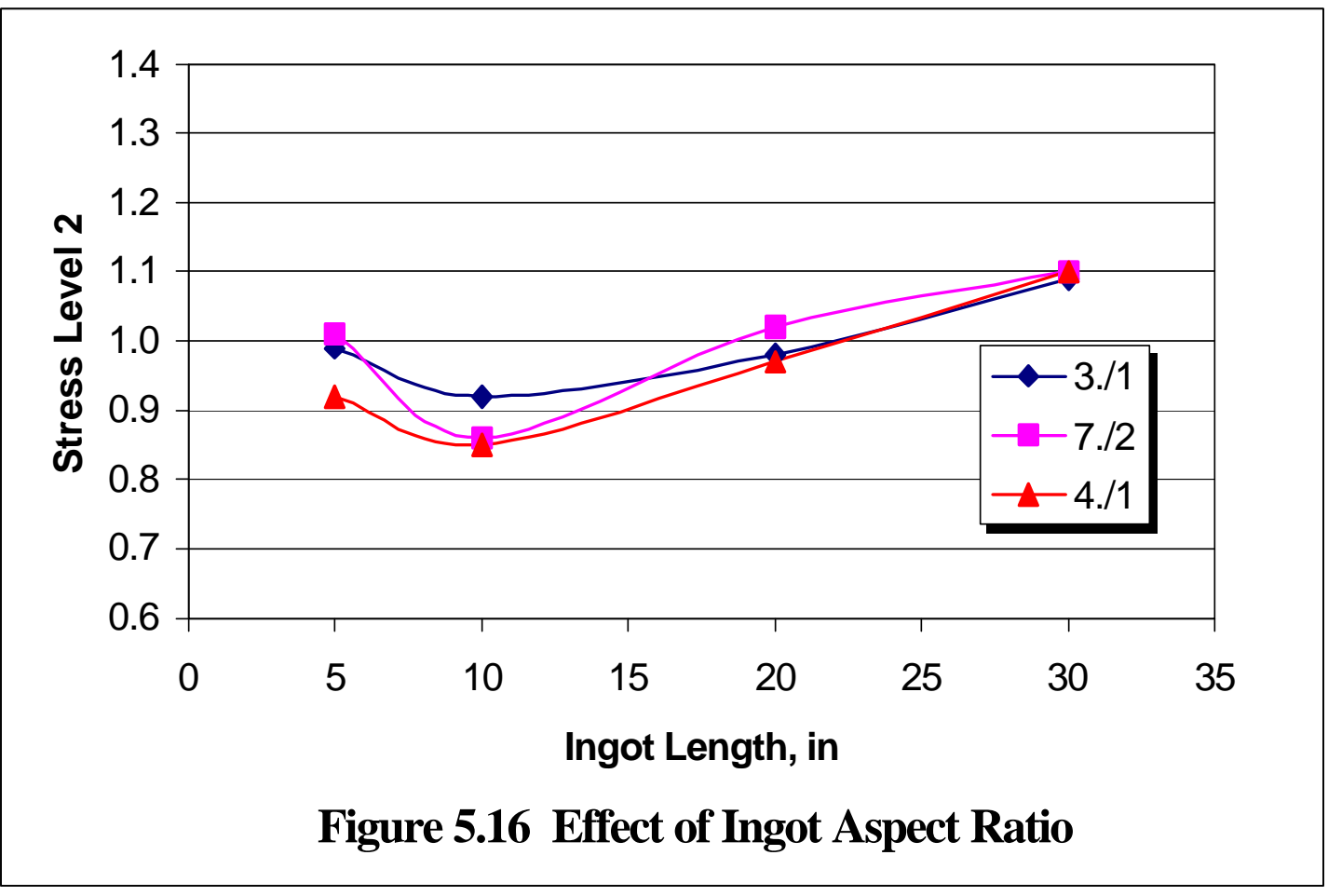

Table 5.7 Normalized Maximum Principle Stresses for Three Aspect Ratios

\begin{tabular}{|c|c|c|c|c|}
\hline \multirow{2}{*}{$\begin{array}{c}\text { Aspect } \\
\text { Ratio }\end{array}$} & \multicolumn{4}{|c|}{ Ingot Length, inches } \\
\cline { 2 - 5 } & 5 & 10 & 20 & 30 \\
\hline $3 / 1$ & 0.99 & 0.92 & 0.98 & 1.09 \\
\hline $7 / 2$ & 1.01 & 0.86 & 1.02 & 1.10 \\
\hline $4 / 1$ & 0.92 & 0.85 & 0.97 & 1.10 \\
\hline
\end{tabular}


Table 5.8 Locations of Maximum Stress Level for Different Aspect Ratios

\begin{tabular}{|c|c|c|c|c|c|c|c|c|c|c|c|c|}
\hline \multirow{3}{*}{$\begin{array}{c}\text { Aspect } \\
\text { Ratio }\end{array}$} & \multicolumn{12}{|c|}{ Ingot Length, inches } \\
\hline & \multicolumn{3}{|c|}{5} & \multicolumn{3}{|c|}{10} & \multicolumn{3}{|c|}{20} & \multicolumn{3}{|c|}{30} \\
\hline & 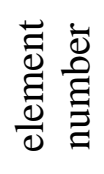 & 总离 & 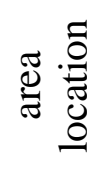 & 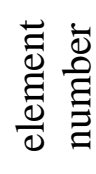 & 怘 & 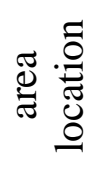 & 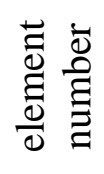 & 芯 & 导 & 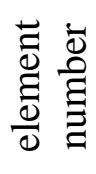 & 悹 & 导 \\
\hline $3: 1$ & ڤે & 2 & $\frac{\bar{\Phi}}{\stackrel{\bar{d}}{ \pm}}$ & $\begin{array}{l}\infty \\
\stackrel{2}{\sigma} \\
\text { aे }\end{array}$ & 38 & $\stackrel{\bar{\Phi}}{\overline{0}}$ & $\begin{array}{l}\text { ¿े } \\
\text { ઠे }\end{array}$ & 1 & 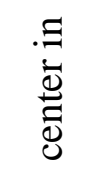 & 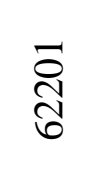 & 45 & $\begin{array}{l}\overline{\bar{v}} \\
\stackrel{\vec{v}}{\vec{\sigma}} . \Xi \\
\vec{\sigma}\end{array}$ \\
\hline $7: 2$ & ్ֶֻ & 2 & $\stackrel{\bar{\nu}}{\overline{0}}$ & 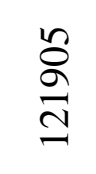 & 40 & 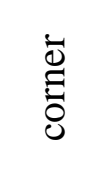 & ठ઼ે & 1 & $\begin{array}{l}. \Xi \\
\stackrel{\Xi}{ \pm} \\
\stackrel{\Xi}{0}\end{array}$ & $\frac{\overline{2}}{6}$ & 35 & 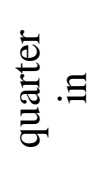 \\
\hline 4:1 & 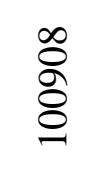 & 20 & 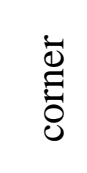 & $\begin{array}{l}\stackrel{\infty}{\circ} \\
\stackrel{\sigma}{0}\end{array}$ & 40 & 苛 & 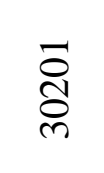 & 3 & 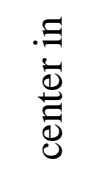 & $\frac{\vec{O}}{\sigma}$ & 25 & 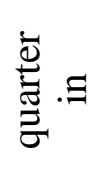 \\
\hline
\end{tabular}

Table 5.9 Maximum Stress Level 2 ( 58"x19" ingot)

\begin{tabular}{|c|c|c|c|c|}
\hline \multirow{2}{*}{$\begin{array}{c}\text { Drop rate } \\
\text { in/min }\end{array}$} & \multicolumn{4}{|c|}{ Ingot Length, inches } \\
\cline { 2 - 5 } & 5 & 10 & 20 & 30 \\
\hline 1.0 & 0.98 & 1.12 & 1.12 & 1.12 \\
\hline 1.5 & 1.01 & 1.01 & 1.02 & 1.00 \\
\hline 1.9 & 0.9 & 0.91 & 0.97 & 1.27 \\
\hline 2.4 & 0.80 & 0.97 & 1.00 & 1.21 \\
\hline 3.0 & 0.96 & 1.11 & 1.08 & 1.18 \\
\hline
\end{tabular}




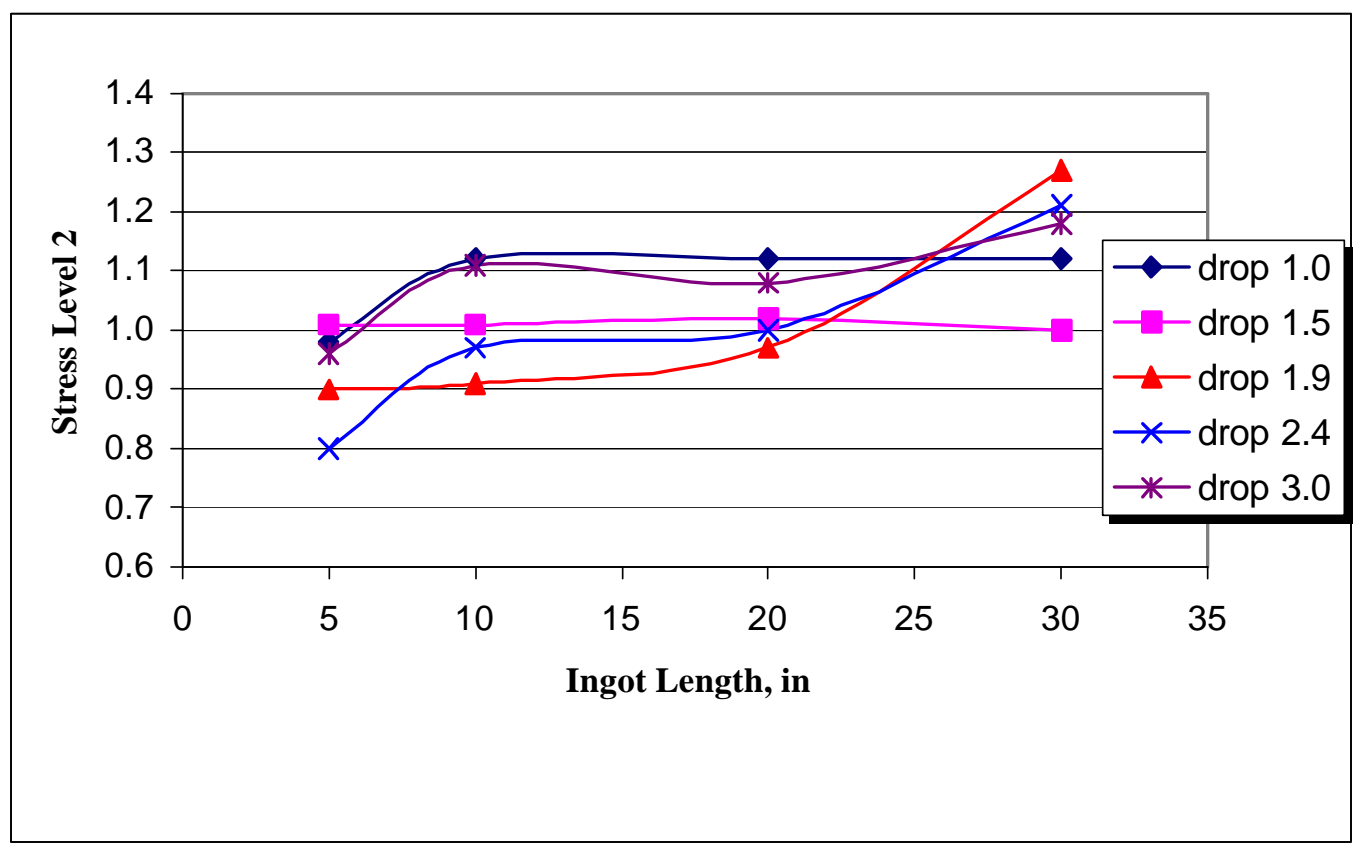


Table 5.10 Locations of the Maximum Stress Level 2 in the Ingots

for Five Drop Rates (58"x19" ingots)

\begin{tabular}{|c|c|c|c|c|c|c|c|c|c|c|c|c|}
\hline \multirow{3}{*}{$\begin{array}{l}\text { Drop } \\
\text { Rate } \\
\text { in/min }\end{array}$} & \multicolumn{12}{|c|}{ Ingot Length, inches } \\
\hline & \multicolumn{3}{|c|}{5} & \multicolumn{3}{|c|}{10} & \multicolumn{3}{|c|}{20} & \multicolumn{3}{|c|}{30} \\
\hline & 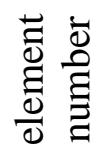 & 总 & 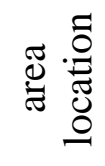 & 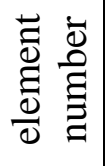 & 悹 & 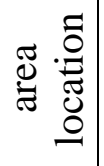 & 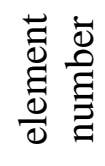 & 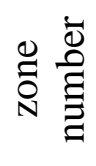 & 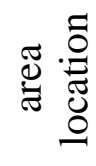 & 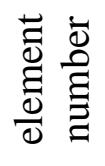 & 怘离 & 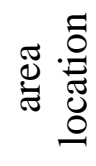 \\
\hline 1.0 & $\begin{array}{l}\text { ஜ̊ } \\
\text { के }\end{array}$ & 18 & 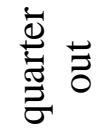 & $\frac{\wp}{\infty}$ & 38 & 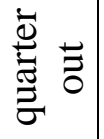 & $\underset{\infty}{\grave{\infty}}$ & 78 & 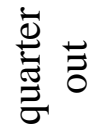 & $\begin{array}{l}\mathscr{2} \\
2 \\
2 \\
\infty\end{array}$ & 118 & $\begin{array}{l}\stackrel{\bar{\omega}}{\bar{E}} \\
\text { है }\end{array}$ \\
\hline 1.5 & 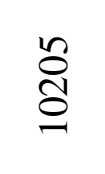 & 2 & $\frac{\bar{\Phi}}{\bar{\Xi}} \overline{0}$ & $\frac{\infty}{\infty}$ & 38 & 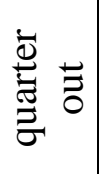 & 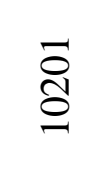 & 1 & $\begin{array}{l}\Xi \\
\vdots \\
\stackrel{\Xi}{0} \\
0\end{array}$ & 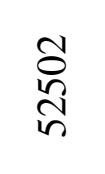 & 35 & 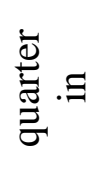 \\
\hline 1.9 & $\begin{array}{l}\text { હิ } \\
\text { రิ }\end{array}$ & 2 & $\frac{\overline{\mathscr{g}}}{\bar{\Xi}} \overline{\mathrm{o}}$ & $\frac{\infty}{2}$ & 40 & 离 & ڤ્仓ે & 1 & 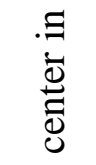 & $\frac{\bar{\sigma}}{\sigma}$ & 35 & 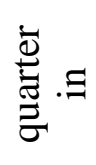 \\
\hline 2.4 & 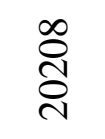 & 2 & $\frac{\overline{\mathrm{d}}}{\overline{\mathrm{g}}} \overline{\mathrm{o}}$ & 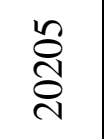 & 2 & 矛 & ণ্ণ & 3 & 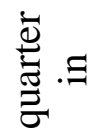 & 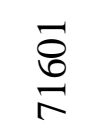 & 37 & $\begin{array}{l}\stackrel{\bar{v}}{\vec{E}} . \Xi \\
\stackrel{\vec{w}}{\sigma}\end{array}$ \\
\hline 3.0 & $\begin{array}{l}\text { ઠิ } \\
\text { రీ }\end{array}$ & 2 & 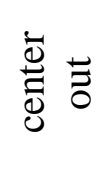 & 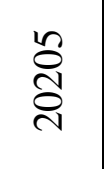 & 2 & $\stackrel{\overline{\vec{v}}}{\overrightarrow{\mathrm{d}}} \overline{\mathrm{o}}$ & 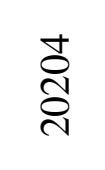 & 1 & 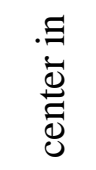 & $\frac{\delta}{\infty}$ & 37 & $\begin{array}{l}\stackrel{\bar{d}}{\bar{E}} . \Xi \\
\stackrel{\vec{\sigma}}{\sigma}\end{array}$ \\
\hline
\end{tabular}




\section{CHAPTER 6}

\section{DATA REDUCTION AND PREDICTION}

In this research, numerous FE DC ingot casting simulation runs based on ABAQUS ${ }^{\mathrm{TM}}$ have been carried out on a Silicon Graphics Challenge workstation. Due to the complexity of the FE simulation, it normally takes two to three days of CPU time to finish a case with large output data files of temperature, displacement, and stress fields. It is obvious that analysis of the FE results is very time consuming. In order to provide ingot casting engineers a simple-to-use tool to obtain the temperature and stress fields and to evaluate the possible locations of ingot cracking, three PC programs were developed in this research. The programs are introduced in the following sections.

\subsection{Program CONVERT}

Program CONVERT is a file format conversion and data reduction program. It is executed in three steps. First, it converts the UNIX ASCII data format of the output files generated from ABAQUS $^{\mathrm{TM}}$ post into PC file format so that the output data can be further analyzed using commercial PC application software and other specially developed programs. Second, it calculates stress levels in the ingot. Third, CONVERT reduces the huge amount of FE output data into manageable data files.

\subsubsection{File Format Conversion}

The first task is to convert UNIX data file to PC file format. The output data extracted from ABAQUS $^{\mathrm{TM}}$ post are in UNIX ASCII data format. Due to certain differences in UNIX and PC 
ASCII file formats, the data files created by ABAQUS ${ }^{\mathrm{TM}}$ could not be transported correctly to a PC. CONVERT reads and converts the UNIX output data file into proper PC ASCII file format.

\subsubsection{Stress Level calculation}

In the second task, CONVERT consolidates information from two output files into one. The stress and temperature data from ABAQUS ${ }^{\mathrm{TM}}$ are in two separate files for each simulation case. CONVERT only reads the useful portions of the data from the two files and writes them into one file in a simpler format. CONVERT then calculates the yield and tensile strengths according to the temperature at the ingot location and determines the normalized stress levels at that location. The relationship between temperature versus yield and tensile strengths has been established by experiment [27] as shown in Figure 6.1. Piece-wise linear interpolation technique is applied in the program to determine the strengths at any given temperature. Then the ratios of the stress to the yield and tensile strengths, which are named as stress levels 1 and 2, respectively, are determined.

A small portion of the UNIX stress output file from ABAQUS ${ }^{\mathrm{TM}}$ is shown in Figure 6.2. The first output file created by CONVERT is partially shown in Figure 6.3. Since the experimental curves in Figure 6.1 only gives definitions of strengths for temperature less than $800^{\circ} \mathrm{F}$, for those area in the model where the temperature is higher than $800^{\circ} \mathrm{F}$, the strengths are undefined and a value of 99999.0 is assigned to the stress, and 99.0 to the stress levels. 


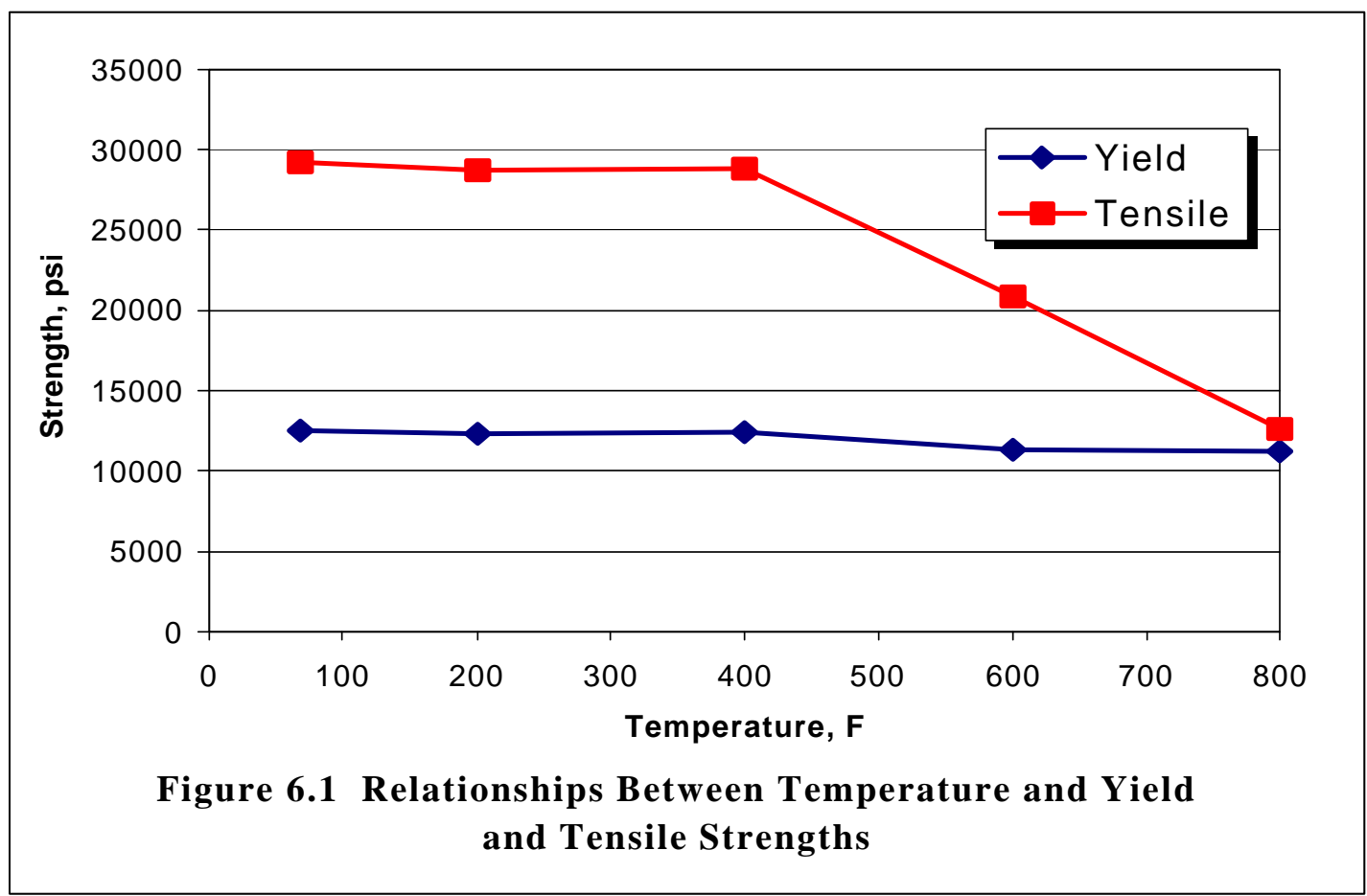

Variable Report :

Integration pt. = All, Section pt. = 1

Elem. No.

$--------$

10101

10102

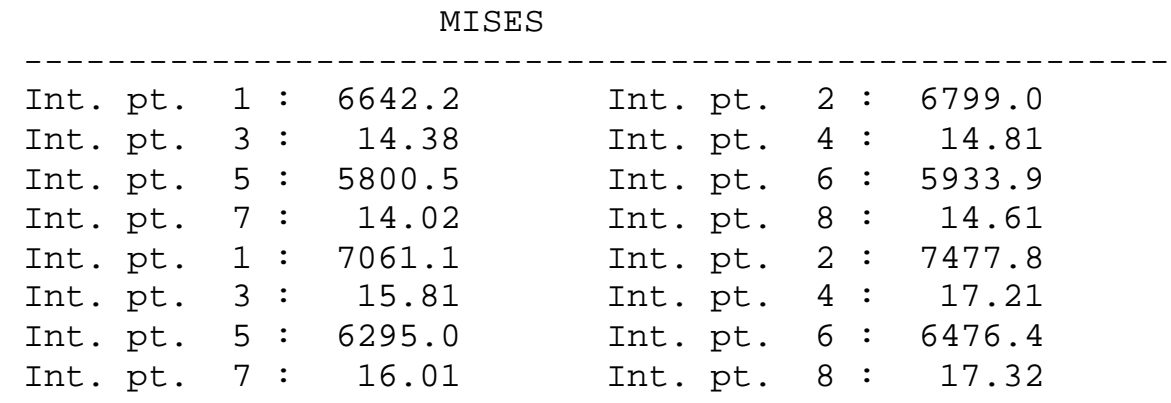

Figure 6.2 Output File from ABAQUS 


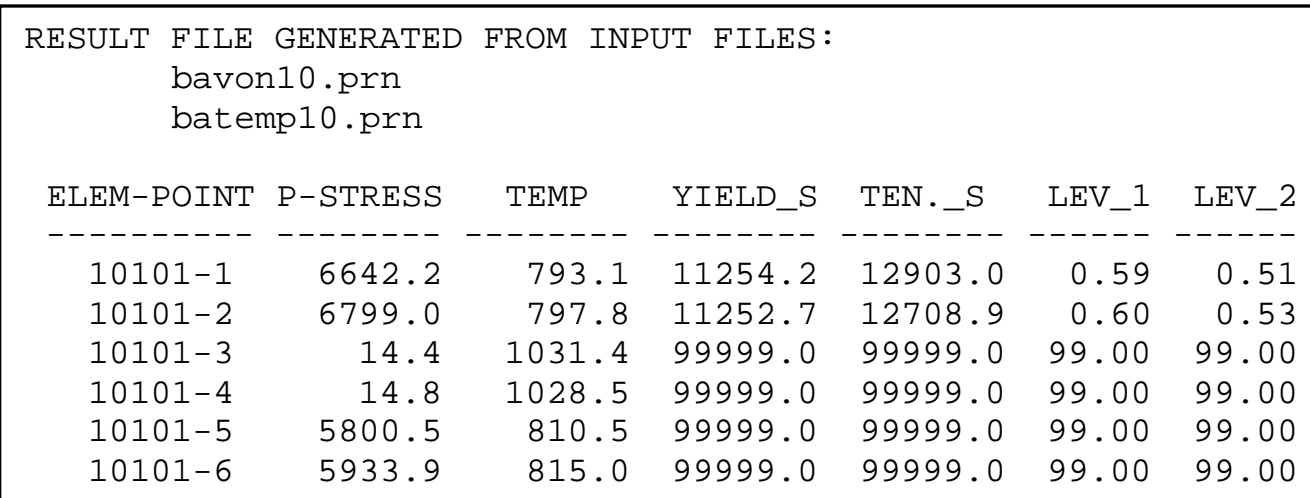

\section{Figure 6.3 The First Output Data File from CONVERT}

\subsubsection{Data Reduction}

The FE mesh layout of the ingot contains 5,664 elements $(8 \times 59 \times 12)$ and there are eight integration points in each element. Therefore, each of the stress or temperature output data files from $\mathrm{ABAQUS}{ }^{\mathrm{TM}}$ contains 45,312 data points and the size of each file is about $1.8 \mathrm{MB}$. In order to reduce the large amount of output data to a manageable level and to preserve the ability to accurately represent the simulation results, a procedure of systematic data reduction is designed and implemented in program CONVERT. For the data reduction, the entire domain of the FE model is divided into 120 sub-zones as shown in Figure 6.4. The numbers shown along the edge of the model depicts the numbering scheme for the sub-zones. The front number identifies the layer location and the number followed in parenthesis shows number of elements inside that layer. Along the x-axis direction, the model (i.e., half thickness of the ingot) is divided into two layers with 4 elements in each layer. Along the y-axis (i.e., the height of the ingot), there are 12 slices with four elements in the bottom slice and five elements in the remaining 11 slices. The model is divided into five blocks along the z-axis direction (i.e., half width of the ingot) with two elements in the first three blocks and three elements in the remaining two blocks. The 


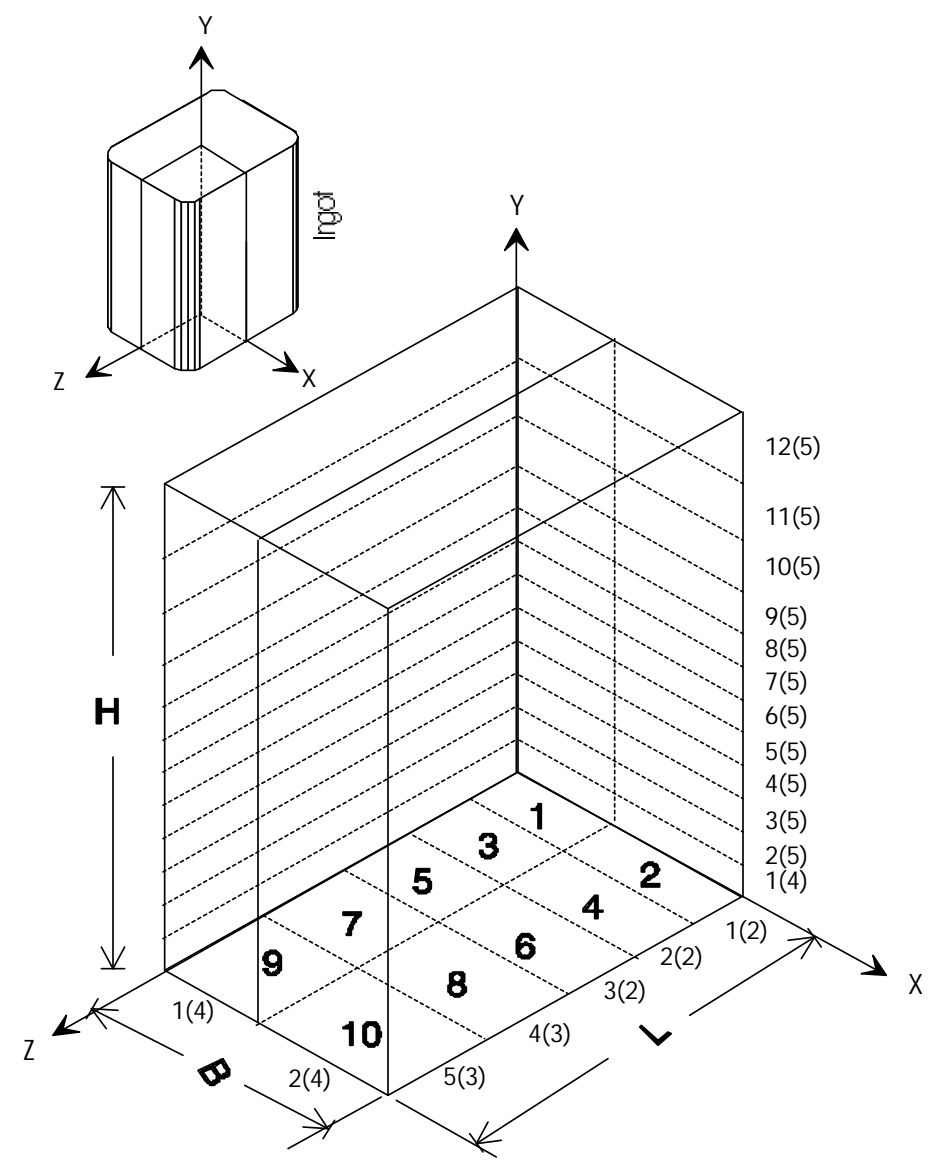

Figure 6.4 Division of Sub-Zones in the Model

identification numbers of the 10 zones in the bottom slice are also shown in Figure 6.4. The element numbers in the sub-zones based on this numbering scheme are automatically generated by a program SUBZONE and stored in an ASCII file called SUBZONE.DAT.

Program CONVERT determines the average, standard deviation, maximum values of the dependent variables (i.e., stress, temperature, stress levels) for each of the 120 sub-zones. These statistical data facilitate the representation of the finite element results in the domain of the model and will be used in further statistical data analysis. A portion of the second output data file generated by CONVERT is shown in Figure 6.5. The data are appeared in blocks with each 
block representing one sub-zone where block identification number is shown on the first row, then four rows of data are shown. The four rows are for the four dependent variables of stress, temperature, and stress level 1 and stress level 2, respectively. The four numbers in each row are the statistical data of the respective dependent variable. The first number represents data average and followed by standard deviation and maximum. The last one is the number of standard deviation of the maximum away from average. If the last number is more than 3 , which indicates a statistically unlikely event, the smoothed maximum (i.e., the third number) is set to be the average plus three standard deviations. However, the last number in the row still preserves the truth of the maximum value. Note that the error calculations shown in Tables 6.1 and 6.2 are all based on the actual maximum data, not the smoothed maximum.

\begin{tabular}{|c|c|c|c|}
\hline \multicolumn{4}{|l|}{1} \\
\hline 1247.99 & 2482.53 & 8695.59 & 3.41 \\
\hline 1011.60 & 90.20 & 1121.30 & 1.22 \\
\hline 0.70 & 0.10 & 0.86 & 1.53 \\
\hline 0.61 & 0.08 & 0.74 & 1.65 \\
\hline \multicolumn{4}{|l|}{2} \\
\hline 9199.85 & 3119.58 & 14563.00 & 1.72 \\
\hline 715.13 & 156.28 & 1007.10 & 1.87 \\
\hline 0.95 & 0.12 & 1.19 & 2.11 \\
\hline 0.60 & 0.11 & 0.90 & 2.75 \\
\hline \multicolumn{4}{|c|}{ Figure 6.5 Second Output Data File Generated by CONVERT } \\
\hline
\end{tabular}

\subsection{Program REGRESS}

Program REGRESS is a regression program. It reads the statistical data (i.e., mean data, standard deviation, and maximum from the output files created by program CONVERT. Four sets of statistical data are then calculated for each of the 120 sub-zones. These four sets of data are principal stress, temperature, the ratio of principal stress to its yield strength (i.e., stress level 
1) and to its tensile strength (stress level 2), respectively. Each set also contains statistical items of the mean, standard deviation, corrected maximum and standard deviations of the maximum and the mean. For each of the dependent variable, when the uncorrected maximum in a sub-zone is more than three times of the standard deviation from its mean, a corrected maximum, $y_{\text {max }}$, is determined as

$$
y^{\prime}{ }^{\prime} \max =\bar{y}+3 \cdot \sigma_{y}
$$

Where $\bar{y}$ and $\sigma_{y}$ are the mean and the standard deviation of the targeted dependent variable, respectively.

\subsubsection{Regression Model and Multi-Linear Regression}

The following polynomial function is proposed to represent the relationship between each of the statistical items of the dependent variables and the independent variables.

$$
y=A+B x_{1}+C x_{2}+D x_{3}+E x_{4}+F x_{1}^{2}+G x_{2}^{2}+H x_{3}^{2}+I x_{4}^{2}
$$

where: $y$ statistical item of the dependent variable
$A, \ldots, I-\quad$ regression coefficients
$x_{1}-\quad$ ingot drop rate
$x_{2}$ - $\quad$ ratio of the water flow rate to ingot width
$x_{3}-\quad$ ingot corner radius
$x_{4}-\quad$ aspect ratio (width to thickness) 
This particular regression model is chosen due to the following two reasons. First, the independent variables $x_{1}, x_{2}, x_{3}$ and $x_{4}$ are unlikely to have any logic inter-dependency among them. Second, each of the independent variables has a nonlinear influence to the targeted dependent variable based on the FE analyses performed. In the proposed regression function, there are nine coefficients, $A, \ldots, I$, to be determined for each statistical item. Therefore, a minimum of nine sets of mutually independent input data is required to perform one set of the regression analysis.

Least square technique is employed in the regression analysis. The residual error between the "measured" and the calculated dependent variable is

$$
\begin{aligned}
e & =\sum_{1}^{N}\left(y-y_{i}\right)^{2} \\
& =\sum_{1}^{N}\left(A+B x_{1}+C x_{2}+D x_{3}+E x_{4}+F x_{1}{ }^{2}+G x_{2}{ }^{2}+H x_{3}{ }^{2}+I x_{4}{ }^{2}-y_{i}\right)^{2}
\end{aligned}
$$

where: $e-\quad$ residual error

$y$ - calculated value for the dependent variable using Eq. 6.2.

$y_{i}{ }^{-} \quad$ "measured" value for the dependent variable

The objective is to find an optimum set of the regression coefficients from the input values of dependent and independent variables so that the residual error is minimized. In order to fulfill this objective, the first partial derivative of the residual error with respect to each of the coefficients should be minimized. 


$$
\frac{\partial e}{\partial A}=0, \frac{\partial e}{\partial B}=0, \ldots, \frac{\partial e}{\partial I}=0
$$

This operation will result in the following set of nine simultaneous linear equations with nine unknowns.

$$
[Q](X)=(Y)
$$

In Eq. (6.5), $[Q]$ is the coefficient matrix. The matrix is a symmetrical one and its elements are evaluated as

$$
[Q]=\left[\begin{array}{ccccccccc}
N & \sum x_{1} & \sum x_{2} & \cdot & \cdot & \cdot & \cdot & \sum x_{3}{ }^{2} & \sum x_{4}{ }^{2} \\
& \sum x_{1}{ }^{2} & \sum x_{1} x_{2} & \cdot & \cdot & \cdot & \cdot & \sum x_{1} x_{3}{ }^{2} & \sum x_{1} x_{4}{ }^{2} \\
& & \sum x_{2}{ }^{2} & \cdot & \cdot & \cdot & \cdot & \sum x_{2} x_{3}{ }^{2} & \sum x_{2} x_{4}{ }^{2} \\
& & & \cdot & \cdot & \cdot & \cdot & \cdot \\
& & & \cdot & \cdot & \cdot & \cdot & \cdot \\
& & & & & \cdot & \cdot & \cdot \\
& & & & & & & \sum x_{3}{ }^{4} & \sum x_{3}{ }^{2} x_{4}{ }^{2} \\
& & & & & & & \sum x_{4}{ }^{4}
\end{array}\right]
$$

The transposed form of the vector of the unknown $(X)$ in Eq. (6.5) is

$$
(X)^{T}=\left(\begin{array}{lllllllll}
A & B & C & D & E & F & G & H & I
\end{array}\right) .
$$

The transposed form of the vector on the right side of Eq. (6.5) is obtained as

$$
(Y)^{T}=\left(\begin{array}{llllll}
\sum y_{i} & \sum x_{1} y_{i} & \sum x_{2} y_{i} & \cdots & \cdots x_{3}^{2} y_{i} & \sum x_{4}^{2} y_{i}
\end{array}\right)
$$


Gauss elimination method is employed in program REGRESS to solve the set of simultaneous linear equations for the regression coefficients $A, B, \ldots$, and $I$.

\subsubsection{Implementation of Program REGRESS}

In order to automate the program execution, program REGRESS first reads a job control file.

Figure 6.6 shows an example file with nine input values.

\begin{tabular}{|l|}
\hline \\
"BA10ST.PRN" \\
$1.9,1.250,1.0,3.5$ \\
"D1010ST.PRN" \\
$1.0,1.250,1.0,3.5$ \\
"D 3010 ST.PRN" \\
$3.0,1.250,1.0,3.5$ \\
"W5010ST.PRN" \\
$1.9,0.893,1.0,3.5$ \\
"W9010ST.PRN" \\
$1.9,1.607,1.0,3.5$ \\
"R07510ST.PRN" \\
$1.9,1.250,0.75,3.5$ \\
"R15010ST.PRN" \\
$1.9,1.250,1.50,3.5$ \\
"R3110ST.PRN" \\
$1.9,1.296,1.0,3.0$ \\
"R4110ST.PRN" \\
1.9,1.094,1.0,4.0 \\
"PSTRESS1.REG" \\
"TEMPTUR1.REG" \\
"STRSLV21.REG" \\
Figure 6.6 Job Control File
\end{tabular}

In the job control file, number of input data sets, and their file names as well as values of the independent variables should be specified. The names of the output data files are shown as the last three items for the principal stress, temperature and stress level 2, respectively. After the 
data input, the program performs a multiple linear regression on each of the statistics and outputs the results in the specified output data files.

A portion of the output file for the principal stress created by program REGRESS is listed below. The first line indicates the type of information contained in the file. 120 blocks of data for the 120 sub-zones then follow it. There are four lines of data in each block. It starts with the ID number of the sub-zone. The next three lines contain the nine regression coefficients for the mean, the standard deviation and the maximum, respectively.

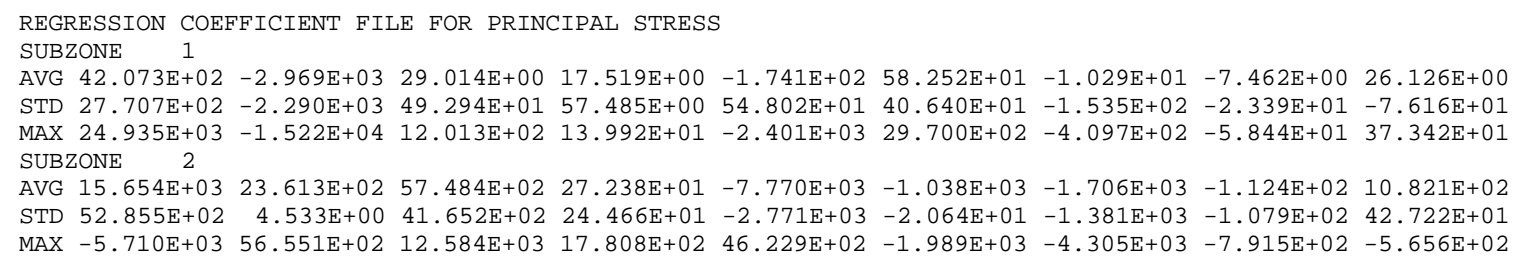

\section{Figure 6.7 Regression Output File}

\subsection{Program PREDICTION}

Prediction is a user-friendly PC program package for the determination of average, standard, and maximum values of the temperature, stresses and stress levels in every zone of ingot. It will give users the interpolation or extrapolation results based on results from REGRESS. It can show user the statistically evaluated results from REGRESS and time curves of dependent variables visually. It is quite convenient for casting engineer to quickly obtain temperature and stress fields of an ingot with user-specified casting parameters. The function features, interpolation models, and package structure will be described below. 


\subsubsection{The Function Features of PREDICTION}

PREDICTION has four functions. First, it give users an interface to input casting parameters. This interface also shows a picture of a quarter-size ingot. Second, it can calculate temperature, stress, and stress level for every zone in the quarter ingot and save them in files for later use. The third function of this package is visual representation of dependent variables for the desired time steps. The graphical picture shows the values of dependent variables with assigned colors. The possible crack location can be evaluated from the stress level distribution. Plots of temperature, principal stress, and normalized stress level versus ingot length for any selected zone can be obtained. This is the fourth function of PREDICTION, which can show increasing or decreasing tendency of zone temperature, stress, or stress level.

\subsubsection{Interpolation model}

PREDICTION can be used to run two types of interpolation. One is interpolating casting parameter. The other is time (or step) interpolation. The model for the former is based on Eq. (6.2) and is repeated here as Eq. (6.6). The nine coefficients A, B, C, D, E, F, G, H, I which are the output of REGRESS for different dependent variables in each zone, were stored in data files in PREDICTION for four time steps. These steps correspond to four ingot length of 5, 10, 20, and 30 inches. The user selects input independent variables, PREDICTION then calculates dependent variable, y, by using Eq. (6.6)

$$
y=A+B x_{1}+C x_{2}+D x_{3}+E x_{4}+F x_{1}{ }^{2}+G x_{2}{ }^{2}+H x_{3}{ }^{2}+I x_{4}{ }^{2}
$$

Time interpolation can be calculated if the user wants to know the tendency of dependent variables from start-up stage to steady-state stage. If the four sets of numerical models generates 
four discrete sets of data points $\left(x_{1}, y_{1}\right),\left(x_{2}, y_{2}\right),\left(x_{3}, y_{3}\right)$ and $\left(x_{4}, y_{4}\right)$, the most possible value at $x$ is defined by Eq. (6.7). A weighting factor is given to each of the four known dependent values. The weighting function is shown as the shaded part as shown in Figure 6.8. A data point located closer to the point of interest (i.e., $x$ ) will have more contribution to the unknown $y$ at $x$ than those located farther away from it.

$$
y(x)=\frac{\sum_{i=1}^{4}\left[y_{i} e^{-\pi\left(\frac{x_{i}-x}{D}\right)^{2}}\right]}{\sum_{i=1}^{4} e^{-\pi\left(\frac{x_{i}-x}{D}\right)^{2}}}
$$

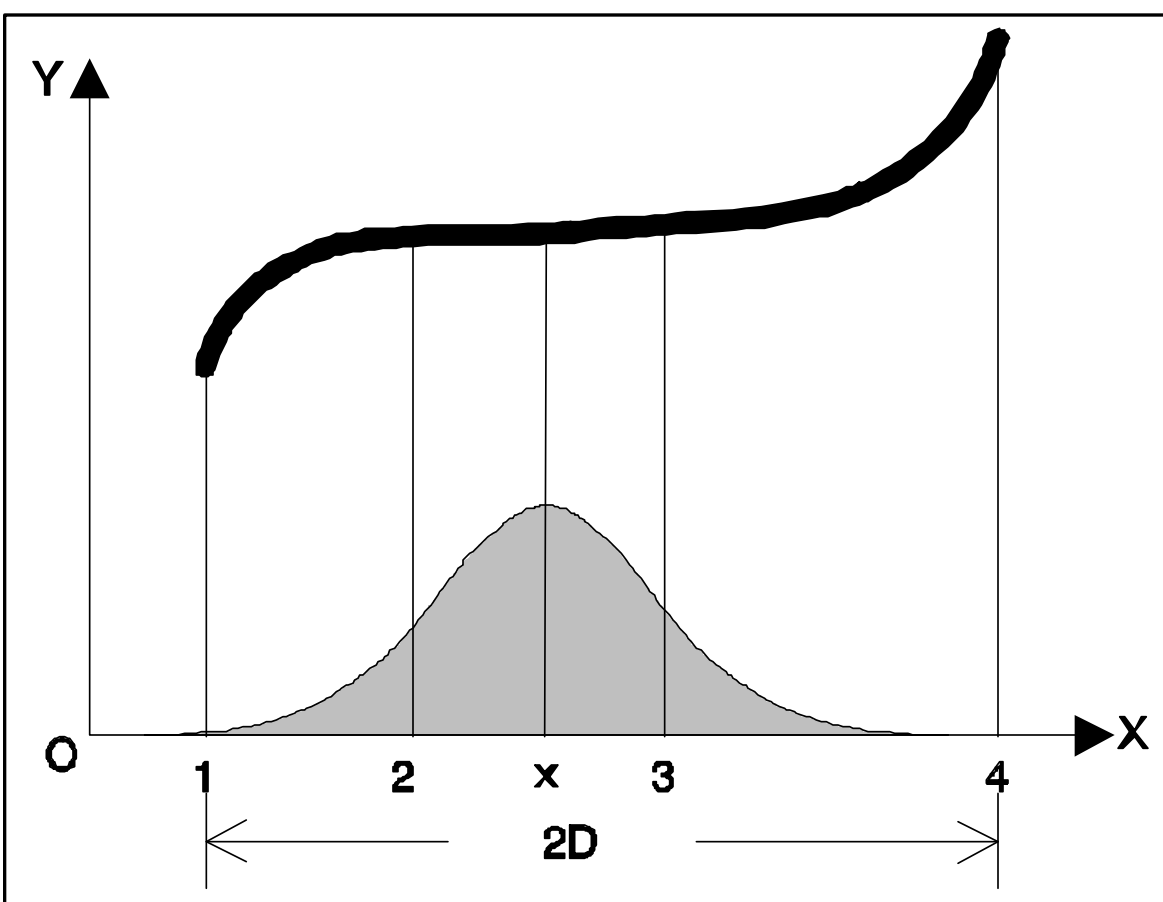

Figure 6.8 Weighting Function Used in Time Interpolation 


\subsubsection{The Structure of PREDICTION}

PREDICTION is constructed in Visual Basic 6.0. There are nine forms and one module in this package. Every form is composed of two parts. The first part is the form itself. It is an interface with object. The second part is the program code. The module is the main program. It controls the procedure of the package. The functions of every form are given as follows.

The frmSplash and frmAbout are designed for a splash picture, which is shown at the beginning of running the package. The form frmMain is a main menu similar to MS Window enviroment, which contains several boxes (File, View, Compute, and Help). Under every box, it is drag down menu which allow user to make further choice. The form datainput is an interface in which user can specify ingot size and casting conditions. It calculates independent variables, $\mathrm{x}_{1}$ to $\mathrm{x}_{4}$. This interface also shows quarter ingot geometry and the order of the zone number. The form Form1 shows the values of independent variables $\mathrm{x}_{1}$ to $\mathrm{x}_{4}$. It gives user a chance to confirm these selected values after making sure these values are correct. The form Form2 is an interface, which let user chose desired zones, dependent variables, and steps to be calculated. The form Form3 is a warning panel. It reminds user to save files. The form distribution is an object, which include interface and picture. The picture shows distribution of dependent variable with colors representing magnitude of the dependent variables. At the interface user can make choice for desired dependent variable, steps, and average, standard, or maximum values. The form curve shows plot of a dependent variable versus ingot length at a selected zone. 


\subsection{PREDICTION Results and Comparison with ABAQUS ${ }^{\mathrm{TM}}$ Results}

A total of nine simulated cases were carried out using ABAQUS ${ }^{\mathrm{TM}}$ and the results were processed to do regression analysis using REGRESS. Three drop rate, 1.0, 1.9, and 3.0 inches / min, three water flow rate, 50, 70, 90 gallon / min / mold, three corner radii, 0.75, 1.0, 1.5 inches, and three aspect ratios, 3/1, 7/2, 4/1 were selected. The results were stored in package PREDICTION. The package PREDICTION was used to predict the temperature and stress fields for two ingots with different drop rate. One drop rate is 1.5 inches / min and the other is 2.4 inches / min. These two ingots have the same water flow rate 70 gallon / min / mold, same corner radius, 1.0 inches, and same aspect ratio, 7/2. The predicted results and numerical results from ABAQUS $^{\mathrm{TM}}$ were compared for stress level 2 and its location as shown in Table 6.1. Except for drop rate 2.4 at ingot length of 5 inches, the differences between ABAQUS ${ }^{\mathrm{TM}}$ results and PREDICTION results are within 10 percent. Most of the maximum stress locations from PREDICTION are the same with ABAQUS ${ }^{\mathrm{TM}}$ results. For drop rate of 1.5 inches / min and at ingot length of 10 and 20 inches, the predicted maximum stress locations from PREDICTION differ those from ABAQUS ${ }^{\mathrm{TM}}$. The reason is that the stress level 2 values are close in these location areas. For example, the value of maximum stress level 2 is 0.97 from ABAQUS ${ }^{\mathrm{TM}}$ result for drop rate of 1.5 inches /min and ingot length of 20 inches. The location is at quarter-out area. In this quarter area the value of stress level 2 is 0.87 from PREDICTION and is not shown in Table 6.1 since it is not the maximum value in this step when compared with the value 0.89 in center-in area. But the values of 0.89 and 0.87 are so close for stress level 2 if 10 percent difference can be accepted. 
PREDICTION was also used to predict temperature and stress fields of 58" x19" ingot under five different drop rates with same water flow rate (84 gallon /min / mold), same corner radius (1.5 inches), and same aspect ratio (58/19). Table 6.2 shows the comparison of PREDICTION and $\mathrm{ABAQUS}^{\mathrm{TM}}$ results. The difference is less than $15 \%$ except for three locations. 
Table 6.1 Comparison of PREDITION and ABAQUS Results for 56" x 16" Ingot

\begin{tabular}{|c|c|c|c|c|c|}
\hline Drop rate & $\begin{array}{l}\text { Ingot length } \\
\text { in }\end{array}$ & 5 & 10 & 20 & 30 \\
\hline \multirow{5}{*}{$1.5 \mathrm{in} / \mathrm{min}$} & $\begin{array}{c}\text { PREDICTION } \\
\text { stress level } 2 \\
\end{array}$ & 0.91 & 0.93 & 0.89 & 1.05 \\
\hline & $\begin{array}{l}\text { PREDICTION } \\
\text { location }\end{array}$ & quarter-out 18 & quarter-out 38 & center-in 1 & quarter-in 35 \\
\hline & $\begin{array}{c}\text { ABAQUS } \\
\text { stress level } 2\end{array}$ & 0.92 & 1.00 & 0.97 & 1.04 \\
\hline & $\begin{array}{l}\text { ABAQUS } \\
\text { location }\end{array}$ & quarter-out 18 & center-out 32 & quarter-out 78 & quarter-in 35 \\
\hline & Difference $\%$ & -5.43 & -7.00 & -8.25 & 0.96 \\
\hline \multirow{5}{*}{$2.4 \mathrm{in} / \mathrm{min}$} & $\begin{array}{c}\text { PREDICTION } \\
\text { stress level } 2 \\
\end{array}$ & 1.04 & 0.83 & 1.04 & 1.19 \\
\hline & $\begin{array}{c}\text { PREDICTION } \\
\text { location }\end{array}$ & center-out 2 & center-out 2 & center-in 1 & quarter-in 37 \\
\hline & $\begin{array}{c}\text { ABAQUS } \\
\text { stress level } 2 \\
\end{array}$ & 0.87 & 0.82 & 0.95 & 1.30 \\
\hline & $\begin{array}{l}\text { ABAQUS } \\
\text { location }\end{array}$ & center-out 2 & center-out 2 & center-in 3 & quarter-in 35 \\
\hline & Difference $\%$ & 19.5 & 1.22 & 9.47 & -8.46 \\
\hline
\end{tabular}

- The numbers, which follow the area locations, are zone numbers. 
Table 6.2 Comparison of PREDITION and ABAQUS Results for 58" x 19" Ingot

\begin{tabular}{|c|c|c|c|c|c|}
\hline Drop rate & $\begin{array}{l}\text { Ingot length } \\
\text { in }\end{array}$ & 5 & 10 & 20 & 30 \\
\hline \multirow{5}{*}{$1.0 \mathrm{in} / \mathrm{min}$} & $\begin{array}{c}\text { PREDICTION } \\
\text { stress level } 2 \\
\end{array}$ & 1.05 & 1.21 & 1.17 & 1.12 \\
\hline & $\begin{array}{c}\text { PREDICTION } \\
\text { location }\end{array}$ & quarter-out 18 & quarter-out 38 & quarter-out 78 & quarter-out 78 \\
\hline & $\begin{array}{c}\text { ABAQUS } \\
\text { stress level } 2\end{array}$ & 0.98 & 1.12 & 1.12 & 1.12 \\
\hline & $\begin{array}{l}\text { ABAQUS } \\
\text { location }\end{array}$ & quarter-out 18 & quarter-out 38 & quarter-out 78 & quarter-out 78 \\
\hline & Difference \% & 7.14 & 8.04 & 4.46 & 0.00 \\
\hline \multirow{5}{*}{$1.5 \mathrm{in} / \mathrm{min}$} & $\begin{array}{l}\text { PREDICTION } \\
\text { stress level } 2\end{array}$ & 0.93 & 1.03 & 0.99 & 1.06 \\
\hline & $\begin{array}{c}\text { PREDICTION } \\
\text { location }\end{array}$ & quarter-out 18 & quarter-out 38 & quarter-in 87 & quarter-in 45 \\
\hline & $\begin{array}{c}\text { ABAQUS } \\
\text { stress level } 2\end{array}$ & 1.01 & 1.01 & 1.02 & 1.00 \\
\hline & $\begin{array}{l}\text { ABAQUS } \\
\text { location }\end{array}$ & center-out 2 & quarter-out 38 & center-in 1 & quarter-in 55 \\
\hline & Difference $\%$ & -7.92 & 1.98 & -2.94 & 6.00 \\
\hline \multirow{5}{*}{$1.9 \mathrm{in} / \mathrm{min}$} & $\begin{array}{c}\text { PREDICTION } \\
\text { stress level } 2 \\
\end{array}$ & 1.02 & 0.91 & 0.99 & 1.08 \\
\hline & $\begin{array}{c}\text { PREDICTION } \\
\text { location }\end{array}$ & center-out 2 & corner 40 & center-in 1 & quarter-in 35 \\
\hline & $\begin{array}{c}\text { ABAQUS } \\
\text { stress level } 2\end{array}$ & 0.90 & 0.91 & 0.97 & 1.27 \\
\hline & $\begin{array}{l}\text { ABAQUS } \\
\text { location }\end{array}$ & center-out 2 & corner 40 & center-in 1 & quarter-in 35 \\
\hline & Difference \% & 13.30 & 0.00 & 2.06 & -14.96 \\
\hline \multirow{5}{*}{$2.4 \mathrm{in} / \mathrm{min}$} & $\begin{array}{c}\text { PREDICTION } \\
\text { stress level } 2 \\
\end{array}$ & 1.06 & 0.82 & 1.02 & 1.13 \\
\hline & $\begin{array}{c}\text { PREDICTION } \\
\text { location }\end{array}$ & center-out 2 & corner 40 & center-in 1 & quarter-in 47 \\
\hline & $\begin{array}{c}\text { ABAQUS } \\
\text { stress level } 2\end{array}$ & 0.80 & 0.97 & 1.00 & 1.21 \\
\hline & $\begin{array}{l}\text { ABAQUS } \\
\text { location }\end{array}$ & center-out 2 & center-out 2 & quarter-in 3 & quarter-in 37 \\
\hline & Difference $\%$ & 32.50 & -15.46 & 2.00 & -6.61 \\
\hline \multirow{5}{*}{$3.0 \mathrm{in} / \mathrm{min}$} & $\begin{array}{c}\text { PREDICTION } \\
\text { stress level } 2 \\
\end{array}$ & 0.95 & 0.84 & 0.99 & 1.24 \\
\hline & $\begin{array}{c}\text { PREDICTION } \\
\text { location }\end{array}$ & center-out 2 & center-out 2 & quarter-out 54 & quarter-in 37 \\
\hline & $\begin{array}{c}\text { ABAQUS } \\
\text { stress level } 2 \\
\end{array}$ & 0.96 & 1.11 & 1.08 & 1.18 \\
\hline & $\begin{array}{l}\text { ABAQUS } \\
\text { location }\end{array}$ & Center-out 2 & Center-out 2 & Center-in 1 & Quarter-in 37 \\
\hline & Difference \% & -1.04 & -24.32 & -8.3 & 5.08 \\
\hline
\end{tabular}




\section{CHAPTER 7}

\section{SUMMARY AND FUTURE WORK}

\subsection{Summary}

FE DC casting simulations of aluminum ingots were conducted. Results of five casting speeds, three water flow rates, three corner radius and three aspect ratios for aluminum 7050 ingot sizes of 56"x16" and 58"x19" were analyzed. A PC program, CONVERT, was developed to process the ABAQUS ${ }^{\mathrm{TM}}$ results to obtain temperature, stress, and normalized stress fields in the ingots. The mechanism and failure modes were evaluated based on the criterion of normalized maximum principal stress. In addition, two PC programs, REGRESS and PREDICTION, were developed. The former was used to do regressional analysis, while the later was used to visualize and make prediction of temperature and stress fields for a given set of casting conditions at four selected ingot lengths. The summarized results are:

1. The temperature field of casting ingots shows the uneven temperature distribution of the ingot. The temperature gradients near the water impinging area are high due to the rapid water chilling, which also causes ingot butt curl. The curling speed of the ingot butt decreases as the ingot length grows. There are three types of high stress regions in the ingot. The first one is called corner stress, which is located alone the vertical corner of the ingot. The tensile corner stress is in the vertical direction. The second type of high stress region is quenching stress, which is located at the water contact region with relative constant magnitude throughout the casting period. The tensile quenching stress is along ingot width direction. The casting stress, which is the third high stress type, exists in the just solidified ingot and the high casting stress location moves from center to quarter region with an 
increasing magnitude. In the center area, tensile casting stress vectors are along the ingot width direction, while in the quarter area tensile casting stress forms an angle with the ingot width direction and the angles depend on the casting speed.

2. The ratio of the maximum principal stress to the tensile strength, which is temperature dependent, was used as a criterion to assess the ingot cracking formation. This ratio was defined as stress level 2. If stress level 2 is above 1.0, the possibility of ingot cracking is high. Stress level 2 and its location as well as directions of maximum principal stress in that location were used to analyze the ingot failure mode.

3. For a 56"x16" ingot, for ingot casting length shorter than 20 inches, the possibility of ingot cracking is low if the casting speed is $2.4 \mathrm{in} / \mathrm{min}$ or higher. However, at the end of start-up stage, the magnitude of Stress Level 2 will start to increase rapidly for these casting speeds. Note that, for low drop rates (below $1.5 \mathrm{in} / \mathrm{min}$ ) the most probable ingot failure is quarter crack in steady state. As drop rate increases, center and quarter cracks can occur and the possibility to generate a $\mathbf{J}$ crack also increases. Drop rate $1.9 \mathrm{in} / \mathrm{min}$ is a complex case that can have any one of the three failure modes. It may initiate center crack from the beginning of start-up stage and as it approaches to steady-state stage, it is likely to have quarter crack or $\mathbf{J}$ crack. For $1.5 \mathrm{in} / \mathrm{min}$ drop rate the possibility to have ingot cracking is lower compared to other drop rates.

4. Water flow rate does little effect to the values and locations of stress level 2 after the ingot reaches 10 inches length. For ingot length shorter than 10 inches, lower water flow rate 
causes lower value of stress level 2. Thus, a lower water flow rate may be considered to reduce crack formation in the start-up stage. When the water flow rate is above certain value, there is not much change of stress level 2 and its location. Also corner radius does not affect stress level 2 and its location. As for the effect of aspect ratio, 4/1 case is the best and 7/2 case is the worst.

5. For a 58"x19" ingot, if the drop rate is low (1.0 in/min), quenching stresses are important for crack formation. For drop rate of $1.9 \mathrm{in} / \mathrm{min}$, crack formation is not likely to occur for an ingot length shorter than 20 inches and stress level 2 can reach a much higher value at 30 inch ingot length, which is the most severe case among the five drop rates. Maximum stress level 2 is also high for a $2.4 \mathrm{in} / \mathrm{min}$ drop rate and a $3.0 \mathrm{in} / \mathrm{min}$ drop rate at steady-state stage. A drop rate of $1.5 \mathrm{in} / \mathrm{min}$ is the best case among the five drop rates. This casting speed is recommended.

6. A user friendly PC package (PREDICTION), which contains data reduction, regression, parametric and time interpolation, was developed to process and visualize the FE simulation results in much simplified forms for easy comprehension. Users of this program can easily visualize the distributions of temperature, principal stress and normalized stress levels in the ingot at four casting steps (5", 10", 20", and 30"). Comparison between ABAQUS ${ }^{\mathrm{TM}}$ and PREDICTION results shows good agreement. The PC based program, PREDICTION, can be used in casting shops as a tool to quickly predict temperature and stress fields of a DC casting ingot with user selected processing conditions. The results can facilitate the 
understanding of the mechanism of ingot cracking and optimization of the DC ingot casting process condition.

\subsection{Suggestion for Future Work}

For future study, more FE DC Casting simulations are suggested so that larger database can be built for program, REGRESS, to improve its accuracy of parameter interpolation. In particular, simulations on larger ingot sizes should be considered. The statistical data obtained from program, PREDICTION, can be further processed to show probability of ingot cracking. 


\section{REFERENCES}

[1] J.B. Wiskel and S. L. Cockcroft, "Heat-Flow-Based Analysis of Surface Crack Formation During the Start-up of the Direct Chill Casting Process: Part I and Part II," Metallurgical and Material Transactions B, 27B, (1996), pp.119-137

[2] P.C. Valley, "The Technology of aluminum and it's Alloy".

[3] E.F. Emley: Int. Met. Rev., 1976,June, pp. 75-115.

[4] J. -M. Drezet and M. Rappaz, " Modeling of Ingot Distortions During Direct Chill Casting of Aluminum Alloys," Metallurgical and Materials Trisections A, 27A, (October 1996), pp.32143225.

[5] K. -M. Chang and B. Kang, "Control of Solidification in High-Strength Aluminum Alloys 1997 Annual Report for Research Project sponsored by Central Aluminum Corporation", West Virginia University, January 31, 1998

[6] B.G.Thomas, "Stress Modeling of Casting Process: An overview," Modeling of Casting, Welding and Advanced Solidification Processes VI, ed. T.B. Piwonks, V.Voller and L.Katgerman, (The Mineral, Metals \& Materials Society, 1993), pp.519-534.

[7] D.C. Weckman and P. Niessen, "A Numerical Simulation of the D.C. Continuous Casting Process Including Nucleate Boiling Heat Transfer," Metallurgical Transactions B, 13B, (December 1982), pp.593-602.

[8] H. Kraushaar, R. Jeschar, V. Heidt, E.K. Jensen and W. Schneider, "Correlation of Surface Temperatures and Heat Transfer by D.C. Casting of Aluminum Ingots," Light Metals, 1995, ed. J. Evans, pp.1055-1059. 
[9] Loic Maenner, Bruno Magnin and Yves Caratini, “A Comprehensive Approach to Water Cooling in DC Casting,” Light Metals 1997, ed. Reidar Hurglen, pp.701-707.

[10] J.F. Grandfield, A. Hoadley and S. Instone, "Water Cooling in Direct Chill Casting: Part 1, Boiling Theory and Control,” Light Metals 1997, ed. Reidar Hurglen, pp.691-699.

[11] J.F. Grandfield, K. Goodall, P. Misic and X. Zhang, "Water Cooling In Direct Chill Casting: Part 2, Effect on Billet Heat Flow and Solidification," Light Metals 1997, ed. Reidar Hurglen, pp.1081-1090.

[12] Hallvard G. Fjaer and Asbjorn Mo, “ALSPEN-A Mathematical Model for Thermal Stresses in Direct Chill Casting of Aluminum Billets," Metallurgical Transactions B, 21B, (December 1990), pp.1049-1061.

[13] T. Inoue and D.Y. Ju, "Simulation of Solidification and Viscoplastic Stress During Vertical Semicontinuous Direct Chill Casting of Aluminum Alloy," International Journal of Plasticity, 8, (1992), pp.161-183.

[14] B. Janin, "Simulation of Thermal Stresses in Continuous Casting of Al Alloys Billets", (paper presented at E-MRS meeting, Strasbourg, June 1986), pp.305-314.

[15] B. Hannart, F. Cialti, R.V. Schalkwijk, “Thermal Stresses in DC Casting of Aluminum Slabs: Application of a Finite Element Model," Light Metals 1994, ed. U. Mannweiler, pp. $879-887$.

[16] B.Q. Li and Yimin Ruan, "Integrated Finite Element Model for Transient Fluid Flow and Thermal Stresses During Continuous Casting”, Journal of Thermal Stresses, 18, (1995), pp.359-381. 
[17] J.-M. Drezet and M. Plata, “Thermomechanical Effects During Direct Chill and Electromagnetic Casting of Aluminum Alloys, Part I: Experimental Investigation," Light Metals 1995, ed. J. Evans, pp.931-940.

[18] J.-M. Drezet M. Rappaz, and Yrahenbuhl, “Thermomechanical Effects During Direct Chill and lectromagnetic Casting of Aluminum Alloys, Part II: Numerical Simulation,” Light Metals 1995, ed. J. Evans, pp.941-950

[19] J.-M. Drezet and M. Rappaz, "Modeling of Ingot Distortions During Direct Chill Casting of Aluminum Alloys," Metallurgical and Materials Transactions A, 27A, (October 1996), pp.3214-3225.

[20] C. Devadas and J.F. Grandfield, "Experiences with Modeling DC Casting of Aluminum,” Light Metals 1991, ed. Elwin L. Rooy, pp.883-892.

[21] Y. Watanabe N. Hayashi, and T.Uno, “3-D Solidification Analysis of The Initial State of D.C. Casting Process,” Light Metals 1996, ed. Wayne Hale, pp.979-984.

[22] S Rogers, S. Flood, D.Hughes and J. Rance, "Solidification and Deformation During the Start of An Aluminum DC Cast," Modeling of Casting, welding and Advanced Solidification Processes VII, ed. M. Cross and J. Campbell, (1995), pp.287-294.

[23] W. Droste, W. Schneider, "Laboratory Investigations about The Influence of Starting Conditions on Butt Curl and Swell of DC Cast Sheet Ingots," Light Metals 1991, ed. Elwin L. Rooy, pp.945-951.

[24] W. Schneider, E.K. Jensen and Bertrand Carrupt, "Development of A New Starting Block Shape for The D.C. Casting of Aluminum Sheet Ingots, Part I: Experimental Results," Light Metals 1995, ed. J. Evans, pp.961-967. 
[25] E.K. Jensen, Elkem and W. Schneider, "Development of A New Starting Block Shape for The D.C. Casting of Sheet Ingots, Part II: Modeling Results," Light Metals 1995, ed. J. Evans, pp.969-978.

[26] Hallvard G. Fjaer and Einar K. Jensen, "Mathematical Modeling of Butt Curl Deformation of Sheet Ingots. Comparison with Experimental Results for Different Starter Block Shapes,” Light Metals 1995, ed. J. Evans, pp.951-959.

[27] H-M. Lu, K-M. Chang and J. Harris, "Constitutive Modeling of High-Strength Aluminum Casting, "Light Metals 1997, ed. R.Huglen, pp.1091-1095.

[28] D.R. Poirier and E.J. Poirier, "Heat Transfer Fundamentals for Metal Casting," Second Edition with SI Units, (TMS, 1994).

[29] K. -M. Chang and B. Kang, "Control of Solidification in High-Strength Aluminum Alloys 1996 Annual Report for Research Project sponsored by Central Aluminum Corporation", West Virginia University, January 31, 1997 